Cahiers Charlevoix

\title{
Lettres des nouvelles missions du Canada, 1843-1852
}

\section{René Dionne}

Volume 2, 1997

URI : https://id.erudit.org/iderudit/1039459ar

DOI : https://doi.org/10.7202/1039459ar

Aller au sommaire du numéro

Éditeur(s)

Société Charlevoix

Presses de l'Université d'Ottawa

ISSN

1203-4371 (imprimé)

2371-6878 (numérique)

Découvrir la revue

Citer cet article

Dionne, R. (1997). Lettres des nouvelles missions du Canada, 1843-1852. Cahiers

Charlevoix, 2, 389-486. https://doi.org/10.7202/1039459ar

\section{Résumé de l'article}

René Dionne, l'auteur de l'Histoire de la littérature franco-ontarienne, examine un autre texte fondateur du patrimoine littéraire de l'Ontario français : les Lettres des nouvelles missions du Canada, 1843-1852 qui sont, à son avis, "l'oeuvre la plus substantielle » de la deuxième période (1760-1865) de cette littérature régionale. En scrutant méthodiquement l'édition Cadieux, l'auteur analyse la série des soixante-dix-sept lettres ontariennes écrites par quatorze missionnaires ; il s'intéresse à leurs destinataires, ordinairement des jésuites européens, au genre plus personnel et moins officiel de ces nouvelles "relations ontariennes ", aux formes, surtout de type narratif et descriptif, et aux contenus édifiants de ces missives, qui rapportent les peines et les travaux des missionnaires. 


\title{
LETTRES DES NOUVELLES MISSIONS DU Canada, 1843-1852
}

\author{
René Dionne
}

Département des lettres françaises

Université d'Ottawa, Ottawa

Cahiers Charlevoix 2, 1997, pp. 389-486. 
SOMMAIRE

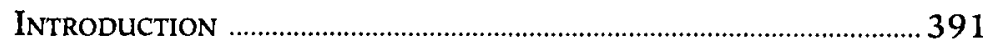

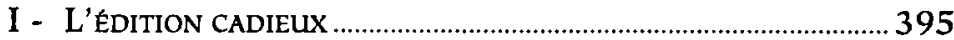

Le protocole

Les lettres ontariennes

II - LES DESTINATAIRES DES LETTRES .................................................404

III - LE GENRE DES LETTRES ……………………………......................... 408

Au supérieur général

Au provincial de Paris

À un père ou frère jésuite

À un père de la même Compagnie

À un parent

À des groupes de scolastiques jésuites

À des groupes d'élèves de jésuites

À un supérieur de séminaire

À un groupe de laïcs

IV - Formes ET CONTENus

La lettre relation de mission

Le récit de voyage apostolique

Le récit d'excursion apostolique

Le récit de voyage

La lettre description

Les descriptions éparses

Les portraits

V - LES TEXTES AMÉRINDIENS

462

Les discours

Les dialogues

Les récits de conversion

Conclusion 


\section{LETTRES DES NOUVELLES MISSIONS DU Canada, 1843-1852}

\section{INTRODUCTION}

Les Lettres des nouvelles missions du Canada, 1843$1852^{1}$, se situent dans la lignée des Relations des jésuites de la Nouvelle-France ${ }^{2}$. Mais pas sans solution de continuité, puisque la publication de celles-ci,

${ }^{1}$ Éditées avec commentaires et annotations par Lorenzo Cadieux, Montréal, les Éditions Bellarmin, et Paris, Maisonneuve et Larose, 1973, 951 p. Désormais: LNMC.

${ }^{2}$ Publiées à Paris par l'éditeur Cramoisy, sauf celle de 1638 qui le fut à Rouen par Jean Le Boulenger, elles ont été éditées pour la première fois au Canada en 1858 (Québec, Augustin Côté, 3 vol.), puis rééditées en 1972 (Montréal, Éditions du Jour, 6 vol.). Cette dernière édition fut un succès de librairie. - Deux éditions savantes ont paru. L'une aux États-Unis (The Jesuit Relations and Allied Documents. Travels and Explorations of the Jesuit Missionaries in New France, 1610-1791, edited by Reuben Gold Thwaites, Cleveland, Burrows Brothers Company, 1896-1901, 73 vol.; New York, Pagent Book Company, 1959, 36 vol.). L'autre au Canada (Monumenta Novoe Francice, I: la première mission d'Acadie (1602-1616), par Luclen Campeau [éditeur], Roma, Apud "Monumenta Historica Societatis Iesu", et Québec, les Presses de l'Université Laval, 1967, 276*, 719 p.; Monumenta Novæe Francioe, II: établissement à Québec (1616-1634), 1979, 141*, 889 p.; Monumenta Nova Francio, III: fondation de la mission huronne (1635-1637), 1987, 54*, 894 p.; Monumenta Novœ Francia, IV: les grandes épreuves (1638-1640), Romae, Institutum Historicum Societatis Iesu, et Montréal, les Éditions Bellarmin, 1989, 48*, 808 p.; Monumenta 
qui avait débuté en 1632, s'était arrêtée en 1672, à la suite de décisions prises, au cours des années précédentes, par la Congrégation de la Propagande et imposées, le 6 avril 1673, par le bref CreditaeNobis coelitus ${ }^{3}$ du pape Clément $\mathrm{X}$. Ce décret ${ }^{4}$ défendait de publier, sans une permission écrite de la Congrégation, tout livre et écrit traitant des missions ou les concernant. Les Jésuites auraient pu demander une permission, mais cette permission, qui aurait dû apparaître en tête de l'ouvrage, n'aurait été d'aucune utilité en France, ce pays ne reconnaissant pas la juridiction de ladite Congrégation ${ }^{5}$.

Nova Francia, V: la bonne nouvelle reçue (1641-1643), 1990 [achevé d'imprimer 1991], 49*, 862 p.; Monumenta Nova Francia, VI: recherche de la paix (1644-1646), 1992, 43*, 805 p.; Monumenta Nova Francia, VII: le témoignage du sang (1647-1650), 1994, 45*, 887 p.; autres volumes en préparation.)

${ }^{3} \mathrm{H}$ [ospice-]A[nthelme] Verreau, «Suppression des Relations de la Nouvelle-France», Revue de Montréal, $1^{\text {re }}$ année, $\mathrm{n}^{\circ} 2$, mars 1877 , pp. 107-116; n 3 , avril 1877, pp. 162-171.

${ }^{4}$ En voici la traduction publiée par Léon Pouliot (Étude sur les «Relations" des jésuites de la Nouvelle-France (1632-1672), Montréal, Scolasticat de l'Immaculée-Conception, et Paris, Desclée de Brouwer \& Cie, 1940, pp. 12-13): "Pour ces raisons [entre autres pour mettre fin à la controverse sur les rites chinois] et pour d'autres non moins graves, de l'avis des susdits cardinaux, par l'autorité apostolique, nous défendons de nouveau, par la teneur des présentes, à toute personne, de quelque état, degré, condition, même de quelque ordre régulier, congrégation, institut que ce soit, et aussi a la société de Jésus, quand il faudrait en faire une mention spéciale et individuelle, de publier elle-même ou par un autre, sans une permission écrite de la congrégation des mêmes cardinaux, laquelle permission devra être imprimée en tête de l'ouvrage, des livres et des écrits dans lesquels il est question des missions ou de choses concernant les missions."

${ }^{5}$ "C'était un article des fameuses libertés gallicanes, qu'on ne reconnaissait en France aucune juridiction des Congrégations cardinalices romaines, que ce fut l'Inquisition, l'Index ou la Propagande. Il en résulte d'abord, qu'aucun ministère, aucun tribunal, n'aurait admis la validité, pour notre pays, du bref de Clément X [...]; ensuite, qu'un livre qui aurait voulu satisfaire aux conditions prescrites dans ce bref, n'eût jamais obtenu en France le visa officiel sans lequel il ne pouvait être légalement publié, et que, s'il avait osé paraître quand même avec l'estampille de la Propagande, il aurait été infailliblement supprimé 
Les jésuites de la Nouvelle-France n'en continuèrent pas moins d'écrire régulièrement à leurs supérieurs pendant au moins sept ans. Leurs manuscrits, déposés aux archives du Collège de Québec, puis confiés à l'Hôtel-Dieu de la même ville, ne furent repérés qu'en 1844 , soit deux ans après le retour des jésuites au Canada ${ }^{6}$, et ce n'est pas avant 1861 que,

par les Parlements. Le «crédit) des Jésuites n'y eât rien falt. On volt clairement qu'll était impossible de continuer les Relations.» Joseph Brucker, "Vie de Mgr de Laval, d'Auguste Gosselin [compte rendu]", Études, t. 52, mars 1891, p. 513. - Volr aussı Plerre Berthlaume, L'Aventure américaine au XVIII' siècle. Du voyage d̀ l'écriture, Ottawa, les Presses de l'Universisté d'Ottawa, "Cahlers du Centre de recherche en civilisation canadienne-française», 27, 1990, pp. 273-274: après avoir examiné diverses circonstances politiques ou ecclésiastiques qui auraient pu contrlbuer à l'interruption des Relations, l'auteur avance que leur succès même aurait pu leur nuire et que, «à la limite», elles seraient disparues «tout bonnement parce qu'elles (avalent) rempli leur mission».

${ }^{6}$ Après la conquête du Canada par l'Angleterre en 1760 et le traité de Paris en 1763, défense ayant été faite aux ordres religieux de se recruter, les jésuites du Canada diminueraient en nombre au long des années. Le 21 julllet 1773, lorsque le bref Dominus ac Redemptor du pape Clément XIV supprima la Compagnie de Jésus dans le monde entier - elle l'avait déjà été au Portugal (1759), en France (1764) et en Espagne (1767) - l'évêque de Québec prit les jésuites du Canada sous sa protection, mais lls n'étaient plus que douze, dont un ou deux (?) seulement en Ontario, à Sandwich. Le demier mourut à Québec en 1800. Voir Joseph Cossette, "Casot, Jean-Joseph», dans Dictionnaire biographique du Canada [désormais: $D B C$ ], sous la direction de Francess G. Halpenny et Jean Hamelin, Québec, les Presses de l'Université Laval, vol. 4, pp. 146-147; [Édouard] Lecompte, Les Anciennes Missions de la Compagnie de Jésus dans la Nouvelle-France (1611-1800), Montréal, Imprimerie du «Messager», 1925, p. [76].

La Compagnie de Jésus fut rétablie le 7 août 1814 par la bulle Sollicitudo du pape Pie VII, mals, accaparée par sa réorganisation, elle n'allait guère reprendre ses grands travaux missionnaires avant la décennie de $1840 . \mathrm{M}^{\mathrm{g}}$ Ignace Bourget, évêque de Montréal, profita de son passage à Rome pour faire appel aux jésuites le 2 juillet 1841 . Le texte de cet appel est cité par le père Félix Martin dans une lettre du $1^{\text {er }}$ juin 1843 à un jésuite de France (lettre 1, dans $L N M C$, pp. 85-86, par. 7). Le 24 avril 1842, neuf jésuites (six prêtres et trols frères coadjuteurs) s'embarquèrent au Havre à destination de New York qu'lls atteigni-

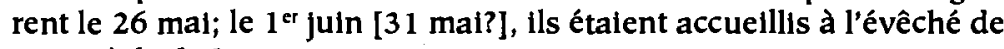
Montréal (ibid., pp. 87-89, par. 9-14). 
préparés par les pères Fortuné Demontézon et Félix Martin $^{7}$, puis dotés par celui-ci d'une introduction et d'un appendice $^{8}$, ils furent publiés en France par l'éditeur-libraire Charles Douniol sous le titre Relations inédites de la Nouvelle-France (1672-1679) pour faire suite aux anciennes Relations (1615-1672), avec deux cartes géographiques'. Ces Relations forment les volumes trois et quatre de la collection que dirigeait alors le père Demontézon: «Voyages et travaux des missionnaires de la Compagnie de Jésus publiés par des Pères de la même Compagnie pour servir de complément aux Lettres édifiantes ${ }^{10}{ }$.

${ }^{7}$ Félix Martin (1804-1886), né le 4 octobre à Auray (Morbihan, France), jésuite (1823), prêtre (1831); arrivé à Montréal le 31 mai 1842, il devient supérieur des jésuites du Bas-Canada en 1844, fonde le Collège Sainte-Marie en 1848 et en est le recteur de 1851 à 1857; supérleur de la résidence des jésuites à Québec en 1859, il doit retourner en France en 1861 pour faire soigner ses yeux; il occupera différents postes, poursuivra ses recherches sur les jésuites de la NouvelleFrance et l'histolre de celle-ci, puis décédera a Paris le 25 novembre 1886. Voir Georges-Émile Giguère, «Martin, Félix (baptisé FélixFrançois-Marie)", dans $D B C$, vol. 11, pp. 649-651; LNMC, pp. 890891 [selon le père Cadieux, le père Martin serait né le 4 septembre]; Édouard Lecompte, Les Jésuites du Canada au XIX siècle, 1842-1872, Montréal, Imprimerie du «Messager», 1920, pp. 117-118, 307, 310, passim.

${ }^{8}$ Selon G.-É. Giguère, «Martin, Félix (baptisé Félix-François-Marie)», dans $D B C$, vol. 11 , p. 650 . L'appendice a pour titre: «Les Missionnaires de la Nouvelle-France au point de vue religieux, politique, scientifique".

${ }^{9}$ Ces relations ont été reproduites en deux volumes ([iii], xi, xxvili, 356 et [iii], 404 p.), en 1974, par les Éditions Élysée de Montréal (la page de couverture des deux tomes porte les dates 1672-1678 au lieu de 1672-1679). Le tome I contient une présentation par Georges-Émile Giguère (pp. 1-xi); elle est suivie de l'introduction (pp. i-xxviii) que le père Félix Martin avait signée à Montréal, le $1^{\text {er }}$ novembre 1860 , pour l'édition de 1861. Le tome II est suivi de l'appendice (pp. [333]-380) rédigé par le père Martin pour la première édition ainsi que de l'article (pp. [381]-400) que H.-A. Verreau avait fait paraître dans la Revue de Montréal, en mars et avril 1877, sous le titre "Suppression des Relations des jésuites de la Nouvelle-France».

${ }^{10}$ Sur cette collection de 34 volumes publiés par les Jésuites de 1702 à 
Auparavant, vers $1857^{11}$, c'est-à-dire à peu près au moment où se préparait ou paraissait à Québec la première édition canadienne (1858) des Relations des jésuites de la Nouvelle-France, le père Félix Martin, qui avait fortement encouragé les responsables de cette réédition, avait publié «à la pierre douce», en deux tomes (1843-1849, 455 p., et 1850-1852, 264 p.), les Lettres des nouvelles missions du Canada, 1843-1852.

\section{I - L'ÉDITION CADIEUX}

Ce sont ces deux tomes que le père Lorenzo Cadieux ${ }^{12}$ édite en un seul en 1973. À l'édition Martin,

1776, voir P. Berthlaume, L'Aventure américaine au XVIII' siècle, pp. 274-311: "Lettres édifiantes et curieuses".

"Selon G.-E. Giguère, «Présentation», dans Relations inédites, t. 1, p. vil.

${ }^{12}$ Lorenzo Cadieux (1903-1976), fils d'Adélard Cadieux et de Clara Dalpé, né le 10 novembre à Granby (Québec), études classiques au Collège Sainte-Marie de Montréal et au Collège des Jésuites d'Edmonton, jésuite (7 septembre 1924), études de lettres (19261928), puis de sciences et de philosophie (1928-1931), professeur de rhétorique et d'histoire au Collège de Gaspé (1931-1934), études de théologie (1934-1938), prêtre (15 août 1937), au Collège Saint-Ignace de Montréal (1938-1939), études de spiritualité (1939-1940), licence en philosophie (Montréal, 1931) et doctorat en histoire (Laval, 1958), professeur de littérature et d'histoire au Collège du Sacré-Cœur de Sudbury (1940-1957), professeur et directeur du département d'histoire de l'Université de Sudbury (1957-1960), puis de l'Université Laurentienne (1960-1969), professeur émérite de l'Université Laurentienne (1971), fondateur de la Société historique du Nouvel-Ontario (1942; président de 1967 à 1976), décédé à Sudbury le 8 décembre 1976. Il avait été directeur de l'Association canadienne des éducateurs de langue française (1955-1959), président de la Société canadienne d'histoire de l'Église (1960), correspondant de l'Institut d'histoire de l'Amérique française, membre de l'Archaeological Historic Sites Advisory Boards en Ontario (1970-1974), de la Société des écrivains canadiens, de l'Association France-Canada. Lauréat du prix Champlain (1958), de l'Ordre du mérite scolaire franco-ontarien à titre très méritant, de l'Award of Merit of the American Association for State and Local History, 
il ajoute un bref avant-propos ${ }^{13}$, une longue introduction ${ }^{14}$ (elle comprend six parties ${ }^{15}$ et inclut quatre cartes du cartographe Raymond Labbé de l'Université Laurentienne de Sudbury ${ }^{16}$ ), des sommaires analytiques qui résument ou indiquent au début de chaque lettre le numéro et le contenu de chacun des paragraphes $^{17}$, une liste des auteurs et des lettres qu'ils ont

(Washington, D. C.), de l'Award of Merit of Canadian Historical Society (1975). (D'après la notice biographique de Lorenzo Cadieux aux Archives des jésuites du Canada français (ASJCF), à Saint-Jérôme (Québec), et les textes cités dans le paragraphe ci-après.)

Au sujet du père Cadieux, voir [Anonyme], "[Notice nécrologique]", Le Devoir, 10 décembre 1976; [Anonyme], "[Notice nécrologique]", Le Voyageur, 15 décembre 1976; Louis-Joseph Pouliot, «Le P[ère] Lorenzo Cadieux (1903-1976), Nouvelles de la province du Canada français, vol. 56, $\mathrm{n}^{\circ} 1$, janvier-février 1977, pp. 21-24; Germain Lemieux, «Le Père Lorenzo Cadieux, S.J.», Revue d'histoire et de traditions populaires de la Gaspésie, vol. 15, no 1 , janvier-mars 1977, pp. 4-6; [Anonyme], «Lorenzo Cadieux, S.J., 1903-1976», Vie française, vol. 31, nos 10-11-12, juinjuillet-août 1977, p. 126; Gaétan Gervais, «Lorenzo Cadieux, S.J., 19031976", Ontario History, Vol. 69, No. 4, December 1977, pp. 214 4-217. À propos de l'ouvrage du père Cadieux, voir Pierre Savard, «Lettres des nouvelles missions du Canada, 1843-1852", Revue d'histoire de l'Amérique française, vol. 28, $\mathrm{n}^{\circ} 2$, septembre 1974, pp. 280-281; Jacques Grisé, «Lettres des nouvelles missions du Canada, 1843-1852 ", Studies in Religion/Sciences religieuses, Vol. 5, No. 2, 1975-1976, pp. 208-209; [Anonyme], «Lettres des nouvelles missions du Canada, 1843-1852», Le Livre canadien, vol. 7, février 1976, $\mathrm{n}^{\circ} 46$; Gaston Carrière, "Lettres des nouvelles missions du Canada, 1843-1852", Revue de l'Université d'Ottawa, vol. 46, $\mathrm{n}^{\circ} 2$, avril-juin 1976, pp. 289-290.

${ }^{13}$ LNMC, p. [7].

${ }^{14}$ Ibid., pp. [9]-76.

${ }^{15}$ I: des relations des jésuites du XVII ${ }^{e}$ siècle aux lettres du XIX $X^{e}$ siècle, pp. [9]-10; II: les lettres et leurs auteurs, pp. [11]-14; III: la civilisation canadienne des années 1840, pp. [17]-34; IV: les Odjibwés dans le milieu ontarien, pp. [37]-42; V: les mours des Odjibwés ou Sauteux, pp. [43]-56; VI: leurs croyances religieuses, pp. [57]-66; VII: le prosélytisme dans les missions indiennes [67]-76.

${ }^{16}$ Ibid., pp. 15 (province de Québec), 16 (Ontario), 35 (Indiens de l'est du Canada), 36 (le lac Supérieur et ses environs canadiens et américains ainsi que la baie de James).

${ }_{17}^{17}$ Voir, par exemple, le sommaire de la lettre 1 (pp. 81-82; 77 paragraphes). 
écrites ${ }^{18}$ ainsi qu'une liste des lieux d'où les lettres ont été expédiées ${ }^{19}$, puis, à la suite des quatre-vingtdouze lettres ${ }^{20}$, des notices biographiques des auteurs de ces lettres et de certains personnages ${ }^{21}$, un lexique toponymique ${ }^{22}$, une liste des noms des tribus indiennes du nord-est de l'Amérique avec l'indication de leurs lieux $\mathrm{d}^{\prime}$ habitation ${ }^{23}$, une bibliographie (sources manuscrites, sources imprimées, ouvrages de référence, études diverses, études sur les Odjibwés de l'Ontario) $^{24}$, un index analytique ${ }^{25}$ et une table des matières détaillée $e^{26}$.

\section{LE PROTOCOLE}

L'éditeur Cadieux affirme qu'il a "respecté l'expression authentique" des lettres. Bien qu'il écrive qu'il n'a corrigé ni «les quelques fautes de syntaxe et d'accord" ni «l'orthographe parfois défectueuse", il a quand même fait un certain nombre de corrections orthographiques qu'il a pris soin de signaler dans

\footnotetext{
${ }_{18}^{18}$ Ibid., p. [79].

${ }^{19} \mathrm{Ibid}$., p. [80].

${ }^{21}$ Ibid., pp. 883-894.

${ }^{22}$ Ibid., pp. [895]-906.

${ }^{23}$ Ibid., p. [907].

24 Ibid., [909]-913,

${ }^{25}$ Ibid., Pp. [915]-943.

${ }^{26}$ Ibid., pp. [945]-951.
}

${ }^{20}$ Ibid., pp. [81]-882. Elles sont présentées dans l'ordre chronologique et numérotées de 1 à 93, mais le texte de la lettre 91 est introuvable selon le père Cadieux (ibid., p. 950); aussi suppose-t-il que cette lettre n'a pas été utranscrite, ou plus probablement numérotée $92^{\circ}$ par inadvertance» (ibid., p. 874). On peut se demander si le premier éditeur n'a pas jugé bon de retirer cette lettre, puls oublié de rectlfier la numérotation des deux lettres suivantes; si tel était le cas, la lettre n'aurait pas nécessairement été détruite et le père se serait montré prudent en confessant simplement qu'll n'avait pu la trouver, car qui sait si, un jour, quelqu'un ne mettra pas la main sur cette introuvable? «[...]: chaque lettre est précédée d'un sommaire dont les chiffres correspondent aux paragraphes numérotés." Ibid., p. [11]. 
l'apparat critique de bas de page ${ }^{27}$; il a mis aussi dans cet apparat le corrigé des fautes qui ont été laissées dans le texte ${ }^{28}$. Il a restitué entre crochets les lettres manquant à l'intérieur des mots ${ }^{29}$, remplacé «les majuscules par des minuscules dans certains adjectifs et substantifs, et vice versa, comme l'exige l'orthographe actuelle ${ }^{30}$ ", "défait et complété les abréviations» et rectifié les inexactitudes dans certaines annotations d'auteur en prenant soin de signaler ces changements de la façon suivante: [corr. de l'éditeur], corrigé la ponctuation et l'accentuation, "afin de faciliter la lecture», lorsqu'elles «ont paru imprécises $^{31}{ }^{\prime}$, mis à jour certaines notes ${ }^{32}$. Notre étude sera basée sur ce texte et nous le citerons tel quel.

Il est regrettable que l'éditeur Cadieux n'ait pas cru bon de renseigner ses lecteurs sur les sources de

${ }^{27}$ Exemples: ibid., p. 105, note a; p. 111 , note a; etc.

${ }^{28}$ Exemples: ibid., p. 118 , note a; p. 131 , note a; etc.

${ }^{29}$ L'éditeur Cadieux a respecté l'orthographe, courante au milieu du $\mathrm{XIX}^{\mathrm{e}}$ siècle, de substantifs et d'adjectifs «tels que: contens, rassurans, parens, enfans, commandemens, etc.», dont le «t» est absent, la graphie des mots "tems», «longtems», qui sont parfois écrits sans «p», celle de "guères" et "naguères», l'élision du «e» muet final de "presque» et «entre" suivis d'un mot commençant par une voyelle - aujourd'hui, on ne tolère l'élision que dans le mot presqu'île. (Ibid., p. 12.)

${ }^{30}$ Exemples: «gouvernement Anglais» est devenu «gouvernement anglais»; "église» a conservé ou pris la majuscule pour désigner «l'ensemble des fidèles d'une même croyance», et la minuscule pour signifier une «maison de prière»; l'appellation Robe-Noire a été uniformisée. Ibid., pp. [1 1]-12.

${ }^{31}$ Ibid., p. 12.

${ }^{32}$ Exemple: à la page 279, par. 2, on trouve entre parenthèses dans le texte de la lettre 15 la localisation suivante: «Bear Creck, la rivière de l'Ourse». Dans la note infrapaginale 2, le père Cadieux écrit: «Bear Creek, la rivière Sydenham», et il renvoie le lecteur à son «Lexique topographique" (p. 904) où il précise que cette rivière se situe "dans le sud-ouest de l'Ontario; elle comprend deux branches qui se joignent à Wallaceburg; cette rivière se jette dans le chenal Écarté, puis dans le lac Sainte-Claire. La rivière Sydenham arrose les comtés de Lambton, de Kent et de Middlesex.» 
son édition. Dans la première partie de son introduction, il se contente d'écrire ce qui suit:

Après la restauration de la Compagnie de Jésus, en 1814, les Jésuites se réorganisèrent avant d'entrer dans le champ des missions. On peut dater de 1841 l'envoi de missionnaires français en Chine. Ceux-ci, par les lettres qu'ils adressaient d'office à leurs supérieurs européens, au Général de l'Ordre et aux provinciaux, écrivaient le récit de leurs travaux. Avec l'assentiment des autorités, on lithographiait ces lettres que des copistes habiles ont transcrites; puis, on les distribuait à un public restreint, amis et bienfaiteurs des Jésuites. Au fur et à mesure que les missions se développèrent, on constitua, semble-t-il, un secrétariat des missions qui se chargeait de lithographier et de répandre ces lettres. Il existe une collection pour la Chine, pour le Proche-Orient et pour le Canada. C'est dans cette dernière collection que s'insèrent les documents que nous publions aujourd'hui et qui ont pour titre: Lettres des Nouvelles Missions du Canada, 1843-1852 ${ }^{33}$.

Dans la deuxième partie de son introduction, l'éditeur Cadieux ajoute que ces lettres «sont des documents à caractère privé, destinés aux Jésuites et à leurs amis» et que «le tirage à l'époque n'a pas été considérable ${ }^{34} »$. Il ne donne aucune indication de la date de ce tirage ni de son responsable ${ }^{35}$. Il reproduit,

\footnotetext{
${ }^{33}$ LNMC, p. 10.

34 Ibid., p. [11].

${ }^{35}$ Nous savons cependant, comme nous l'avons écrit plus haut, grace au père Georges-Emile Giguère (voir notre note 11), que cette édition a été préparée par le père Félix Martin vers 1857 . Une visite à SaintJérôme (Québec) aux Archives de la Compagnie de Jésus du Canada français (ASICF), dont le père Robert Toupin est le conservateur, nous a permis de voir deux exemplaires de cette édition (ASJCF, $n^{\circ} 271.598$ 1651); on n'y trouve ni la date du tirage, ni le nom du responsable de l'édition. Selon le père Toupin, le lieu de l'édition aurait pu être le scolasticat jésuite de Laval (préfecture du département de la Mayenne, dans l'ouest de la France). Le père Giguère, dans une lettre qu'il nous a adressée le 30 septembre 1995, écrit qu'il «(a) plutôt la conviction, la quasi certitude que les lettres ont été préparées Icl [au Canada] sur la pierre douce».
} 
cependant, les pages de titre des deux volumes qu'il utilise; elles ne portent ni le nom de l'éditeur, ni l'endroit de leur publication. Toutefois, il met entre crochets, dans le texte qu'il édite, la pagination de l'édition qu'il utilise. De la présentation et de l'état du texte de celle-ci, il ne dit rien, sauf ce que nous avons rapporté plus haut à propos des changements minimes et des corrections qu'il a jugé bon de faire.

Comme l'éditeur Cadieux mentionne dans sa bibliographie des sources manuscrites qui se trouvent aux Archives des jésuites du Canada français, à celles de l'Université de Sudbury et aux Archives publiques du Canada, il aurait été intéressant pour le lecteur de savoir ce que contenaient ces archives et s'il les avait utilisées de quelque manière: s'agissait-il uniquement des lettres originales transcrites par le premier éditeur ou d'un lot de lettres parmi lesquelles ce dernier aurait choisi celles qu'il a publiées? Le père Cadieux a-t-il confronté le texte du premier éditeur à ces originaux, afin de savoir si ce dernier avait respecté non seulement la langue des textes, mais aussi, ce qui est beaucoup plus important, l'intégralité des lettres ${ }^{36}$ ? Qu'est-ce qui explique l'absence du nom du

${ }^{36}$ Le père Cadieux n'a pas pu confronter le texte de l'édition qu'il utilisait avec les originaux, car ceux-ci n'existent pas dans les archives qu'il a consultées (ASICF). Selon le père Georges-Émile Giguère, avec lequel nous avons eu une conversation téléphonique le 9 août 1995, les originaux ont probablement été détruits, comme les jésuites le faisaient souvent à l'époque, une fois les manuscrits publiés. Le père Lucien Campeau doute, cependant, que l'on ait fait subir aux lettres autographes le même sort qu'aux manuscrits de livre (conversation téléphonique du 18 août 1995). Quol qu'll en soit, il pense comme nous que le père Cadieux n'a pas confronté son texte avec les lettres autographes qui pourraient se trouver aux archives romaines de la Compagnie de Jésus. Nous ne savons pas sur quoi s'est appuyé Jacques Legris pour écrire, dans son compte rendu (Studies in Religion/Sciences religieuses, vol. 5, $\mathrm{n}^{\circ} 2,1975-1976$, pp. 208-209) de l'édition Cadieux, 
destinataire dans l'en-tête de quatre-vingt-neuf des quatre-vingt-douze lettres publiées? Cette absence est-elle due à l'éditeur de l'édition lithographiée? À la disparition des adresses postales? À qui devonsnous les notes qui identifient les destinataires qui ont rang de provincial, de général et, parfois, de supérieur local? Comment cette identification s'estelle faite ${ }^{37}$ ? À quel texte l'éditeur Cadieux a-t-il apporté des corrections ou des changements: au texte manuscrit ou au texte lithographié ${ }^{38}$ ? L'éditeur de ce dernier l'avait-il annoté ou commenté? L'avait-il fait précéder d'une introduction, suivre d'une postface,

que «ce sont les lettres conservées aux archives générales des Jésuites à Rome qui sont publiées» dans cet ouvrage.

${ }^{37}$ La lettre 91 et les noms des destinataires, sauf ceux des deux lettres (16 et 75) adressées à des non-jésuites, sont absents dans l'édition lithographiée tout comme dans celle du père Cadieux. Le premier éditeur est donc responsable de cette absence, pour des raisons que nous ne connaissons pas, mais qui ne s'expliquent probablement pas par la destruction des adresses, car les lettres originales que nous avons vues aux ASICF portent bien leurs adresses, mais le nom du destinataire n'est pas au début des lettres (elles commencent par un appel comme «Mon Révérend Père», "Mon bien cher Frère», etc.). Les destinataires identifiés dans les notes infrapaginales et dans la table des matières l'ont été par le père Cadieux à l'aide des catalogues de la Compagnie de Jésus qui se trouvent aux ASJCF.

${ }^{38}$ C'est bien le texte lithographié que le père Cadieux a corrigé parfois, selon ce qu'il a écrit à ce sujet dans son introduction. Mais il a aussi tenu compte des corrections que l'on trouve dans les deux exemplaires lithographiés qui sont conservés aux ASJCF. Certaines corrections sont attribuées au père Félix Martin, mais la plupart seraient dues au père Theodore Fleck [d'après la notice biographique du père aux ASJFC, il est né en 1827 à Nierderbrom (ne serait-ce pas plutôt Niederbronn-les-Bains, dans le Bas-Rhin?), diocèse de Strasbourg; il entre au noviciat jésuite d'Issenheim (Haut-Rhin, France) le 24 octobre 1850 , arrive au Canada en 1865 , prononce ses vœux de coadjuteur spirituel le 15 août 1866, retourne en Europe en 1891 (?), décède à Metz (France) le 30 octobre 1897]. Le père Cadieux a reproduit ces notes avec leur attribution (voir $L N M C$, lettre 1, pp. 82-121, notes 1, 4, $6,7,8,11,12,15,20,21,26,36$ (la correction de «Normand" en "champenois" se trouve sans attribution dans les exemplaires des ASJCF), 44, 52, 55, 60, etc.). 
accompagner de documents, etc. ${ }^{39}$ ? Ce sont là autant de questions auxquelles l'auteur d'une édition de texte ancien doit répondre à la fois pour valider la qualité de son travail, rendre service aux chercheurs et satisfaire la légitime curiosité de son lecteur. L'éditeur Cadieux, historien de profession, a dû avoir ses raisons pour ne pas fournir ces renseignements; comme tous ses lecteurs sérieux, nous aurions aimé connâ̂tre ses motifs, afin de pouvoir l'excuser, de mieux lire son texte et de ne pas nous sentir obligé de faire des recherches dont il devait déjà connaître les résultats positifs ou négatifs. Il reste que notre tâche se limite ici à la présentation et à l'étude du texte qu'il a publié $e^{40}$.

\section{LES LETTRES ONTARIENNES}

Les lettres sont de vingt-trois auteurs jésuites (vingt pères et trois frères coadjuteurs). Elles ont une longueur moyenne de huit pages et demie. La plus longue compte quarante-trois pages; la plus courte, deux pages. Quatorze ont été écrites au Québec, soit à Montréal (10), Laprairie (2) et Québec (2); soixantetrois en Ontario, dans les endroits suivants: Chatham (1), lac Nipigon (1) , Penetanguishene (1), Rivière-auxTourtres [Pigeon River] (5), Sandwich [Windsor] (15), Fort William [Thunder Bay] (9), île Walpole (4), île

\footnotetext{
${ }^{39}$ Le responsable de l'édition lithographiée n'a ajouté ni introduction, ni postface, ni document au texte, mais il est l'auteur des sous-titres marginaux (le père Cadieux n'a fait que les reproduire) et il a fait quelques annotations que le père Cadieux a conservées et bien attribuées au premier éditeur.

${ }^{40}$ Nous citerons le texte des lettres tel qu'il se trouve dans l'édition Cadieux, c'est-à-dire avec les coquilles et les fautes que l'on y rencontre parfois, mais qui n'étaient pas toujours des fautes au dix-neuvième siècle.
} 
Manitouline [Wikwemikong] (26), Wilmot près Petersburg (1); quinze aux États-Unis: au Sault-Sainte-Marie (12), à l'île Royale (1), à La Pointe (1) et à New York (1).

Nous laisserons de côté celles qui ont été écrites au Québec ${ }^{41}$ et à New York ${ }^{42}$; elles ne manquent pas d'intérêt ${ }^{43}$, mais ne contiennent que quelques paragraphes sur l'Ontario ${ }^{44}$. Nous considérerons cependant celles qui ont été écrites par les pères Jean-Pierre Choné à La Pointe ${ }^{45}$ et Nicolas Frémiot à l'île Royale ${ }^{46}$, alors qu'ils étaient en excursion missionnaire dans ces sites américains à partir de leurs postes ontariens. Font aussi partie du corpus que nous examinerons les douze lettres écrites par les missionnaires du Sault-Sainte-Marie ${ }^{47}$; logés sur la rive sud (américaine),

${ }^{41} \mathrm{Ce}$ sont les lettres suivantes (indiquées entre parenthèses) des pères Jean-Baptiste Falleur (72), Nicolas Frémiot (41), Arsène Havequez (60), Adolphe Larcher (70), Paul Luiset (24), Marie-Jean Mainguy (14), Félix Martin (1, 8, 18, 25, 31), Jean-Marie Mercier (90), Rémi Tellier $(2,50)$.

${ }^{42}$ La seule lettre qui y ait été écrite (34) est du père Martin Férard.

${ }^{43}$ Sont particulièrement intéressantes celles des pères Félix Martin sur le retour des jésuites et le diocèse de Montréal en 1842-1843 (LNMC, 31, pp. 81-29), Jean-Baptiste Falleur sur la ville et la région de Québec en 1850 (ibid., 72, pp. 671-682) et Martin Férard sur les Irlandais et le typhus à Montréal en 1847 (ibid., 34, pp. 399-404).

${ }^{44}$ Nous les devons au père Félix Martin (LNMC, lettre 1, pp. 108-109, par. 52-53: situation du diocèse catholique de Toronto; pp. 118-119, par. 65: une retraite à Bytown [Ottawa]) et au père Adolphe Larcher (ibid., lettre 70, pp. 655-658, par. 24-28: situation du Collège Regiopolis de Kingston).

${ }^{45}$ Ibid., lettre 52. - La Pointe est un "village métis de l'île Madeleine, la plus grande des Îles des Douze Apôtres (Apostle Islands); ces îles sont situées au sud-ouest du lac Supérieur, dans l'État du Wisconsin". Ibid., p. 899.

${ }^{46}$ Ibid., lettre 86. - L'île Royale est «située au nord-ouest du lac Supérieur et au sud de Thunder Bay; elle appartient à l'État du Michigan». Ibid., p. 898.

${ }^{47} \mathrm{Ce}$ sont des lettres des pères Jean-Pierre Choné (32), Jean-Baptiste Menet $(33,35,36,38,68)$, Joseph-Urbain Hanipaux $(44,46)$, Nicolas Frémiot $(47,75)$, Auguste Kohler $(73,74)$. 
ils n'en travaillaient pas moins sur la rive nord (canadienne). Ces quatorze lettres s'ajoutant aux soixante-trois écrites en territoire ontarien, c'est sur soixante-dix-sept lettres de quatorze auteurs que portera essentiellement notre étude.

\section{II - Les destinataires des LeTtres}

Bien que ces lettres s'inscrivent dans la lignée des Relations des jésuites de la Nouvelle-France, elles en diffèrent en plusieurs points comme le feront voir les comparaisons qui suivent.

Les Relations des jésuites de la Nouvelle-France avaient pour destinataire principal le provincial de Paris et le grand public en devenait le destinataire ultime quand ce provincial en confiait l'impression à l'éditeur. Les relations «québécoises» avaient d'abord eu un premier destinataire dans la personne du supérieur de Québec. C'est à lui que les missionnaires adressaient leurs rapports annuels et c'est lui qui préparait le texte destiné au provincial de Paris. Dès 1634 , ce «rapport annuel ne s'adress(a) plus au seul Provincial de Paris ou aux seuls jésuites; dans la pensée même de son auteur, il (fut) désormais de droit public; sauf quelques exceptions ${ }^{[48]}$, quand il part(ait) du Canada, il (était) déjà prêt à imprimer ${ }^{49}$ . Il importe de noter, cependant, que les relations «ontariennes» du dix-septième siècle, — c'est-à-dire celles qui constituent, de 1635 à 1648 , la seconde partie, sauf quatre fois ${ }^{50}$, de la relation du supérieur

\footnotetext{
${ }^{48}$ L. Pouliot, Etude sur les «Relations» des jésuites de la Nouvelle-France (1632-1672), p. 19 et pp. 285-286, n. 6.

${ }^{49}$ Ibid., p. 18.

${ }^{50}$ En 1643, l'original ayant été saisi par les Iroquois, on ne put en publier une cople que l'année suivante; en 1647, les attaques iroquoises
} 
de Québec sous le titre «Relation de ce qui s'est passé dans le pays des Hurons» ou «aux Hurons» ou "en la mission des Hurons" -, ont été préparées par le supérieur de la mission huronne; le supérieur de Québec ne fait que les ajouter à son texte ${ }^{51}$.

Les lettres ontariennes du dix-neuvième siècle ont un caractère plus privé, qui les rapproche plutôt des Lettres édifiantes et curieuses ${ }^{52}$. Elles ne sont pas d'abord destinées à la publication et elles sont envoyées directement à des individus, sauf quatre ${ }^{53}$ d'entre elles qui le sont à un groupe.

empêchèrent la rédaction du texte; en 1649 , c'est toute la Relation de cette année-là qui est consacrée à la Huronie; en 1650, la «Relation de ce qui s'est passé en la mission des pères de la Compagnie de Jésus aux Hurons [...]» occupe la première partle de la Relation.

${ }^{51}$ L. Pouliot, Etude sur les "Relations» des jésuites de la Nouvelle-France (1632-1672), p. 21. - Plusieurs de ces relations du pays des Hurons sont adressées au provincial de Paris et non pas au supérieur de Québec; ce sont celles de 1641 (p. 59), 1642 (p. 55), 1644 (p. 68), 1645 (p. 38), 1646 (p. 53), 1648 (p. 45).

${ }^{52}$ Selon P. Berthiaume (l'Aventure américaine au XVIII ${ }^{e}$ siècle, pp. 275276), «on retrouve dans les Lettres édifiantes nombre de caractéristiques des Relations, ne fût-ce que parce qu'elles touchent deux publics distincts, laïc et religieux, et qu'elles ont pour mission de témoigner des progrès de l'évangélisation auprès des païens, d'illustrer la foi des convertis, enfin d'aider les missionnaires dans leur ministère. Mais différence importante, les Lettres ne forment jamais des relations annuelles comme c'était le cas au XVII ${ }^{\mathbf{e}}$ siècle; elles demeurent des missives qui possèdent un caractère d'autant plus personnel qu'elles paraissent répondre à des demandes particulières d'amis ou de connaissances. Certes, les missionnaires pensent toujours en termes de (pieuse curiosité), mais ils insistent davantage sur le caractère privé de leurs échanges épistolaires. [...] Au XVIII ${ }^{e}$ siècle, les missionnaires n'écrivent plus pour obéir aux ordres de la Compagnie, mais par plaisir d'informer qui un ami, qui un confrère, ce qui a pour conséquence de conférer à leur témoignage une gratuité qui ne peut qu'accroître son authenticité: plus personnels et partant plus libres, leurs propos paraissent plus vrais.»

${ }^{53}$ Cinq si l'on compte la lettre 54 que le frère coadjuteur Jean Véroneau écrivit à sa mère et fit tenir aux frères coadjuteurs jésuites de SaintAcheul. 
Tous ces destinataires sont Européens; ils habitent la France (68), la Belgique (2), l'Italie (1), Montréal (1) et New York (1). Soixante-treize lettres sont adressées à des jésuites (pères, scolastiques ou frères coadjuteurs). De ce nombre, trente-huit le sont aux supérieurs provinciaux qui se succédèrent à Paris entre 1843 et $1852^{54}$, une au supérieur général à Rome $^{55}$, une au supérieur de la mission de Montréal ${ }^{56}$, cinq au supérieur de la mission de New York ${ }^{57}$, vingt à des pères non identifiés ${ }^{58}$, trois à des scolastiques non identifiés ${ }^{59}$, une à un scolastique de Brugelette (Belgique) ${ }^{60}$, une à un frère coadjuteur ${ }^{61}$, deux aux scolastiques de Laval (France) ${ }^{62}$, une du frère coadjuteur Joseph Jennesseaux à son frère Pierre, père jésuite $^{63}$. La seule autre lettre ontarienne à un parent ${ }^{64}$ a été écrite par le frère coadjuteur Véroneau à sa mère et il l'a fait tenir telle quelle, précédée simple-

\footnotetext{
${ }^{54}$ Six au père Clément Boulanger (LNMC, lettres 3, 4, 5, 7, 9, 15, 19), vingt et une au père Ambroise Rubillon (17, 19, 20, 21, 28, 29, 40,42, $44,46,47,49,51,53,56,61,63,64,65,69,71)$, onze au père Frédéric Studer $(76,77,79,80,82,83,85,87,89,92,93)$. - Chacun de ces pères reçut aussi une lettre $(2,70,90)$ en provenance de Québec durant son supériorat.

${ }^{55}$ Le père Jean-Philippe Roothaan, ibid., lettre 27.

${ }^{56}$ Le père Félix Martin, ibid., lettre 58.

${ }^{57}$ Le père Clément Boulanger, ibid., les lettres $62,73,74,84,86$.

${ }^{58}$ Ibid., les lettres $11,12,13,22,23,26,30,33,35,36,38,39,43,48$, $52,55,59,67,68,81$. - Neuf lettres québécoises $(1,8,18,24,25,41$, $50,60,72$ ) et une de New York (34) étaient adressées à des pères non identifiés.

${ }^{59}$ Ibid., lettres 10, 45, 78.

${ }^{60} \mathrm{Ibid}$, lettre 37 . - Brugelette est un bourg de la province du Hainaut.

${ }^{61}$ Ibid., lettre 6.

${ }^{62}$ Ibid., lettres 66,68 . - Une lettre québécoise (14) était adressée au supérieur de la malson de Laval. - Laval est une préfecture de la Mayenne (département de l'ouest de la France).

${ }^{63}$ Ibid., lettre 57.

${ }^{64}$ Ibid., lettre 54. - Dans les lettres du Québec, une seule était adressée à un parent: celle du père Félix Martin à son frère aîné Arthur, jésuite, en France.
} 
ment d'un simple paragraphe justificatif, aux frères coadjuteurs jésuites de Saint-Acheul (France) ${ }^{65}$. Les destinataires non jésuites (une lettre chacun), sont, outre la mère du frère coadjuteur Véroneau, monsieur Micard, supérieur du Séminaire de Saint-Dié (France) $^{66}$, les élèves du Collège de Brugelette ${ }^{67}$ et MM. les membres du Conseil central de l'œuvre de la Propagation de la foi, à Lyon (France) ${ }^{68}$.

Tout compte fait, ce sont ces trois dernières lettres seulement qui étaient destinées à un public plus large que celui de la Compagnie de Jésus; encore faut-il noter que les collégiens de Brugelette étaient élèves de jésuites et que le séminaire de Saint-Dié était, lui aussi, un milieu clérical et limité en nombre, tandis que le Conseil central de l'œuvre de la Propagation de la foi à Lyon regroupait des laïcs catholiques. Certaines lettres ont certainement circulé dans l'entourage de leur destinataire ${ }^{69}$, mais il ne semble pas y avoir eu de publication de l'ensemble avant l'édition Martin, soit environ quatorze ans après la rédaction de la première lettre et quatre ou cinq ans après celle de la dernière. Selon le père Cadieux, le tirage de ces «documents à caractère privé, destinés aux jésuites et à leurs amis, n'(avait) pas été considérable»; en 1973, les deux tomes étaient «devenus rares» et ils n'avaient pas été réédités en France $^{70}$.

\footnotetext{
${ }^{65}$ Saint-Acheul est un faubourg d'Amiens (département de la Somme). ${ }^{66}$ Lettre 75, dans LNMC. - Saint-Dié est une sous-préfecture du département des Vosges, dans l'est de la France.

${ }^{67}$ Ibid., lettre 32.

${ }^{68}$ Ibid., lettre 16.

${ }^{69}$ Voir lettre 10, dans $L N M C$, p. 215, par. 2; lettre 16, ibid., p. [281], note de présentation.

${ }^{70}$ LNMC, p. [1 1 ].
} 
L'occasion s'offrait donc de les éditer pour les publics français et canadien, et elle était d'autant plus attrayante que la réédition des Relations des jésuites de la Nouvelle-France, l'année précédente ${ }^{71}$, continuait d'être un succès de librairie. Ces écrits faisaient partie d'un patrimoine culturel canadien-français que le mouvement nationaliste québécois des années 1970 s'employait à récupérer et à promouvoir. L'édition des Lettres des nouvelles missions du Canada, 1843-1852 ne connut pas le même succès. Livrées au grand public pour la première fois, ces lettres n'étaient jamais entrées dans la tradition de lecture canadiennefrançaise; bien plus, le patrimoine québécois n'en pouvait réclamer que quinze. Toutes les autres font partie du patrimoine littéraire franco-ontarien; elles avaient reposé jusque-là avec des centaines de lettres du dix-neuvième siècle que l'on n'a encore ressuscitées qu'en partie, celles des Oblats et des sœurs Grises entre autres ${ }^{72}$. Les unes et les autres sont pourtant des sources riches en renseignements de toutes sortes sur la vie ontarienne et il s'en trouve un bon nombre dont on ne peut contester la qualité littéraire.

\section{III - LE GENRE DES LETTRES}

Le genre des lettres dépend en grande partie de la qualité du destinataire, de la personnalité du destinateur et du but visé par ce dernier.

\footnotetext{
${ }^{71}$ Relations des Jésuites, contenant ce qui s'est passé dans les missions des Pères de la Compagnie de Jésus dans la Nouvelle-France, Montréal, Editions du Jour, 1972, 6 vol.

${ }^{72}$ Sœur Jeanne d'Arc Lortie, s.c.o., a commencé à publier, en 1989, aux Éditions Paulines de Montréal, les Lettres d'Elisabeth Bruyère dans une collection qui pourrait comprendre plusieurs volumes; deux ont paru: $1839-1849$ et $1850-1856$.
} 
AU SUPÉRIEUR GÉNÉRAL

Des quatre-vingt-douze lettres de l'édition Cadieux, une seule est adressée au supérieur général de la Compagnie à Rome, le père Jean-Philippe Roothaan ${ }^{73}$. Son destinateur, le père Joseph-Urbain Hanipaux ${ }^{74}$ l'a écrite avec soin ${ }^{75}$. On dirait qu'il veut se faire pardonner une attitude passée: «Je croyais d'abord que la faiblesse des sauvages et leur indifférence étaient sans remède; je les regardais comme incapables d'une vertu généreuse. Cependant, celui qui peut changer les pierres en vrais enfants d'Abraham, change aussi quand il le veut les sauvages en vrais disciples du Christ $^{76} . »$ Et le père de faire avec délicatesse, en deux pages, un portrait vivant de ces disciples fidèles et avides d'approfondir leurs connaissances religieuses; malheureusement, les livres leur manquent, et les missionnaires aussi, qui les accompagneraient dans leur démarche et arracheraient les infidèles à leur misère.

\footnotetext{
${ }^{73}$ Jean-Philippe Roothaan (1785-1853), né le 23 novembre à Amsterdam (Hollande), il entre chez les jésuites en 1804 à Daugavpils [en français: Dunabourgl, ville de la Lettonie qui, en 1772, est devenue partie de la Russie, pays où la Compagnie de Jésus, protégée par l'impératrice Catherine II la Grande, a échappé à la suppression de 1773; il est ordonné prêtre en 1812 et élu supérieur général de la Compagnie - il en est le vingt et unième - en 1829 . Voir LNMC, p. 893; G. de Vaux, S.J., et H. Riondel, S.J., Le Père Jean Roothaan, XXI Général de la Compagnie de Jésus (1785-1853).

${ }^{74}$ Joseph-Urbain Hanipaux (1805-1872), né à Saint-Georges de Dougueux (France), prêtre (1829), jésuite (1837), arrivé au Canada le 31 mai 1842, missionnaire à Laprairie (1842-1845) et à Wikwemikong (1845-1871), décédé à Québec le 12 mars 1872 . Voir LNMC, pp. 888889; P. Servais, Le R. P. Hanipaux, jésuite, notice biographique, Langres [France], Imprimerie Firmin Dangien, 1873, 76 p; É. Lecompte, Les Jésuites du Canada au XIX' siecle, 1842-1872, pp. 55-56, 58, 201-202, 218-220, 228, passim. - Selon ce dernier, (ibid., p. 201), le père Hanipaux serait né à Donjeux et non pas à Dougueux.

${ }^{75}$ Lettre 27, Sainte-Croix, île Manitouline, 9 février 1847, dans LNMC, pp. 363-366.
}

${ }^{76}$ Ibid., p. 364, par. 1. 
Au fond, cette lettre n'a qu'un seul but: émouvoir celui qui peut envoyer des ouvriers à la vigne. Elle témoigne du cour apostolique de l'auteur et de la simplicité avec laquelle un simple jésuite peut s'adresser à son supérieur général.

\section{Al provinclal de Paris}

Les lettres ontariennes destinées aux supérieurs provinciaux de Paris par des supérieurs locaux diffèrent des Relations ${ }^{77}$ du dix-septième siècle. Elles ne sont ni annuelles ni soumises à des dates de tombée; elles sont plus fréquentes, et envoyées à différents moments de l'année. De plus, plusieurs ne portent que sur les travaux de deux ou trois pères et frères, voire sur ceux de l'unique père en poste, alors que les Relations portaient sur l'ensemble des activités missionnaires en Nouvelle-France. Il n'empêche que certaines lettres ontariennes du dix-neuvième siècle ressemblent partiellement aux Relations.

Ainsi, la première lettre ${ }^{78}$ du père Pierre Chazelle ${ }^{79}$, écrite de Sandwich le 15 juillet 1844 , se rapproche

\footnotetext{
${ }_{77}$ Désormais, ce mot en italique désignera les Relations des jésuites de la Nouvelle-France, et c'est généralement aux textes intitulés «Relation de ce qui s'est passé au pays des Hurons» que nous comparerons les lettres contenues dans les Lettres des nouvelles missions du Canada, 1843-1852, car, dans celles-ci comme dans celles-là, à quelques exceptions près, il s'agit du milieu amérindien de l'Ontario, et le territoire couvert par les missionnaires des Odjibwés ou Sauteux est à peu près celui qu'avaient habité ou visité leurs confrères du dix-septième siècle.

${ }^{78}$ Lettre 4, dans LNMC, pp. 168-172.

${ }^{79}$ Pierre Chazelle (1789-1845), né à Saint-Just-en-Bas (France), prêtre (1812), jésuite (1822); nommé supérieur des missions jésuites en Amérique du Nord, il arrive aux États-Unis en février 1831 et devient recteur du St. Mary's Seminary (Kentucky); en 1841, il séjourne à Rome, puis en France; nommé supérieur des jésuites du Canada, il recrute les huit jésuites avec lesquels il arrivera à Montréal le 31 mai
} 
des Relations par le champ qu'elle couvre, soit l'ensemble des missions ontariennes desservies par les jésuites, mais elle s'en distingue par sa brièveté: en quatre pages, le père supérieur des missions de la Compagnie de Jésus au Canada, - titre équivalant à celui de supérieur de la mission du Canada à Québec au dix-septième siècle -, fait rapport au père Clément Boulanger ${ }^{80}$, provincial de Paris, des activités des diverses missions ontariennes qu'il a visitées, donne des nouvelles des missionnaires, évalue leur travail, rend compte des difficultés qu'ils rencontrent et décrit brièvement les lieux et la population.

Les deux lettres ${ }^{81}$ que le père Chazelle adressa par la suite au même provincial ont trait à des affaires

1842; le 31 juillet 1844, à la demande de Mgr Michael Power, évêque de Toronto, «la mission jésuite du Canada est divisée en deux sections: Chazelle est supérieur de la nouvelle mission du Haut-Canada tandis que Félix Martin l'est pour celle du Bas-Canada»; il décède à Green Bay (Wisconsin) le 4 septembre 1845. Voir G.-É. Giguère, "Chazelle, Jean-Pierre", dans $D B C$, vol. 7, pp. 185-186; LNMC, p. 885; É. Lecompte, Les Jésuites du Canada au XIX ${ }^{e}$ siècle, 1842-1872, pp. 28-30, 36-37, 40, 42-44, 46, 48, 51, 54-55, 60, 62-65, 69-70, 77, $82,87,106,116,118,159,184-185,201$, passim. - Selon É. Lecompte (ibid., p. 28) et le père Cadieux (loc. cit.), le père Chazelle serait né à Montbrison (Loire, France); le 12 janvier selon le premier et G.-É. Giguère (op. cit., p. 185), le 12 février selon le second.

${ }^{80}$ Clément Boulanger (1790-1868), né le 30 octobre à Saint-Clément (Meurthe et Moselle, France), prêtre et professeur de théologie, jésuite (1823), provincial des jésuites de France (février 1842-1 ${ }^{\text {er }}$ avril 1845), puis visiteur des missions françaises d'Amérique du Nord, il les réunit en 1846 sous le nom de mission New York-Canada et il en sera le supérieur, avec résidence à New York, jusqu'en 1855; de retour en France (1856), ll sera supérieur de la résidence des fésuites de Nancy, puis recteur du Collège de Laval (1861-1865); retraité à Nancy, il y décède le 12 juin 1868. Voir G.-É. Giguère, «Boulanger, Clément (baptisé Clément-Quentin)», dans $D B C$, vol. 9, pp. 73-74; LNMC, p. 884 .

${ }^{81}$ Lettre 7, Sandwich, 10 août 1844, dans LNMC, pp. [188]-196; lettre 15. Sandwich, 13 mars 1845 , pp. 278-280. - Quand le père Chazelle écrit la première de ces deux lettres, il a déjà été nommé, le 31 juillet précédent, supérieur des missions de la Compagnie de Jésus dans le 
particulières: l'opposition que rencontre la construction d'une église catholique à l'île Walpole et l'état de santé bien différent des pères Pierre Point ${ }^{82}$, que les fièvres avaient épuisé, et Dominique du Ranquet ${ }^{83}$, qui ne souffrait jamais du «moindre rhume» ni de «la plus légère indisposition", même dans les pires conditions de voyage. C'est un genre de lettres que l'on ne trouvait pas dans les Relations.

\section{$\grave{A}$ UN PERE OU FRÈRE JÉSUITE}

Étaient également absentes des Relations les lettres à un père ou à un frère de la même Compagnie. Elles sont au nombre de vingt-six dans les Lettres ${ }^{84}$. Il arrive que le destinateur répète à ses confrères une partie de ce qu'il a dit à son provincial, encore que, le plus souvent, s'il traite des mêmes sujets, il le fasse

\footnotetext{
Haut-Canada [c'est ce titre que porte l'en-tête de la lettre 15], mais peut-être ne l'a-t-ll pas encore appris, car l'en-tête de cette lettre 7 le donne encore comme supérieur des missions de la Compagnie de Jésus au Canada.

${ }^{82}$ Pierre Point (1802-1896), né le 7 avril à Rocroy (Ardennes, France), prêtre (1826), jésuite (1839), supérieur à Sandwich (1843-1859), supérieur de la résidence de Québec (1861-1872), directeur spirituel au Collège Sainte-Marle de Montréal, où il décède en 1896. Voir LNMC, p. 892; É. Lecompte, Les Jésuites du Canada au XIX' siècle, 1842-1872, pp. 82, 84-103, [163]-181, 251, 290-291, passim. Le père Pierre Point est l'auteur d'une Histoire de Sandwich (ASJCF).

${ }^{83}$ Dominique Chardon du Ranquet (1813-1900), né le 20 janvier à Chalut (Puy-de-Dôme, France), jésuite (1838), prêtre (1842), arrivé au Canada le 31 mai 1842, il étudie la langue algonquine à Oka (juillet 1842-mai 1843), puis à Sandwich (1843-1844), missionnaire aux endroits suivants: île Walpole (1844-1850), île Manitouline (18501852), résidence de Fort-William (1852-1877), Wikwemikong (18771900), où il décède le 19 décembre 1900. Voir LNMC, p. 886; É. Lecompte, Les Jésuites du Canada au XIX ${ }^{e}$ siècle, 1842-1872, pp. 64, 186-192, 209-223, passim.

${ }^{84}$ Désormais, ce mot en italique désignera dans notre texte l'édition Cadieux des Lettres des nouvelles missions du Canada, 1843-1852.
} 
d'une façon plus ou moins semblable, mais, parfois, tout à fait différente, et pour des raisons qui varient.

Ainsi, le père Chazelle, dans sa lettre du 10 août 1844 à son provincial, le père Clément Boulanger, avait exposé la situation difficile dans laquelle le père Dominique du Ranquet se trouvait par suite de l'opposition des Odjibwés à la construction d'une église catholique sur l'île Walpole, puis il avait rapporté les longues discussions qui avaient eu lieu entre les opposants et les deux pères; il avait ensuite donné une appréciation des débats, exprimé son admiration pour l'éloquence et l'intelligence des opposants.

Le 8 septembre suivant, le père écrit à un frère scolastique de Laval ${ }^{85}$. La lettre est plus longue, la documentation plus abondante, la parole plus chaude, le style plus libre. Le père commence par rappeler à son destinataire que, revenant de Rome en 1841, il a eu la bonne fortune d'être conduit par lui à Milan. Cette année (1844), lors de la fête de saint Ignace (le 31 juillet), il a vécu "un jour véritablement singulier, extraordinaire». Les lignes suivantes nous apprennent que le père s'attendait à ce que le destinataire de la lettre du 10 août l'ait fait circuler, et c'est chaleureusement qu'il annonce au scolastique qu'il lui fait tenir une lettre plus longue et plus complète qui lui plaira, étant donné ce qu'il est. Ces lignes valent la peine d'être citées pour l'éclairage qu'elles projettent sur le caractère particulier des lettres aux confrères par rapport à celui des lettres d'office ou d'affaires aux supérieurs provinciaux:

Vous savez déjà probablement de quoi il s'agit; car je l'ai annoncé au R. P. Provincial. Mais, quoique fort longue,

${ }^{85}$ Lettre 10, Sandwich, 8 septembre 1844 , dans LNMC, pp. [2 14 ]-225. 
ma lettre ne contient pas tout. J'ai pensé qu'un supplément ne serait pas sans intérêt; et c'est à vous que je l'adresse. Il contiendra des choses qui pourront faire plaisir à un professeur de Rhétorique, à un jeune Théologien, mais surtout à un enfant de la Compagnie. Je pense d'ailleurs que l'élève de Montmorillon ${ }^{[86]}$ et de Fribourg ${ }^{[87]}$ verra autre chose que ce qu'elle contient: des souvenirs de sa pieuse mère, de sa vocation, et d'un attachement qui est resté inaltérable. Si d'autres que vous lisent cette lettre, ces particularités, ces épanchements, ils savent bien que les rapports des membres de la Compagnie entre eux ont toute l'effusion et la simplicité de la famille ${ }^{88}$.

Paradoxalement, c'est cette lettre du père Chazelle à un scolastique, et non celle d'office du 10 août dont nous avons parlé plus haut — du même père à son provincial, qui se rapproche le plus des Relations. En effet, passé le paragraphe cité, qui clôt une introduction de deux paragraphes, le contenu de cette lettre de onze pages se divise en deux parties: une longue description du pays (l'île Walpole, la rivière SainteClaire et les bateaux et canots qui y circulent) et de sa population (nombre, mœurs et croyances de 700 autochtones de la nation des Sauteux), comme on en trouvait généralement en introduction à une relation du dix-septième siècle, et la description d'une assemblée de village dont sont rapportés, à la manière vivante des Relations, les propos des participants. Cette assemblée eut lieu quelque temps avant le 31 juillet [en fait, le 23 juillet $^{89}$ ] et le père Dominique du Ranquet avait dû y faire face aux chefs et aux anciens de l'île.

\footnotetext{
${ }^{86}$ Sous-préfecture de la Vienne (France) et chef-lieu d'arrondissement, sur la Gartempe.

${ }^{87}$ Ville de l'ouest de la Suisse, chef-lieu du canton du même nom, sur la Sarine.

${ }^{88}$ Dans $L N M C$, p. 215 , par. 2.

${ }^{89}$ Selon la lettre 13, du même père, Sandwich, 24 janvier 1845 , dans LNMC, p. 253, par. 1 .
} 
La lettre du 10 août, elle, ne comportait qu'une mention de l'île Walpole et un récit-résumé de l'affrontement du 31 juillet 1844 entre le père Chazelle, accompagné du père du Ranquet, et les chefs et les anciens du groupe amérindien. Le destinateur mentionnait que cet affrontement avait été la conséquence d'une rencontre précédente pendant laquelle le père du Ranquet avait dû affronter le même groupe, et il ajoutait: "Je pourrai peut-être dans une autre occasion vous parler de cette assemblée qui présenta plusieurs particularités d'intérêt ${ }^{90} . "$ Or, c'est cette assemblée qui est racontée dans la lettre au scolastique. Tout se passe donc, dans cette famille jésuite, comme si le père ne pouvait s'offusquer du fait que le texte qu'on lui avait annoncé soit envoyé à l'un de ses fils. On peut aussi voir dans cette façon d'agir un autre indice de la possibilité, sinon du souhait, que cette lettre circule dans la maison, voire dans la province; d'autant plus que la lettre se termine par une demande qui s'adresse à plus d'un: «Vous priez sans doute pour moi et pour nos Missions, mais j'espère de vous à présent et de vos confrères un secours plus spécial; vous le voyez, nos besoins sont grands ${ }^{91} . »$

\section{À UN PÈRE DE LA MÊME COMPAGNIE}

Les lettres «à un père de la même Compagnie» ne sont pas sans ressemblance avec celles destinées aux pères provinciaux; nous sommes même enclin à penser que plusieurs d'entre elles ont pu leur être adressées. Un appel de lettre comme «Mon Révérend Père» nous y invite, bien qu'il puisse aussi

\footnotetext{
${ }^{90}$ Lettre 7, Sandwich, 10 août 1844, dans ibid., p. 189, par. 3.

${ }^{91}$ Lettre 10, Sandwich, 8 septembre 1844, dans ibid., p. 225.
} 
désigner le supérieur d'une mission locale ou d'une maison de la Compagnie, ou encore un père plus âgé à qui le destinateur veut marquer son respect. Dans certains cas, le contenu de la lettre confirme la suggestion de l'appel. Deux lettres du père Chazelle appartiennent à cette catégorie de destinataires.

Celle du 11 novembre $1844^{92}$ commence par «Mon Révérend et bien cher Père», une formule qui laisse entrevoir l'existence de quelque amitié, mais dans le corps de la lettre, trois appels se lisent "mon Père ${ }^{93}$ " et sept «mon Révérend Père ${ }^{94} »$, dont celui de la salutation finale, lequel est suivi d'une formule qui n'a rien de familier: «avec le plus respectueux attachement en Notre Seigneur, votre tout dévoué Serviteur».

Dans la deuxième partie de la lettre ${ }^{95}$, c'est bien en sa qualité de supérieur des missions de la Compagnie de Jésus dans le Haut-Canade que le père Chazelle expose ses "pensées" et ses «vues» à la fois pour et contre la fondation, au Sault-Sainte-Marie, d'une mission «à laquelle (il) voudrai(t) bientôt donner l'existence» ainsi que sur les avantages d'établir «une mission au-delà du lac Supérieur»; ce sont deux fondations que réclame l'évêque ${ }^{96}$ de Détroit. Dans la troisième partie $e^{97}$, le père Chazelle invite le destinataire à faire avec lui un pèlerinage à «Sainte-Marie

\footnotetext{
${ }_{92}$ Lettre 11, Sandwich, 11 novembre 1844, dans ibid., pp. [226]-237.

${ }^{93}$ Dans ibid., par. 14, 17, 20.

94 Dans ibid., par. 2 (deux fois), 7, 8, 14, 19, 20.

${ }^{95}$ Dans ibid., pp. 229-231, par. 8-13.

${ }^{96}$ Pierre-Paul Lefèvre [Lefebvre] (1804-1869), né à Roulers (FlandreOccidentale, Belgique), émigrant aux États-Unis (1828), prêtre (1831), évêque coadjuteur et administrateur du diocèse de Détroit (1841), décédé le 4 mars 1869 . Voir $L N M C$, p. 890; É. Lecompte, Les Jésuites du Canada au XIX $X^{\mathrm{e}}$ siècle, 1842-1872, p. 87.

${ }^{97}$ Dans LNMC, pp. 23 I-237, par. 14-20.
} 
qui était autrefois comme la Métropole du pays des Hurons»; il aimerait convaincre son compagnon de l'importance et de l'urgence qu'il y a pour les jésuites d'y faire des fouilles, afin d'en dégager le trésor spirituel avant que des chercheurs d'or ne s'y amènent. Les trois souhaits ou demandes du père Chazelle ne peuvent guère s'adresser qu'à un provincial, le père Clément Boulanger, celui de Paris en l'occurrence. Une fois cette constatation faite, on ne doute plus que la première partie du texte ${ }^{98}$ était bien un rapport à ce provincial sur la situation des missions existantes et l'on comprend que l'auteur de la lettre ait tellement insisté sur les besoins de la mission de l'île Manitouline: il les exposait à celui qui devait y pourvoir.

À la différence de la précédente, la lettre du 24 janvier $1845^{99}$ débute par un simple «Mon Révérend Père». Les premières lignes font état d'une promesse à tenir:

Dans une lettre que vous avez sans doute reçue, il était question d'une assemblée de sauvages dans l'île Walpole. J'ai oublié de vous dire qu'elle eut lieu le 23 juillet [1844]. Aujourd'hui voici le 31 juillet [1844] que je vous ai promis et que vous attendez peut-être avec quelque impatience. Je vous avouerai que je me suis un peu repenti de ma promesse, pour plusieurs raisons. La difficulté d'être aussi complet et aussi exact que je le désire a été une des principales.

Maintenant, le destinateur a terminé son travail et, examen fait par le père du Ranquet, tous deux ont conclu que le texte était satisfaisant. À qui le fera-t-il tenir, sinon à celui à qui il a promis le texte des discours du 31 juillet? Mais à qui a-t-il fait cette

${ }_{98}$ Ibid., pp. [226]-229, par. 1-7.

${ }^{99}$ Lettre 13, Sandwich, dans ibid., pp. 252-275. 
promesse? Deux lettres nous fournissent des indices. À la fin de sa lettre au frère scolastique de Laval, le père Chazelle lui annonçait une lettre qui ne contiendrait que des discours. Tel est bien le contenu de la présente. Il se trouve, cependant, que l'appel du début et celui de la salutation finale se lisent: «Mon Révérend Père» et non pas «Mon bien cher Frère». La lettre du 10 août laissait à entendre au provincial de Paris que son destinateur pourrait «peut-être dans une autre occasion" lui parler de la discussion qui avait eu lieu entre le père du Ranquet et les chefs et anciens de l'île Walpole; nous avons vu qu'il en avait plutôt fait tenir le compte rendu au scolastique de Laval.

Mais il avait aussi laissé à entendre le 10 août qu'il n'était pas satisfait du compte rendu qu'il allait faire du 31 juillet: «[...] je n'ai ni le loisir, ni la connaissance nécessaire pour vous rapporter au long les harangues qui me furent adressées." Ce n'était pas une promesse, mais peut-être sentait-il déjà l'obligation qui, un jour, s'imposerait à lui de rédiger, pour bien éclairer son provincial ou justifier sa façon de procéder, un compte rendu précis des discussions du 31 juillet; or, le problème existait toujours et il s'était même aggravé, car il avait été porté jusqu'au gouverneur général, sir Charles Metcalfe ${ }^{100}$, qui, maintenant, persécutait les pères.

L'oubli de la date de la première assemblée est également un indice, bien que l'on remarque la même omission dans la lettre au scolastique et dans celle au père Boulanger. En effet, c'est plutôt à ce provincial

\footnotetext{
${ }^{100}$ Il fut gouverneur général du Canada de 1843 à 1845 . Voir Donald Robert Beer, «Metcalfe, Charles Theophilus, $1^{\text {et }}$ baron Metcalfe», dans $D B C$, vol. 7, pp. 653-660.
} 
qu'il importait de connaître cette date avec précision et c'est chez lui que l'impatience s'explique le mieux. De même, certaines lignes de la conclusion de la lettre ne se comprennent bien que si l'auteur s'adresse à quelqu'un à qui il doit rendre compte de ses activités. Ce sont les suivantes: «Si par hasard vous aviez besoin de quelqu'explication, indiquez-moi votre doute ou votre désir. Je serais bien aise de savoir ce que vous pensez de nos Indiens de l'île du Sud ou Walpole. J'ai trouvé un véritable plaisir à vous les faire connaître, parce que j'ai cru que vous désiriez les connaître $[. . .]^{101}$.»

Une lettre du père Nicolas Frémiot ${ }^{102}$ «à un père de la même Compagnie» pourrait bien, elle aussi, avoir été destinée au provincial de Paris. Datée du 24 juillet $1848^{103}$, elle aurait été reçue par le père Ambroise Rubillon ${ }^{104}$. Elle commence comme suit: "Vous savez sans doute mon départ de la Prairie et ma nouvelle destination. Dans une lettre précédente,

${ }^{101}$ Ibid., pp. 274-275.

${ }^{102}$ Nicolas Frémiot (1818-1854), né le 5 octobre à Bellefontaine (Vosges, France), jésuite (1841), prêtre (1847), à Laprairie (1847-20 mai 1848), missionnaire à Pigeon River (1848-20 juillet 1849), L'ImmaculéeConception, près le Fort William [Thunder Bay] (1849-juin 1852), Wikwemikong (1852-1854); il se noya dans la rivière Mississagi, près de Blind River le 4 juillet 1854. Voir $L N M C$, pp. 887-888; Elizabeth Arthur, «Frémiot, Nicolas-Marie-Joseph (baptisé Nicolas-Joseph)», dans $D B C$, vol. 8, pp. 341-343; id., "Le Père Frémiot à Thunder Bay, de 1848 à $1852 "$, Revue d'histoire de l'Amérique française, vol. $25, \mathrm{n}^{\circ} 2$, septembre 1971, pp. [205]-223; Thunder Bay District, 1821-1892, a collection of documents, edited with an Introduction by Elizabeth Arthur, [Toronto], The Champlain Society for the Government of Ontario, University of Toronto Press, 1973, pp. xxix-xxx, xlvi-xlviil, 12, 79 note, 13-16, 73-76; É. Lecompte, Les Jésuites du Canada au XIX ${ }^{e}$ siècle, 1842-1872, pp. 124, 230-240, 248, 274.

103 Lettre 48, Rivière-aux-Tourtres [Pigeon River], dans LNMC, pp. 512-521.

${ }_{104}$ Ambroise Rubillon (1804-1888), provincial de Paris du 16 mars 1845 au 19 mars 1851 , selon le père Cadieux, ibid., p. 893. 
j'ai parlé assez longuement de mon voyage jusqu'au Sault-Sainte-Marie.» Le «sans doute» de la première phrase peut surprendre, puisque, normalement, c'est le provincial qui assigne à ses sujets leur lieu de résidence et de travail; il s'explique ici par le fait que le père Félix Martin, supérieur des missions jésuites du Bas-Canada, ignorait la destination ultérieure du père Frémiot lorsqu'il l'a envoyé à Sandwich. C'est là seulement que ce dernier a appris du père Pierre Point, supérieur local, qu'il était «destiné à aller avec le Père Choné fonder une nouvelle mission à Pigeon-River ${ }^{105}$ m. Ce renseignement se trouve justement dans la «lettre précédente» où le père Frémiot a raconté son voyage de Montréal au Sault-SainteMarie, et ladite lettre avait été envoyée au père Rubillon le 24 juin 1848 . Cet indice nous incite à croire que la lettre du 24 juillet, qui continue le récit entrepris dans la précédente et y fait référence, doit avoir le même destinataire.

D'autres destinataires de lettres «à un père de la même Compagnie» ne sont certainement pas des provinciaux, même si l'appel est presque toujours «Mon Révérend Père». C'est sur un ton d'amitié qui ne trompe pas que le père Jean-Pierre Choné ${ }^{106}$ écrit

\footnotetext{
${ }^{105}$ Lettre 47, Sault-Sainte-Marie, 24 juin 1848, dans ibid., p. 509, par. 6.

${ }^{106}$ Jean-Pierre Choné (1808-1878), né à Secourt (diocèse de Metz, France), prêtre (1932), jésuite (1837), études de théologie à Vals

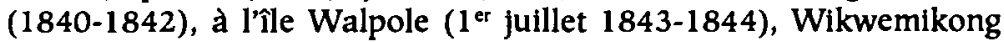
(1844-1847), Rivière-aux-Tourtres [Pigeon River] (1848-1849), Fort William (1849-1860), Wikwemikong (1860-1878); il décède à ce dernier endroit le 14 décembre 1878 . Voir $L N M C$, p. 885; É. Lecompte, Les Jésuites du Canada au XIX ${ }^{e}$ siècle, 1842-1872, pp. 84-86, 96, 100, 196-208, 210-215, 230, passim. - Selon É. Lecompte (ibid., p. 197), le père Choné serait né à Lecourt et sa date de naissance serait le 11 août, mais le père Cadieux (loc. cit.) écrit le 4 août. - Voir aussi $\mathrm{E}$. Arthur, «Frémiot, Nicolas-Marie-Joseph (baptisé Nicolas-Joseph)», dans
} 
le premier paragraphe de sa lettre du 22 janvier $1845^{107}$ :

Avant-hier, au moment où je rentrais à la maison revenant d'une excursion, on m'apporta votre bonne lettre. Je vous remercie de toute l'effusion de coeur que je ressentis en vous lisant. Je vous ai suivi et accompagné fidèlement partout. Vals ${ }^{[108]}$ et Mons ${ }^{[109]}$ m'ont rappelé des souvenirs qui ne s'effaceront jamais: ce sont des souvenirs d'un enfant caressé sur les genoux de sa mère au milieu de ses frères joyeux.

Dans le paragraphe suivant, le père remémore le temps de ses études théologiques à Vals et il termine sa lettre en évoquant avec émotion les beaux jours qu'il y a vécus au milieu d' «âmes généreuses». Le salut final, simple, n'a rien de la révérence due à un supérieur.

Deux des cinq lettres sans chaleur du père JeanBaptiste Menet ${ }^{110}$ ont une fin brusquée par le manque

$D B C$, vol. 8, p. 342; id., «Le Père Frémiot à Thunder Bay, de 1848 à $1852 "$, Revue d'histoire de l'Amérique française, vol. $25, \mathrm{n}^{\circ} 2$, septembre 1971, pp. 208-2 10, 21 2-2 16, 222-223; Thunder Bay District, 1821 1892, a collection of documents, edited with an Introduction by Elizabeth Arthur, [Toronto], The Champlain Society for the Government of Ontario, University of Toronto Press, 1973, pp. xxix, xlvil, 69, 73 note, 77-79, 80-81, 98, 175, 179, 186-187.

107 Lettre 12, Sainte-Croix, Grande Ile Manitouline, dans LNMC, pp. 237-252.

${ }_{108}$ Vals est une commune de l'Ardèche (France), arrondissement de Privas, sur la Volane.

${ }^{109}$ Mons est le chef-lieu de la province du Hainaut (Belgique). Les jésuites y avaient un collège.

${ }^{110}$ Jean-Baptiste Menet (1793-1869), né le 6 mars à Nantes (préfecture de la Loire-Atlantique, France) ou à Vigneux (France), jésuite (en Russie, 1815), prêtre (vers 1825), professeur en France (1825-1834) et en Galicie (1834-1845), missionnaire a Sandwich (1845-1846), au Sault-Sainte-Marie (1847-1860), à Troy [New York] (1860-1864), au Sault-Sainte-Marie (1864-1868); retraité à Québec, il y décède le 24 juin 1869. Voir LNMC, p. 891 ; É. Lecompte, Les Jésuites du Canada au $\mathrm{XIX}^{\mathrm{c}}$ siècle, 1842-1872, pp. 218-228, passim. - Selon É. Lecompte, (ibid., p. 218), le père Menet serait né près de Nantes. 
de temps ${ }^{111}$ et l'obligation de se rendre auprès d'un mourant $^{112}$; les trois autres se terminent par l'expression simple de "sentiments d'estime et d'affection ${ }^{113}$ ", ou de «respectueux attachement ${ }^{114}$ », ou une recommandation aux prières ${ }^{115}$ du destinataire; celui-ci n'apparaît jamais comme un ami, mais n'est certes pas un provincial. Comme le texte des quatre premières lettres s'enchaîne pour décrire la mission du Sault-Sainte-Marie en 1847, elles doivent avoir eu le même destinataire. Vraisemblablement, celui de la cinquième, en 1850 , fut différent, car, en reprenant la description des mêmes lieux alors qu'ils n'avaient pas beaucoup changé, le père Menet n'aurait guère appris à son destinataire de 1847 .

\section{À UN PARENT}

Seulement deux lettres ontariennes sont adressées à un parent, et elles sont écrites par deux frères coadjuteurs temporels. On pourrait s'attendre à ce qu'ils parlent de leur famille ou posent des questions à leur sujet. Mais tel n'est pas le cas. Les marques de familiarité sont presque inexistantes et le cœur ne livre ses sentiments qu'en peu de lignes.

La lettre ${ }^{116}$ du frère Joseph Jennesseaux ${ }^{117}$ à son

${ }^{111}$ Lettre 33, Sault-Sainte-Marie, 27 août 1847, dans LNMC, pp. 395399.

112 Lettre 36, Sault-Sainte-Marie, 24 septembre 1847, dans ibid., pp. 408-412.

${ }_{113}$ Lettre 35, Sault-Sainte-Marie, 10 septembre 1847, dans ibid., pp. 405-408.

${ }^{114}$ Lettre 68, Sault-Sainte-Marie, 12 juillet 1850 , dans ibid., pp. 629633.

115 Lettre 38, Sault-Sainte-Marie, 10 novembre 1847, dans ibid., pp. 423-427. Voir aussi la fin semblable dans la lettre 36.

${ }_{116}$ Lettre 57, île Walpole, $1^{\text {er }}$ avril 1849, dans ibid., pp. 563-565.

${ }^{117}$ Joseph Jennesseaux (1810-1884), né le 12 avril à Reims (Marne, 
frère, père jésuite, ne commence pas par «Mon cher Pierre $^{118} »$, mais par un appel aussi peu familier que «Mon Révérend Père et bien cher frère». Le frère Joseph décrit la situation difficile dans laquelle lui et le père Dominique du Ranquet se trouvent depuis que l'un des opposants à leur présence dans l'île Walpole a profité de leur absence d'une nuit pour incendier leur église et leur habitation. Les circonstances du malheur une fois décrites, le frère Joseph lance un appel émouvant:

Tous nos amis sont affligés de cette perte; mais très peu pourront nous aider à sortir de notre indigence. Recommandez-nous donc aux bonnes âmes de France, mon cher frère, me voilà médecin sans livres et sans médecines; chirurgien, dentiste, sans instruments. Je n'ai pas seulement une petite médaille pour contribuer à la nourriture spirituelle de mon âme; inutile donc de vous donner d'autres détails sur mes besoins, vous les comprenez assez. Le dénûment dans lequel se trouve le Père du Ranquet doit également exciter votre compassion; quand tout est brûlé, il ne reste plus rien.

Le frère Joseph termine sa lettre dans les mêmes dispositions filiales que le Job de la Bible. Sa famille est toute spirituelle: sa mère, c'est la pauvreté; Dieu, son père:

Il me semble que j'ai toujours aimé la pauvreté comme ma

France), jésuite (décembre 1831); arrivé à Montréal le 31 mai 1842, il étudie l'algonquin à Oka (1842-1844); il est ensuite missionnaire à l'île Walpole (1844-1850) puis à Wikwemikong (1850-1884), où il décède le 29 juin. Voir LNMC, p. 889; Alphonse Gauthier, «Il fut grand... sans bruit! Joseph Jennesseaux, s.j., 1810-1884», Héros dans l'ombre, mais héros quand même, Sudbury, la Société historique du Nouvel-Ontario (Collège du Sacré-Cœur), «Documents historiques», 32, 1956, pp. 20-32.

118 Pierre Jennesseaux (1804-1884), né à Reims (Marne, France), jésuite (1823); après avoir souffert d'un «continuel épuisement de forces" durant presque toute sa vie religieuse, il décède le 18 juin 1884. Voir ibid., p. 32. 
mère, mais ne l'ayant pas encore vue de si près, je n'en connaissais pas tous les charmes. C'est maintenant que je me trouve heureux d'être son enfant, et que je goûte les douceurs de lui appartenir. Dieu m'avait donné l'usage des choses les plus nécessaires, il me l'a ôté; que son saint nom soit béni! C'est un bon père, il sait ce dont j'ai besoin pour travailler et pour procurer sa gloire; me troubler de ce qu'il me manque serait l'offenser. Oui, je suis toujours content, et je l'espère avec la grâce du bon Dieu et le secours de vos prières, j'irai toujours en avant ${ }^{119}$.

Ces lignes d'un humble frère coadjuteur sont les plus spirituelles du volume. Elles expliquent la quasiabsence de la famille biologique: celle-ci, la plus lointaine, a été quittée pour celle-là, qui est devenue la plus proche, la plus intime.

La lettre du frère coadjuteur temporel Jean Véroneau $^{120}$ à sa mère a été copiée par lui dans une lettre adressée aux frères coadjuteurs de SaintAcheul $^{121}$. Cette lettre est, par le ton, un petit joyau de finesse et de tendresse qui adoucissent quelque peu la quasi-absence dont nous venons de parler.

Le cœur est présent dès le début. L'appel est chaleureux comme pas un autre dans les Lettres: «Mes bien chers frères en Jésus-Christ», et le premier paragraphe sourd d'une délicate simplicité fraternelle:

J'ai souvent pensé que je vous ferais grand plaisir, si de ce

\footnotetext{
${ }^{119}$ Lettre 57, Île Walpole, $1^{\text {er }}$ avril 1849, dans LNMC, pp. 564-565. 120 Jean Véroneau (1813-1859) né le 20 mars à Le Perrier (Vendée, France), jésuite ( 30 avril 1842), arrivé à Wikwemikong le $1^{\text {er }}$ décembre 1846, il va solgner ses rhumatismes au collège Sainte-Marie de Montréal (19 juillet 1857-1858), revient à Wikwemikong (1858), puis, à cause de sa maladie, retourne au collège Sainte-Marie ( 25 juillet 1859), où il décède le 3 août. Voir LNMC, p. 894; A. Gauthier, "L'Homme aux cent métiers, Jean Véroneau, s.j., 1813-1859", Héros dans l'ombre, mais héros quand même, pp. 13-19.

121 Lettre 54, Sainte-Croix, île Manitouline, 9 octobre 1848, dans LNMC, pp. [545]-548.
} 
pays lointain je vous envoyais une lettre qui fit passer jusqu'à vous un peu de l'air que nous respirons ici. Cependant, comme vous voyez, ma pensée et le désir qui l'accompagnait ont été souvent, depuis plus de deux ans que je suis en Amérique, comme ces désirs en songe dont parle Rodriguez $^{[122]}$ dans son traité de la Perfection Chrétienne. Pourtant, me suis-je dit un jour, il faut en finir: voici une belle occasion, je vais en profiter. Mais, nouvel embarras; ma mère, elle aussi, a été mise au même régime que vous; j'ai done deux lettres à écrire pour satisfaire à toutes mes obligations; par où commencer? et comment finir? Enfin, je me suis résolu à faire d'une pierre deux coups, et de vous envoyer tout simplement la lettre que j'écris à ma mère ${ }^{123}$.

La lettre suit. Le frère se dit heureux dans la vocation qu'il a choisie, même s'il est «bien loin» de sa mère et qu'il «travaille beaucoup tous les jours», car "ce travail et cette absence, quoiqu'il en coûte à la nature, (il) les aime parce qu'ils glorifient Dieu». Il décrit sa tâche, son milieu de vie, fait part des difficultés, porte un jugement nuancé sur les Odjibwés. Ils se comportent "presque déjà comme des civilisés». Païens, ils étaient cruels et vindicatifs; chrétiens, ils «vivent entre eux comme de bons frères».

À l'intérieur du texte, on lit deux appels: «ma bien chère mère» et "ma chère mère». La salutation finale est affectueuse:

Je finis cette lettre, ma chère mère, en vous embrassant de tout mon cœur; souvenez-vous de moi dans vos prières, je ne cesserai pas non plus de me souvenir de vous devant le bon Dieu et la Sainte Vierge.

Votre respectueux et tout dévoué fils ${ }^{124}$.

122 «Alphonse Rodriguez (1526-1616), Jésuite espagnol, publia en 1609 un livre: La Pratique de la perfection chrétienne, qui fut traduit dans presque toutes les langues européennes." LNMC, p. [545], note 2.

${ }^{123}$ Lettre 54, Sainte-Croix, île Manitouline, 9 octobre 1848, dans LNMC, p. [545].

${ }^{124}$ Dans ibid., p. 548. - Parmi les lettres québécoises, il s'en trouve une qui est destinée à un parent. Elle est adressée de Montréal le 27 
À DES GROUPES DE SCOLASTRQUES JÉSUITES

Les lettres écrites à des groupes de scolastiques jésuites ont toujours pour but de susciter des vocations pour les missions indiennes de l'Ontario.

Quand le père Nicolas Frémiot écrit aux scolastiques jésuites de Laval le 11 mai $1850^{125}$, il fait l'éloge du courage des Amérindiens de la région de Thunder Bay pendant le très rude hiver qui a fait des victimes de la faim et du froid, puis il raconte «une de (s)es excursions un peu aventureuse»: pour porter les secours de la religion à une jeune malade, il a risqué sa vie plusieurs fois pendant une marche de huit jours, à la fin d'avril, sur la glace fondante des lacs, dans l'eau froide des rives ou dans la neige des montagnes. Le 7 août $1852^{126}$, c'est le récit d'un voyage de "près de 300 lieues, [...] depuis le Lac Nipigon, jusqu'à la Grande Manitouline», qu'il envoie aux scolastiques de la même maison; cette fois, c'est la vie de l'Église (ministères des prêtres et pratique des fidèles) qu'il décrit. Le dernier paragraphe de chaque lettre est une invitation pressante à venir œuvrer dans les missions indiennes de l'Ontario.

L'appel de la première lettre se termine par un

juillet 1847 par le père Félix Martin à son frère Arthur, père jésuite. L'appel familier, «Mon cher Arthur», est le seul du genre dans les Lettres. Il n'y a pas d'appel dans le corps du texte et il n'y est pas question de la famille. Le discours porte uniquement sur le typhus à Montréal en 1847. La lettre se termine de la façon suivante: «Adieu, mon cher Arthur, vous voyez que nous avons besoin de vos prières. Ne soyez pas surpris si vous entendez parler bientôt des victimes que la contagion aura faites dans nos rangs. À la volonté de Dieu! Tout à vous en Notre-Seigneur." Lettre 31, dans $L N M C$, pp. 385-388.

${ }^{125}$ Lettre 66, L'Immaculée-Conception, près le Fort-William, dans $i b i d$., pp. [616]-623.

${ }_{126}$ Lettre 88, Sainte-Croix, Grande Manitouline, Lac Huron, dans ibid., pp. [842]-849. 
commandement évangélique qui s'adresse aux pères tout autant qu'aux scolastiques:

Et vous, mes RR. PP. et mes chers FF., quand donc viendrez-vous avec nous [...]? Venez; c'est ici que vous attendent de nobles travaux, de glorieuses conquêtes et de bien douces jouissances ${ }^{127}$.

L'invitation de la seconde lettre est plus émouvante:

$[\ldots]$, mes Révérends Pères et mes chers Frères, $[\ldots]$ je ne puis vous dire adieu sans pousser jusqu'à vous le soupir de mon humble prière, sans faire appel à l'ardeur de votre zèle. Ah! pour l'amour de Notre Seigneur qui a bien voulu nous enrôler dans sa petite Compagnie, pour l'amour de ces âmes si abandonnées, pour lesquelles néanmoins il a versé son sang, aidez-nous, je vous en conjure, aidez-nous de vos prières, et, autant que la Sainte Obéissance vous le permettra, aidez-nous de vos personnes. Car, si la moisson n'est pas aussi abondante ici qu'en d'autres contrées, elle est peut-être plus précieuse, mais surtout il faut le dire plus disproportionnée au nombre des ouvriers. Puisse notre cri de détresse trouver écho dans vos cœurs généreux! Puissiez-vous y répondre par le cri des braves: Eamus et nos et moriamur ${ }^{128}$.

\section{À DES GROUPES D'ÉLEVVES DE JÉSUITES}

La lettre du père Jean-Pierre Choné aux élèves du collège jésuite de Brugelette a le même but que celles du père Frémiot aux scolastiques de Laval, mais ce but n'est pas explicité ${ }^{129}$.

Le père Choné avait déjà envoyé aux collégiens des objets accompagnés de petites notes qui les

\footnotetext{
${ }^{127}$ Lettre 66, dans ibid., pp. 622-623, par. 12.

${ }^{128}$ Lettre 88, dans ibid., pp. 848-849, par. 11. - Traduction de la phrase latine: "Allons, nous aussi, et mourons avec lui.» Évangile de saint Jean, chap. XI, verset 16.

${ }^{129}$ Lettre 32, Sault-Sainte-Marie, 7 août 1847, dans LNMC, pp. 388-395.
} 
avaient renseignés sur «les mœurs et les usages» des Odjibwés. Cette fois, c'est un «aperçu» de sa vie de missionnaire qu'il veut leur donner. Il commence par le récit de l'une de ses "petites excursions". Il l'a faite auprès d'un malade qui désirait recevoir le baptême, mais changea d'idée après l'intervention d'un jongleur. Le missionnaire ne put que rendre quelques services aux catholiques du village, et le voyage de retour par mauvais temps fut très pénible. L'échec amène le père Choné à parler du "caractère faible" des convertis et du peu de fermeté de leur foi, surtout quand interviennent les méthodistes «qui les tourmentent sans cesse" et vont même jusqu'à leur dire "que le gouvernement favorise plus les protestants que les catholiques, que ceux-ci dans quelque temps ne recevront plus les présents ordinaires, qu'ils seront même chassés du village tandis que les protestants seront toujours bien traités ${ }^{130}$ ». Il arrive cependant que des méthodistes, fidèles ou pasteurs, reviennent au catholicisme ou y adhèrent. La lettre se termine par le récit de conversion d'un chef amérindien, dont la tradition familiale avait conservé le souvenir des Robes-Noires d'autrefois, et le baptême d'une octogénaire qui avait "résisté aux exhortations de ses enfants catholiques» durant des décennies.

Nous pouvons aussi considérer comme une lettre destinée indirectement, mais explicitement, aux élèves du collège de Brugelette, celle que le père Frémiot adressa le 18 octobre $1851^{131}$ «à un scolastique de la même Compagnie». En effet, le contenu de la lettre nous permet de déterminer que ce scolastique non

${ }^{130}$ Dans ibid., p. 392 , par. 5.

${ }^{131}$ Lettre 78, L'Immaculée-Conception, près le Fort William, Lac Supérieur, dans ibid., pp. [752]-762. 
seulement avait été le condisciple du père au dit collège, mais qu'il y occupait maintenant une chaire où il pouvait former à la fois de bons citoyens pour la France et des apôtres pour les missions indiennes du Canada. Le père Frémiot s'en réjouit dans le premier paragraphe de sa lettre:

[...], heureux ami, gardien et maître de l'enfance, connaissez votre bonheur, connaissez votre sublime mission; faites, faites des apôtres et sans sortir de votre modeste chaire, vous aurez plus conquis d'âmes à leur seul légitime Souverain que votre serviteur, malgré tous ses sermons, malgré toutes ses courses, ses fatigues et ses périls $[\ldots]^{132}$.

Et le père de nommer les destinataires qu'il recherchait par l'entremise de son confrère en commençant, de la façon suivante, son long récit d'une course apostolique à l'île Royale: «Permettez-moi, mon cher Frère, de vous raconter, aujourd'hui, pour le profit de vos futurs missionnaires, une petite promenade de ma façon.»

Dans l'avant-dernier paragraphe de sa lettre, le père revenait à la charge:

Ah! puisse une noble ambition s'emparer de ces cours généreux que vous formez à la science et à la vertu, et tourner leur ardeur pour la gloire, non vers la carrière des Alexandre, des Démosthène, des Homère ou autres célébrités profanes mais bien vers celle des Paul, des Xavier, des Ricci, des Spinola et de tant d'autres qui l'ont parcourue après eux! L'une vient se briser devant la poussière du tombeau, l'autre s'élance par-delà les ruines de l'univers et n'a de terme que dans l'éternité ${ }^{133}$.

Enfin, dans le dernier paragraphe, le père souhaite aux élèves, «dans les carrières des sciences, des succès

${ }^{132}$ Dans ibid., p. 753, par. 1.

${ }^{133}$ Dans ibid., pp. 761-762, par. 17. 
qui répondent à leur application, et qui sont comme un prélude indispensable à la vocation apostolique». Le missionnaire n'a jamais quitté sa ligne de visée: faire naître des vocations missionnaires chez les élèves de son confrère.

\section{À UN SUPÉRIEUR DE SÉMINAIRE}

C'est la même ligne qu'il avait suivie, huit mois plus tôt, dans sa lettre ${ }^{134}$ à monsieur Micard, supérieur du séminaire de Saint-Dié. Toutefois, il avait procédé différemment. Après avoir assuré son destinataire qu'il n'avait pas oublié ses vieilles connaissances, il avait entrepris de lui faire connaître sa «solitude», c'est-à-dire de décrire de façon systématique le pays qu'il habitait, ses travaux de missionnaires ainsi que la vie, les mœurs et les coutumes des Odjibwés ou Sauteux qu'il desservait ou essayait de gagner à la foi catholique. La qualité documentaire et littéraire des vingt-neuf pages ${ }^{135}$ qu'il a consacrées à cette description apparente sa lettre aux meilleures Relations.

S'il l'a faite si longue, c'est que, par l'intermédiaire de monsieur Micard, il veut rejoindre les séminaristes. On le voit à la fin de sa lettre. L'appel du missionnaire ne compte pas moins de cinq pages ${ }^{136}$. Elles sourdent émouvantes du cœur d'un homme sensible et tout empreintes de la rhétorique touchante du romantisme. Si l'écrivain-orateur interpelle d'abord son destinataire et lui rappelle la phrase de saint François-Xavier, à savoir que «aller au bout du

${ }^{134}$ Lettre 75, Sault-Sainte-Marle, 2 févrler 1851, dans LNMC, pp. 707741.

${ }^{135}$ Dans ibid., pp. 708-736, par. 3-39.

${ }^{136}$ Dans ibid., pp. 736-741, par. 40-44. 
monde, sauver une âme et mourir, c'est là un sort digne d'envie», c'est que, en brandissant cet idéal dont il n'exclut pas la possibilité du martyre, si minime soit-elle en 1851 , il ne pourra qu'en appeler avec plus d'autorité et de fascination aux jeunes séminaristes de monsieur Micard. Voyons-le déployer son style sur une de ses pages-appelantes:

Oh! que ne puis-je, en ce moment, me transporter de corps, comme je le fais en esprit, au milieu de votre nombreuse et fervente communauté! ou plutôt que ne puis-je leur faire voir des yeux, leur faire toucher du doigt, les misères dont je suis le triste témoin! que ne puis-je faire retentir à leurs oreilles les cris de détresse de tant d'âmes qui se perdent jour et nuit!... Que dis-je? leurs cris de détresse... disons vrai, les clameurs de leur joie insensée qui se précipite sans souci vers l'abîme, et les transports d'infernale allégresse que la ruine de ces nobles enfants de Dieu arrache à l'ennemi de tout bien. Oui, que ne puisje voler au milieu de vous, chers Séminaristes de SaintDié, ou vous transporter avec moi le long de ces fleuves et de ces lacs, images du temps et de l'éternité, où des millions d'êtres à forme humaine, doués d'une âme raisonnable et immortelle végétent dans la misère et la dégradation, se jouent avec toutes les superstitions de l'enfer, et périssent victimes de leur ignorance. Si ce vœu de mon cœur pouvait se réaliser, je vous dirais, les genoux en terre et l'image de mon Sauveur à la main:

O vous tous, qui m'êtes unis par les liens d'une patrie commune, par la même vocation sacerdotale, par l'éducation cléricale sous les voûtes du même sanctuaire, souffrez qu'un inconnu vous parle, vous prie, vous conjure; au nom de tous ces titres déjà si puissants, au nom de vos plus chers désirs - Dieu les connaît, ils sont pour sa gloire, ils sont pour les âmes -; au nom de cette générosité d'âme qui distingue toujours les vrais enfants des Vosges; que dirai-je encore? au nom de Jésus le divin conquérant des âmes, regardez, je vous en supplie, contemplez, prêtez l'oreille. Ne voyez-vous pas ces pauvres sauvages plus nus, plus misérables, plus dégradés et presque aussi ignorants que les animaux de leurs forêts; décimés par 
le froid, par la faim, par la contagion; perpétuels jouets enfin des plus grossières superstitions, jusqu'à ce qu'ils périssent ensevelis dans une même ruine avec l'infernal tyran qui sut capter leurs hommages! Infortunés aveugles! ils sont religieux, oui sans doute; mais ce n'est que pour honorer le démon qui les abuse d'une manière si cruelle! Et personne ne songe à leur découvrir le piège! personne n'est là pour leur jeter un cri de salut, et leur tendre une main secourable!... La soif de l'or pousse mille aventuriers jusqu'aux coins les plus reculés de ces sombres forêts: elle leur impose les plus rudes privations, des sacrifices non d'un jour, mais de toute une vie, et ils s'y résignent, et ils les acceptent avec bonheur. Et ces âmes plus précieuses que l'or, ces perles inestimables qu'un Dieu est venu retirer de cette fange terrestre pour en faire l'ornement des cieux, personne n'y songe, personne ne se dévoue pour les recueillir, les dégrossir, les laver dans le sang de l'Agneau et les enchâsser comme autant de pierres vivantes dans les murs impérissables de la Jérusalem Céleste ${ }^{137}$ !

\section{À UN GROUPE DE LAÏCS}

Bien différente est la seule lettre ${ }^{138} \mathrm{du}$ volume qui soit adressée à un groupe de laïcs - aucune ne l'est à une personne laïque en particulier: celle du frère Jean Véroneau à sa mère ne nous est donnée à lire dans les Lettres que transcrite dans celle qu'il a adressée aux frères coadjuteurs de Saint-Acheul. Écrite à Sandwich [Windsor], le 17 avril 1845, par le père Chazelle, alors supérieur des missions de la Compagnie de Jésus dans le Haut-Canada, cette lettre unique a pour destinataires messieurs les membres du Conseil central de l'CEuvre de la Propagation de la foi ${ }^{139}$, qui

\footnotetext{
${ }^{137}$ Dans ibid., pp. 737-738, par. 41.

${ }^{138}$ Lettre 16, dans ibid., pp. [281]-291.

${ }^{139}$ Cette œuvre avait pris naissance à Lyon le 3 mai 1822 lors d'un rassemblement de laïcs qui avaient pour but de lever des fonds pour les missions de la Louisiane. Le groupe se joignit ensuite à Pauline Jaricot qui organisait des collectes pour les Missions étrangères de
} 
la firent publier la même année dans les Annales de la Propagation de la foi ${ }^{140}$.

\section{Cette lettre est un tribut de reconnaissance à l'endroit}

Paris depuis 1818. On adopta sa façon de procéder et les bénéfices de l'œuvre (prières et collectes) furent étendus à toutes les missions. Pauline Jaricot abandonna presque aussitôt la direction générale de l'œuvre. Plusieurs années plus tard, le pape Léon XIII la reconnaîtra officiellement comme fondatrice de l'œuvre. Celle-cl sera dirigée de France par un conseil de laïcs français jusqu'en 1922, alors que le siège en est déménagé à Rome. Le pape Ple XI la restructure par la suite et en fait la principale pourvoyeuse de fonds pour toutes les missions catholiques. D'après the New Encyclopedia Britannica, Fifteenth Edition, 1984, Vol. 8, p. 239, et Encyclopaedia Universalis, vol. 19, sixième publication, novembre 1978, p. 966.

Dans sa lettre du 22 janvier 1845, écrite de Salnte-Crolx, grande île Manitouline, «à un père de la même Compagnie", le père Choné rapporte que l'association de la propagation de la fol a été établie dans la mission; "on en récite les prières» tous les jours et les "sauvages donnent pour la propagation de la foi des nattes, du sucre d'érable, des fruits de la terre". (Lettre 12, dans LNMC, p. 239.) On avait donc procédé rapidement à l'établissement de cette association, puisque le père Choné n'était arrivé à Sainte-Croix que le 8 ou le 9 juillet précédent (Lettre 5, ibid., p. 172, par. 1 et note 4.)

Prêté au collège Regiopolis de Kingston à la demande de Mgr Patrick Phelan, évêque-coadjuteur du diocèse de Kingston, le père RémlJoseph Tellier, arrive au collège le 6 octobre, en prend la direction le 10, s'empresse d'y établir l'ouvre de la propagation de la foi le 3 décembre sulvant et «form(e) trois dizaines d'associés». Ce fut "dans le diocèse de Kingston, le premier noyau de cette admirable institution". (Lettre 70, du père Jean-Baptiste-Adolphe Larcher au R. Père Provincial à Paris [le père Ambroise Rubillon], Montréal, le $1^{\text {er }}$ octobre 1850 , dans ibid., pp. 655 et 656, par. 24 et 27 .)

Si l'on en juge d'après ces deux gestes hâtlfs et l'éloge contenu dans la lettre du père Chazelle, le 17 avril 1845, aux membres du Conseil central de l'œuvre, à Lyon (Lettre 16, dans ibid., pp. [281]-282, par. 1-6), les jésuites des nouvelles missions du Canada auralent accordé beaucoup d'Importance à l'CEuvre de la Propagation de la fol.

${ }^{140} \mathrm{~N}^{\circ} 3$, novembre 1845 , pp. 449 et sulvantes. - Le père Martin avait signalé cette lettre dans son édition des Lettres, mais ne l'y avait pas insérée [serait-ce parce que, lancée dans le public une dizaine d'années auparavant, elle était bien connue? ou bien parce qu'elle ne s'adressait pas au milieu de la Compagnie? ou pour quelque autre raison?]. Le père Cadieux, qui visait le grand public, a jugé bon, avec raison, de la transcrire dans la sienne. 
de l'CEuvre qui vient d'apporter son secours à la nouvelle mission du Haut-Canada. Le père fait l'éloge de cette œuvre qui, après des débuts modestes, en est venue à répandre ses bénéfices à travers le monde entier et il se réjouit de ce que Dieu ait voulu qu'elle voit le jour à Lyon, «ville qui, après Rome, est la ville des Martyrs", et sa "patrie ${ }^{141}$ ».

La partie centrale de la lettre ${ }^{142}$ est une esquisse de l'histoire des Amérindiens depuis le dix-septième siècle. Elle comprend une présentation des différentes tribus des deux Canadas et une description de leur situation et de leur vie depuis le départ des jésuites après la conquête britannique et l'arrivée des méthodistes en 1830. Le père Chazelle expose ensuite les projets apostoliques de ses missionnaires et décrit leurs lieux de travail: Sandwich, une paroisse presque entièrement composée de Franco-Canadiens; l'île Walpole, où les Indiens, fiers d'avoir conservé fidèlement les coutumes de leurs ancêtres, résistent au catholicisme; une réserve indienne voisine que les méthodistes ont conquise; l'île Manitouline, qui

141 Lettre 16, dans LNMC, p. 282, par. 6. - C'est près de Lyon (Saint-
Just-en-Bas ou Montbrison) sinon dans cette ville même, que le père
Chazelle était né; puis il avait fait ses études classiques et théologiques
au séminaire de Montbrison [chef-lieu d'arrondissement de la Loire, a
quelque soixante-dix kilomètres au sud-ouest de Lyon et à 34 kilomè-
tres au nord-ouest de Saint-Étienne] avant d'y enseigner la philoso-
phie, la théologie et la rhétorique (selon G.-E. Giguère, dans DBC, vol.
7 , p. 185). Avant de quitter la France pour le Canada, il avait falt partie
de la province jésuite de Lyon (d'après É. Lecompte, Les Jésuites du
Canada au XIX' $X^{\circ}$ siecle, $1842-1872$, p. 36). Ainsi s'explique le fait qu'il
considère Lyon comme sa patrie et que, s'adressant à un groupe de
Lyonnais parmi lesquels il avait probablement quelques connaissances,
il puisse écrire, après avoir fait l'éloge des succès de l'Cuvre de la
Propagation de la foi: «Vous savez, Messieurs, quel est celui qui écrit,
et il n'est pas nécessaire de vous dire si son coeur est touché de cette
nouvelle gloire de sa patrie.» ${ }^{142}$ Dans LNMC, pp. 283-289, par. 7-28. 
pourrait devenir une terre promise, car elle compte près de sept cents catholiques parmi ses onze cents habitants, malgré le fait que l'Église d'Angleterre y ait réuni ses convertis dans un village qu'elle a bâti. Et des projets sont en cours pour des établissements catholiques au Sault-Sainte-Marie et au lac Supérieur.

Le père Chazelle termine son esquisse par un éloge de l'Indien"143. Il a, malgré ses "grandes infortunes nationales» et sa "misère privée, qui est quelquefois extrême», "des qualités estimables qui se révèlent à un sage observateur». Et le missionnaire d'affirmer que «seule» l'Église catholique, qui «sait donner à chaque peuple, comme à chaque individu, ce qu'il lui faut pour cette vie et pour l'autre [...] peut, modifiant la nature et les habitudes de l'Indien, le rendre chrétien, fervent et heureux, sans qu'il cesse d'être sauvage». Pour y arriver, il faudra le garder «loin des sectes et des vices des hommes civilisés, loin des marchands et surtout des vendeurs de boissons enivrantes». À cette fin, la Grande Manitouline pourrait être un «refuge».

\section{IV - FORMES ET CONTENUS}

De la lecture des deux paragraphes du père Frémiot que nous avons cités plus haut, il ne faudrait pas avoir conclu que le lyrisme romantique imprègne toutes les pages des Lettres. Il n'est, au contraire, présent que par petites touches dispersées, même dans les lettres du père Frémiot, exception faite des cinq pages dont nous avons tiré les deux paragraphes reproduits. C'est plutôt le classicisme qui domine

${ }^{143}$ Ibid., pp. 289-290, par. 29-35. 
dans les Lettres, et encore est-ce souvent celui sans éclat de la fin du dix-huitième siècle. La mystique qui inspirait les missionnaires de la Huronie et faisait lever leurs textes ne se retrouve pas chez les missionnaires des Odjibwés; ceux-là recherchaient avec ardeur la gloire du martyre, ceux-ci ne la fuiraient pas, mais ne la croyant guère accessible ${ }^{144}$, ils n'ambitionnent que l'héroïsme sans auréole d'un quotidien de misère et d'impuissance devant l'ampleur de la tâche à accomplir.

Leurs lettres se ressentent de cet état d'esprit. À l'inverse de ce que l'on trouvait dans les Relations, les difficultés personnelles des pères et les sentiments qui les habitent y occupent presque autant de place que les comptes rendus apostoliques. Cette façon de faire ainsi que les appels à l'aide que lancent régulièrement les auteurs des Lettres ontariennes laissent deviner la pesanteur d'un fardeau que les missionnaires de la Huronie ne jugeaient jamais trop lourd.

Aussi peut-on appliquer aux Lettres ontariennes ce que Pierre Berthiaume ${ }^{145}$ a conclu de sa lecture des Lettres édifiantes, à savoir qu'elles "parlent moins de martyres que des "peines" et des "travaux" des pères qui, tout pénibles qu'ils sont, demeurent en deçà de la sainteté», et qu'elles "produisent moins des saints que des hommes qui témoignent de leur expérience

144 Après avoir écrit que le missionnaire ne pourra «peut-être» pas avolr le bonheur de verser son sang dans les missions indiennes de l'Ontario au dix-neuvième siècle, le père Nicolas Frémlot s'explique: "Peut-être!.. car enfin, la palme du martyre n'est pas ce me semble à jamais bannie de ces régions assises à l'ombre de la mort, où le démon tient encore le triple sceptre de la cruauté, de la licence et de la superstition.» Lettre 75, Sault-Sainte-Marie, 2 février 1851 , dans $L N M C$, p. 737.

${ }^{145}$ L'Aventure américaine au XVIII' siècle, p. 293. 
avec son lot de maux et d'émotions». La comparaison suivante, que Berthiaume a établie entre les Relations et les Lettres édifiantes, vaut aussi dans le cas des Lettres ontariennes: "Autant les Relations demeuraient pudiques sur les émotions intimes des rédacteurs, autant les Lettres édifiantes témoignent des sentiments des missionnaires, fussent-ils des plus simples, voire teintés d'une certaine ambiguïté ou d'amertume ${ }^{146} »$. Il n'en demeure pas moins que les rédacteurs des Lettres ne visaient pas, comme ceux des Lettres édifiantes, le grand public. On ne peut donc affirmer de celles-là ce que Berthiaume a écrit de celles-ci, à savoir que leur écriture plus personnelle, plus humaine, avait pour but de «rapprocher les prêtres des hommes ${ }^{147}$ ". Il n'empêche que cette écriture, qui, à la différence de celle des Relations, établit un contact plus intime avec le lecteur en donnant plus de place à l'itinéraire personnel du missionnaire, a pu produire, sur le public restreint des jésuites de France et sur leur entourage ainsi que sur les lecteurs de l'édition Cadieux, le même effet que Berthiaume attribue à l'écriture des Lettres édifiantes:

L'apparition du sujet, ou plus exactement l'exploitation de sa présence au sein du récit, a le double mérite, sinon la double fonction, de fonder les observations et les descriptions sur le vécu des narrateurs et, par là, de leur conférer le sceau de la vérité, comme l'exige la définition du terme «relation", et de faire du missionnaire un témoin, d'autant plus efficace sur le plan pastoral qu'il aura su créer des liens privilégiés avec le lecteur dont il partage l'intimité ${ }^{148}$.

Toutefois, le caractère personnel des Lettres ne les empêche pas d'être des relations. Même si le destinataire

${ }_{146}$ Ibid., p. 294.
${ }^{147}$ Ibid., p. 293.
${ }_{148}$ Ibid., p. 294. 
n'est plus le grand public, mais un individu ou un groupe, et que le cadre classique de la lettre a transformé la présentation du texte - il ne se découpe plus en chapitres comme la plupart des Relations ni en parties comme celles de 1636, 1659 (trois lettres), 1671 et 1672 , mais en paragraphes seulement comme celles de $1626,1632,1633$ - il reste que, tout comme les narrateurs des Relations, ceux des Lettres relatent ce qu'ils ont fait et observé dans les lieux qu'ils habitent ou qu'ils ont traversés ou sillonnés; ils injectent cependant un peu plus d'âme et de subjectivité à un genre teinté d'objectivité. Bien plus, ils utilisent les mêmes formes littéraires: le récit et la description, sans que leurs Lettres, tout comme les Relations, cessent de tenir du journal, quand le récit est découpé, voire structuré par des dates, ou du mémoire et du rapport ou du compte rendu, quand le narrateur expose une situation ou des faits à son supérieur. Et plus encore, la description s'insère tout autant dans les récits des Lettres que dans ceux des Relations et, dans celles-là comme dans celles-ci, le récit est presque toujours au service de l'idéologie missionnaire. C'est ce que fera ressortir la présentation de quelques lettres.

\section{LA LETTRE RELATION DE MISSION}

Nous appelons «lettre relation de mission» celle qu'un jésuite missionnaire dans le Canada du dixneuvième siècle écrit d'office à son provincial de Paris pour rendre compte de ce que lui et ses confrères ont fait ou observé dans leur milieu de travail ${ }^{149}$.

\footnotetext{
${ }^{149}$ Peut-être est-il bon de rappeler ici, pour éviter que l'on confonde cette espèce de lettre avec le genre des Relations de la Nouvelle-France, que la meilleure définition de celles-ci serait la suivante, selon le père
} 
Ainsi, la lettre ${ }^{150}$ que le père Luc Caveng ${ }^{151}$ écrit le $1^{\text {er }}$ février 1848 de Wilmot [St. Agatha] ${ }^{152}$ près Petersburg ${ }^{153}$, au père Ambroise Rubillon, est une lettre d'office, c'est-à-dire fondamentalement le compte rendu que le missionnaire doit faire, à son provincial de Paris, de ses activités et de celles de ses deux confrères, le père Bernard Fritsch ${ }^{154}$ et le frère Fidèle Joset ${ }^{155}$, depuis leur départ de New York, le 27 juin 1847, pour la mission allemande de la région de Kitchener-Waterloo ${ }^{156}$ que Mgr Michael

L. Pouliot [Étude sur les «Relations» des jésuites de la Nouvelle-France (1632-1672), p. 7]: «Rapports annuels envoyés par le Supérieur de Québec au Provincial de Paris, imprimés au XVII ${ }^{\mathfrak{e}}$ siècle, répandus dans le grand public et dont le but est d'attirer des sympathies, des bienfaiteurs spirituels et temporels aux missions de la Nouvelle-France». ${ }^{150}$ Lettre 42, dans $L N M C$, pp. [455]-470.

${ }^{151}$ Luc Caveng (1806-1862), né le 25 mars à Tavetsh (Suisse), jésuite (1830), arrivé en Amérique en 1847; tl décède à Buffalo (New York) le 27 mars 1862. Voir LNMC, p. 884; É. Lecompte, Les Jésuites du Canada au XIX $X^{\mathrm{e}}$ siècle, 1842-1872, pp. 254-257.

152 "Canton organisé en 1825, situé au sud-ouest du comté de Waterloo.» Dans $L N M C$, p. [455], note 3. Selon nous il s'agirait plus précisément de St. Agatha, village situé à la croisée des routes 9 et 12, à trois kilomètres au nord-ouest de Petersburg, car le nom de la parolsse où résident les missionnaires de Wilmot est Sainte-Agathe de Wilmot (Lettre 42, dans ibid., p. [455], par. 1, et p. 463, par. 13).

${ }^{153}$ Village situé au sud-ouest de Kitchener, entre cette ville et Baden, à la crolsée des routes 6 et 12 .

${ }^{154}$ Bernard Fritsch (1812-1891), né le 15 février à Amberg (Bavière, Allemagne), jésulte (1840), arrivé en Amérique en 1847; 1l décède à Arlon (Luxembourg, Belgique) le 2 mal 1891 . Voir LNMC., p. 888.

155 Fidèle Joset (1802-1852), né à Courfaivre (Berne, Suisse) le 3 février, jésulte (1822), arrivé au Canada en 1847; 1 décède à New York le 12 janvier 1852 . Volr ibid., p. 889.

156 «Ces deux villes et leur région périphérıque sont à l'origine un vaste espace de $243000 \mathrm{~h}$ [ect]a[res] que la Couronne brit[annique] a attribué aux Six nations indiennes (1784). Une partie de ce territoire, subdivisé et vendu en 1798 , est le site de la future municipalité de Waterloo. Acheté tout d'abord par des spéculateurs, il est revendu à des Mennonites de Penn[sylvanie], devenant le berceau d'une colonie d'Allemands ayant quitté leur pays lors de l'exode du XIX ${ }^{e}$ s[tècle] et composé d'habiles artisans, de commerçants et d'agriculteurs. Les 
Power ${ }^{157}$, évêque de Toronto, avait confiée aux jésuites. Ce compte rendu se transforme en rapport lorsque le destinateur fait part à son destinataire de ce qu'il a vu, observé et appris du pays et de ses habitants.

La forme matricielle choisie pour communiquer ce compte rendu et ce rapport s'accuse dès le premier paragraphe, qui se lit comme suit:

Ce fut le 27 juin de l'année dernière que je partis de NewYorck avec mes deux compagnons, le Père Fritsch et le F. Joset, pour aller prendre soin de la mission allemande que Mgr de Toronto a bien voulu nous confier. Nous nous arrêtâmes trois jours à l'ancienne Yorck, aujourd'hui Toronto, où Mgr nous donna une généreuse hospitalité et nous instruisit de tout ce qui concerne la mission. Enfin, le 3 juillet vers dix heures du soir, nous arrivâmes à la chapelle de Ste-Agathe de Wilmot que nous saluâmes par ces paroles du Psalmiste: «C'est ici le lieu de mon repos! c'est ici que j'habiterai! ${ }^{158}$,

Dès ces premières lignes, il est évident que nous sommes en présence d'un récit de voyage qui sera scandé, un peu comme un journal, par des dates ou

villages se forment dans les années 1850 , Kitchener s'appelant d'abord Berlin. Durant la Première Guerre mondiale, elle est rebaptisée en l'honneur de lord Kitchener." Kenneth McLaughlin, "KitchenerWaterloo», dans l'Encyclopédie du Canada, Montréal, Stanké, 1987, vol. 2, p. 1049.

${ }^{157}$ Michael Power (1804-1847), né le 17 octobre à Halifax (NouvelleÉcosse), études à Montréal et à Québec, prêtre (1827), missionnaire à Drummondville (1827-1831), curé de Montebello (1831-1833), SainteMartine près de Valleyfield (1833-1839) et Laprairle (1839-1842), avant de devenir le premier évêque de Toronto (1842-1847); il meurt le $1^{\text {er }}$ octobre 1847 , victime du typhus qu'il avait contracté en visitant des malades. Voir Robert Choquette, "Power, Michael», dans DBC, vol. 7, pp. 763-765; id., L'Église catholique dans l'Ontario français du dix-neuvieme siècle, Ottawa, Editions de l'Unlversité d'Ottawa, «Cahiers d'histoire», 13, 1984, pp. 96-100, passim (voir index, p. 364).

${ }^{158}$ Lettre 42, Wilmot près Petersburg, $1^{\text {er }}$ février 1848 , dans $L N M C$, pp. 455-456. 
des points de repère chronologiques ${ }^{159}$. La citation qui termine le paragraphe peut laisser croire que le voyage est terminé. Il n'en sera pas ainsi cependant, car, ces missionnaires devant desservir toute une région, Sainte-Agathe de Wilmot ne sera qu'un repère spatial, le centre d'un cercle à l'intérieur duquel les pères ne cesseront, en rayonnant, de poursuivre un périple missionnaire qui sera le thème principal du narrateur.

Celui-ci se présente d'abord comme un «je», puis presque immédiatement comme un "nous" qui inclut ses deux ${ }^{160}$ compagnons et ne laissera place au "je» que, à quelques reprises et au moment de la signature, car le périple missionnaire est une œuvre grosse du parcours de chacun. C'est ce que nous rappelle la première phrase du second paragraphe en attribuant au "nous» les premières activités du trio: les célébrations du premier dimanche et l'entente qui s'ensuivit avec les chefs de famille. Les jésuites ayant déclaré leur intention de demeurer à Wilmot et demandé seulement le strict nécessaire pour leur entretien, les fidèles promirent volontiers de subvenir à tous leurs besoins et leur offrirent comme résidence provisoire la maison qui servait d'école.

La description de celle-ci tient en quatre lignes, mais celle de la construction de l'habitation permanente constitue le troisième paragraphe, tandis que la description des chapelles occupe les deux tiers du quatrième. Le cinquième est une longue description

${ }^{159}$ On trouve au moins une date ou un repère chronologique dans les paragraphes $1,2,3,4,5,9,10,11,12,13,14,16,17,19$.

160 À partir du 18 janvier 1848, lls sont trois par suite de l'arrivée du père Sadler. Ibid., p. 469, par. 19. 
du pays (géographie, population, climat, agriculture, industrie) et les deux suivants renseignent sur les mœurs et la foi des gens de la région: une population très considérable d'immigrants venus de divers pays européens, pionniers rudes, mais hospitaliers, privés d'éducation et, pour la plus grande partie pendant une vingtaine d'années, de services catholiques, mais sollicités par une trentaine de sectes religieuses auxquelles un certain nombre de familles catholiques n'ont pas accepté d'adhérer.

Une fois les missionnaires ainsi situés dans leur milieu géographique et humain, le narrateur s'applique à décrire les travaux apostoliques (offices religieux, prédications, confessions, conversions, baptêmes, création d'écoles catholiques, etc.) qu'ils ont accomplis au fil du temps à Wilmot et dans les lieux environnants (un village allemand ${ }^{161}$, NouvelleAllemagne [New Germany] ${ }^{162}$, Preston ${ }^{163}$, une petite colonie ${ }^{164}$, la forêt royale [Queens-bush $\left.{ }^{165}\right]$ ). Ce récit missionnaire s'étend depuis le huitième paragraphe jusqu'au dix-huitième, lequel lui sert en quelque sorte de conclusion, car le narrateur quantifie les résultats

\footnotetext{
161 Situé à dix-sept milles de Wilmot, selon le père Caveng (ibid., p. 460 , par. 9).

${ }^{162}$ Une colonie située à quinze milles de Wilmot, selon le père Caveng (ibid., p. 457, par. 4); «un petit peuplement au nord-est du canton de Waterloo, dans le comté de Waterloo", selon le père Cadleux (ibid., note 8 ).

${ }^{163}$ Ville située à seize milles de Wilmot, selon le père Caveng (ibid., p. 463, par. 13); «dans le comté de Waterloo, [...] à huit milles au sud de Kitchener», selon le père Cadieux (ibid., note 10).

${ }^{164}$ Située à dix-sept milles de Wilmot, selon le père Caveng (ibid., p. 465 , par. 15 ).

165 «Queen's Bush, terme employé pour désigner un territoire (Huron Track) d'environ deux millions d'acres, situé entre Goderich et la baie Georgienne. E. C. Guillet, Early Life in Upper Canada, Toronto, The Ontario Publishing Co., 1933, pp. 173, 227, 520." Note du père Cadieux, LNMC, p. 464, note 11 .
} 
du travail raconté et présume qu'ils pourraient être plus considérables si l'argent ne manquait pas:

Dans ces quelques mois, nous avons entendu 2350 confessions dont 500 , à peu près, générales; nous avons baptisés 140 enfants, béni 30 mariages et visité 70 malades ou moribonds. Nous ne connaissons pas encore le chiffre exact des fidèles de notre mission, mais nous estimons qu'elle renferme de 8 à 10 mille Allemands ${ }^{[166]}$ catholiques. Nous avons déjà 7 écoles catholiques dont la plus importante est fréquentée par 130 enfants, une autre par 70 à 80 , et les autres par un plus petit nombre. Si les ressources pécuniaires ne nous manquaient pas, nous pourrions réaliser bien d'autres œuvres; mais la pauvreté de nos colons est un grand obstacle à ce qu'ils puissent pourvoir à tout ce qui est nécessaire pour les églises et pour l'éducation de la jeunesse ${ }^{167}$.

Les trois derniers paragraphes décrivent les travaux dominicaux, l'installation solennelle d'une statue de la Vierge Marie, puis le climat d'accueil qui menace de se gâter à la suite des attaques vomies par le rédacteur d'un journal fort mauvais qui n'a pas digéré les succès des pères ${ }^{168}$.

\section{LE RÉCIT DE VOYAGE APOSTOLIQUE}

Dans la lettre que nous venons de considérer, le récit que nous avons qualifié de missionnaire occupait onze des vingt et un paragraphes. Ce genre de récit est présent, de façon plus ou moins importante, dans presque toutes les Lettres ontariennes.

Il se trouve aussi des lettres qui sont consacrées entièrement, ou presque, au récit de ce que les

${ }^{166}$ Les pères regrettent fort de ne pas savoir l'anglais: «Si nous savions l'anglais de manière à pouvoir exercer le saint ministère parmi les Irlandais qui habitent sur le territoire de notre mission, quel vaste champ ne s'ouvrirait pas devant nous!" Ibid., p. 466, par. 16.

${ }^{167}$ Ibid., pp. 467-468.

${ }^{168}$ Ibid., pp. 468-470, par. 19, 20 et 21. 
missionnaires appellent une excursion ou des excursions, et qui n'est autre qu'une tournée pastorale de différents lieux à partir de leur résidence centrale. Nous considérerons ces lettres comme des récits de voyage apostolique et nous n'utiliserons l'appellation d'excursion que pour désigner la course aller et retour que le missionnaire fait à un seul endroit pour un service précis, qui peut être aussi bien une visite à un mourant qu'une mission de prédication. Pour illustrer ce qu'est le récit de voyage apostolique, nous présenterons deux lettres du père Joseph Hanipaux au père Ambroise Rubillon, provincial de Paris.

La première ${ }^{169}$ est du 28 avril 1848 . Le missionnaire raconte simplement, dans les six premiers paragraphes, ce qu'il a fait et observé sur le plan pastoral dans chacun des six endroits qu'il a visités: Garden River ou Rivière-au-désert ${ }^{170}$, Pumpkin Point ou Pointe-à-la-Citrouille ${ }^{171}$, l'île Saint-Joseph ${ }^{172}$, Bruce Mines ${ }^{173}$, Takouamining ${ }^{174}$ et la baie de Goulais [Goulais Bay] ${ }^{175}$. Dans le septième paragraphe, le père

\footnotetext{
${ }^{169}$ Lettre 46, Sault-Sainte-Marie, dans ibid., pp. 495-503.

170 «Village [...], situé à 9 milles à l'est du Sault-Sainte-Marie.» LNMC, p. 897. 171 «[...]; cette pointe est située à 12 milles au sud de Garden River, sur les bords du lac George, à proximité de l'île Saint-Joseph.» Ibid., p. 902. ${ }^{172}$ Cette île du district d'Algoma est "située dans le chenal entre le lac Huron et le lac Supérieur, à environ 20 milles au sud-est du SaultSainte-Marie.» Ibid., p. 903.

173 «Village situé sur la rive nord du Lac Huron, dans le district d'Algoma, à 37 milles à l'est du Sault-Sainte-Marie; ainsi nommé d'après Lord Elgin (James Bruce), ancien gouverneur du Canada (1847-1854). Une plaque commémorative de la Commission des Lleux historiques de l'Ontario rappelle qu'on exploitait cette mine de cuivre dès 1847." Ibid., p. 896.

174 «[...], probablement Tahquamenon, village indien de l'État du Michigan, sur la côte ouest de Whitefish Bay, à environ 36 milles à l'ouest du Sault-Sainte-Marie.» Ibid., p. 905.

175 «Située sur la rive nord du lac Supérieur, à environ 28 milles du Sault-Sainte-Marie.» Ibid., p. 897.
} 
raconte son retour difficile au Sault-Sainte-Marie, puis, dans le huitième et dernier, il exprime sa peine de quitter ses ouailles du Sault-Sainte-Marie pour l'île Manitouline, son nouveau lieu de résidence, et il signale les besoins apostoliques de Michipicoten ${ }^{176}$ et de Batchawana ${ }^{177}$.

La seconde lettre ${ }^{178}$ est du 18 octobre 1850 . Le premier paragraphe tient en deux lignes: «Je dois vous rendre compte aujourd'hui des excursions que j'ai faites depuis quelques mois et du résultat que j'ai obtenu.» En fait, il s'agit d'une tournée apostolique qui a été coupée en deux parties, à cause de l'obligation dans laquelle le missionnaire s'est trouvé de revenir à sa résidence centrale pour accueillir le père Clément Boulanger, supérieur de la mission New YorkCanada. Rien n'est dit de cette visite. Comme dans la lettre précédente, c'est au fil des endroits visités que se forment les paragraphes et se structure le texte: Mississagi ${ }^{179}$, Fort La Cloche ${ }^{180}$, Owen Sound ${ }^{181}$, Penetanguishene ${ }^{182}$, Manitowaning ${ }^{183}$, Penetanguishene.

176 «Village indien situé sur la rive nord du lac Supérieur, à environ 138 milles du Sault-Salnte-Marle.» Ibid., p. 900.

177 «Village situé sur la côte nord du lac Supérleur, à environ 45 milles du Sault-Sainte-Marie.» Ibid., p. 896.

${ }^{178}$ Lettre 71, Sainte-Crolx, Grande Manitouline, dans ibid., pp. 664670.

179 «Situé à environ 2 milles à l'ouest de Blind River.» Ibid., p. 664, note 3 .

${ }^{180}$ «Fort situé près de la réserve Indienne de Spanish River, au sud de Massey et à 9 milles au nord de Little Current.» Ibid., p. 899.

181 «Ville du comté de Grey, en Ontario, située dans la bale d'Owen Sound, au sud-ouest de la bale Georglenne.» Ibid., p. 901.

${ }_{182}$ «Ville du canton du Tíny, dans le comté de Simcoe (Ontario), située dans une anse au sud-est de la bale Georgienne et voisine de la ville de Midland." Ibid.

${ }^{183}$ "Village situé sur la Grande île Manitouline, à 58 milles au sud d'Espanola.» Ibid., p. 900. 
LE RECIT D'EXCURSION APOSTOLIQUE

Le récit d'excursion apostolique, tel que nous l'avons défini plus haut, ne constitue le plus souvent qu'une partie de lettre, s'il s'agit, par exemple, simplement d'une visite à un mourant. Mais, même en pareil cas, il peut en devenir le sujet principal et l'occuper presque tout entière, comme on le constate dans une lettre ${ }^{184}$ du père Frémiot aux scolastiques de Laval. La visite à une jeune fille que son père dit astucieusement en danger de mort deviendra un voyage de huit jours, décevant, pénible et dangereux, en avril, la pire saison de l'année pour voyager sur un lac, comme l'illustre bien le récit détaillé que le père en fait dans dix des douze paragraphes de sa lettre.

La lettre ${ }^{185}$ que le père Auguste Kohler adresse de Wikwemikong à l'un de ses condisciples jésuites le 29 novembre 1847 appartient à la même catégorie de récit. À la demande d'un chef indien, le père se rend auprès d'un jeune homme malade. C'est sa première excursion. Il prend plaisir à la raconter. Il a marché dans l'eau froide et dans les broussailles de la forêt, partagé le souper de son hôte ("on avait ce soir-là un morceau de lard») et, enveloppé de son manteau, il s'est étendu sur une peau de buffle pour la nuit:

Nous étions onze couchés dans une loge un peu plus grande que la cellule d'un séminariste. Mon sommeil fut interrompu de temps en temps d'abord par le froid qui me réveillait lorsque les bûches du foyer étaient consumées, puis par deux chats qui venaient attraper des souris autour de ma tête ou s'amuser avec le bout de mes pieds. De plus, un petit cochon de lait, après avoir fait la ronde dans la

${ }^{184}$ Lettre 66, L'Immaculée-Conception, près le Fort-William, 11 mai 1850, dans ibid., pp. [616]-623.

${ }^{185}$ Lettre 39, dans ibid., pp. 427-432. 
loge, vint se blottir auprès de moi et partager ma couche où il dormit en paix jusqu'au lendemain ${ }^{186}$.

Le missionnaire profita de sa visite au malade pour prêcher aux adultes le matin et aux enfants pendant le jour. Le soir, on donna en son honneur un repas à tous les Indiens des environs, puis la prière faite, le père, qui ne maîtrisait pas encore la langue de ses ouailles, leur apprit à se confesser par interprète:

J'avais une petite chaîne dont le pénitent tenait un bout et moi l'autre; l'interprète était placé entre deux, mais le dos tourné vers la chaîne afin qu'il ne pût rien voir. Il était convenu d'avance que lorsque le pénitent avait commis souvent le même péché, il tirerait plus fort, et que, s'il se rappelait le nombre, il pouvait l'indiquer par de petites secousses ${ }^{187}$.

Comme on peut le constater à partir des textes cités, le récit d'excursion apostolique renseigne abondamment sur le pays et ses habitants, même s'il a d'abord un but missionnaire.

\section{LE RECIT DE VOYAGE}

Mais il existe aussi, dans les Lettres, des récits dont les narrateurs, tout missionnaires qu'ils fussent, n'ont eu guère d'yeux que pour le pays et ses habitants à la façon des premiers découvreurs de la Nouvelle-France. Ces lettres sont essentiellement des récits de voyage. Leurs auteurs sont en route pour leur poste de mission et, jusqu'au moment où ils l'atteindront, c'est en touristes qu'ils observent le pays qu'ils traversent et les endroits où ils font escale.

Le père Frémiot raconte un voyage de cette sorte dans la lettre ${ }^{188}$ qu'il adresse du Sault-Sainte-Marie

186 Ibid., pp. 429-430, par. 3.

${ }^{187}$ Ibid., p. 431 , par. 6.

${ }^{188}$ Lettre 47, dans ibid., pp. [504]-512. 
au père Ambroise Rubillon, provincial de Paris, le 24 juin 1848. Parti de Laprairie le 20 mai précédent, il a été témoin à Montréal d'une "des plus belles solennités" qu'il ait jamais vues, le couronnement, selon le rite romain, d'une statue de la Vierge par Mgr Ignace Bourget. Le père décrit la cérémonie longuement, puis raconte comment le grand évêque a réussi, en publiant un mandement «onctueux» et "touchant", à faire adopter en deux jours deux-cent-vingt-neuf orphelins irlandais ${ }^{189}$.

Le père avait passé quatre jours à Montréal. Lui et son compagnon, l'abbé Jean-Baptiste Proul ${ }^{190}$, ne s'arrêtèrent pas même une heure à Kingston, «qui n'a de beau que son marché, vaste bâtiment surmonté d'une coupole, comme c'est d'usage dans ce pays pour ces sortes d'édifices». Quant à Toronto, où le père semble avoir passé plus de temps puisqu'il décrit en détails la situation du diocèse, «elle n'est à l'exception d'une rue qu'un village silencieux et désert»; la cathédrale, «la seule église catholique de la ville, est une misérable chapelle en bois»; le diocèse ne compte que treize prêtres et une seule paroisse,

\footnotetext{
${ }^{189}$ lbid., pp. [504]-507, par. 2 et 3.

190 Jean-Baptiste Proulx (1808-1881), né le 8 mai à Lachine (Québec), études classiques (1825-1830), études théologiques (1831-1835), prêtre (le 26 julllet 1835), vicaire à Laprairie (26 septembre-octobre 1835), missionnaire à Penetanguishene (novembre 1835-1837), à l'île Manitouline (1837-1846), à Newmarket (19 décembre 1846-1848), à Oshawa (1848-1860); il exerce ensuite son ministère à Toronto: à la cathédrale Saint-Michael (1860), auprès de la garnison (aumônier de 1860 à 1862), à la paroisse Saint Mary (adjoint de 1862 à 1867, puis curé de 1867 à 1870), à la cathédrale Saint-Michael (doyen de 1870 à 1881); il décède subitement le 25 mars 1881 à Terrebonne (Québec), alors qu'il rendait visite à son frère. D'après Douglas Leighton, «Proulx, Jean-Baptiste», dans DBC, vol. 11, pp. 791-793. - Dans LNMC, p. 893, certaines dates sont absentes ou diffèrent de celles données par D. Leighton. - Le nom de l'abbé Proulx apparaît sur les pages suivantes de $L N M C$ : $170,174,183,184,210,211,245,248,286,288$.
} 
Sandwich; «le reste est mission ${ }^{191} »$.

En route pour Buffalo, le père Frémiot passe quarante-huit heures aux chutes Niagara. Le tremblement de terre qu'elles produisent fait frémir le touriste et le spectacle arc-en-ciel de l'eau qui tombe l'enchante, tandis que la visite derrière la chute, dont on lui «avait fait grand-peur», ne l'impressionne guère:

Je m'attendais à quelque chose de terrible, je n'en vis point. Il est vrai que c'est un vacarme affreux, que l'eau vous fouette de toutes parts avec violence, tellement qu'il est presque impossible d'ouvrir les yeux; mais, après tout, ce n'est que de l'eau qui tombe, et vous avez au moins l'avantage de prendre un excellent bain ${ }^{192}$.

À Sandwich, le père Frémiot apprend du supérieur local, le père Pierre Point, que sa destination ultime est Pigeon River où il doit fonder une nouvelle mission avec le père Choné. Il reprend la route, quelques jours plus tard, avec le père Nicolas Point:

Le mardi de la Pentecôte, je dis adieu à Sandwich et au Détroit; c'était presque dire adieu à la civilisation, car le Sault-Sainte-Marie, qui en aura bientôt conquis tous les avantages, offre déjà une idée de la vie sauvage. À côté de l'élégante maison du riche, se dresse l'humble loge de l'indien, tantôt sous la forme de cône; ce sont celles des Ottawas, Courte-oreilles; tantôt sous la figure d'une coupole, ce sont celles des Chippewais ou Sauteux. Quelques perches recouvertes d'écorces de cèdre en font toute la façon. Une natte qui sert à la fois de table, de siège et de lit, une marmite au milieu sous le trou qui sert tout ensemble de fenêtre et de cheminée, voilà les meubles. C'est ici que j'ai vu pour la première fois des loges de sauvages et des canots d'écorces. Encore un peu de temps et je ne verrai presque plus autre chose ${ }^{193}$.

${ }^{191}$ Lettre 47, dans $L N M C$, p. 507, par. 4.

192 Ibid., p. 509, par. 5.

${ }^{193}$ Ibid., p. 511 , par. 8. 
Le 16 juillet, après avoir eu «tour à tour sous les yeux, l'Américain, l'Irlandais, le Canadien, le Métis et le Sauvage», le père quitta le Sault-Sainte-Marie pour la Rivière-aux-Tourtres ${ }^{194}$. Il a raconté cette dernière partie du voyage dans la lettre ${ }^{195}$ qu'il a $^{\prime}$ adressée de ce dernier endroit à un père de la même Compagnie, le 24 juillet 1848 .

C'est un voyage de même sorte que le père Auguste Kohler raconte, le 16 octobre 1847 , à un frère scolastique de Brugelette ${ }^{196}$. En poste à Georgetown (Washington, D.C.), où les jésuites avaient une université de ce nom ${ }^{197}$, il s'est rendu à New York, puis il a quitté cette ville le 6 juillet à destination de Sainte-Croix, Grande Manitouline. Le voyage se fait par bateau à vapeur de New York à Albany, puis par chemin de fer jusqu'à Buffalo, en passant par Rochester, ensuite par bateau à vapeur jusqu'à Détroit; de là, le père traverse la rivière Détroit et revient par terre jusqu'à Sandwich où il demeure quelques jours. Le 26 juillet, il entreprend la dernière partie de son voyage sur un bateau à vapeur qui traverse le lac Sainte Claire, longe l'île Walpole, re monte

\footnotetext{
${ }^{194}$ Aujourd'hui Pigeon River, «sur la rive nord-ouest du lac Supérieur, a la frontière internationale de l'Ontario et du Minnesota, à environ 47 milles au sud de Thunder Bay. Elle prend sa source au Lac-à-la-Pluie (Rainy Lake), coule vers l'est et se jette dans le lac Supérieur.» LNMC, p. 902.

${ }^{195}$ Lettre 48, dans ibid., pp. 512-521.

196 Lettre 37, Sainte-Croix, Grande Manitouline, dans ibid., pp. 412 423.

197 Fondée en 1789 par John Carroll, elle obtient sa charte en 1815 , puis sa constitution en société civile [incorporation] en 1844. (D'après The New Columbia Encyclopedia, Edited by William H. Harris and Judith S. Levey, Fourth Edition, Third Printing, New York and London, 1975, p. 1065. - Le père Cadieux écrit ce quil suit dans $L N M C$, p. 413 , note 3: "L'Université catholique de Georgetown, fondée en 1817 , à Washington, États-Unis, dans le district fédéral de Columbia.»
} 
la rivière Sainte Claire, entre dans le lac Huron, fait escale à Mackinaw (27 juillet) et à l'île Saint-Ioseph, puis l'emmène au Sault-Sainte-Marie, où il passe quelques jours avant de se rendre à l'île Manitouline, lieu de sa mission.

\section{Le père Kohler écrit que}

le voyage de New York à Sandwich est vraiment un pèlerinage pour un missionnaire de la Compagnie. Les bords de l'Hudson et du St-Laurent rappellent tant de souvenirs qui se rattachent aux anciennes missions de nos Pères, que l'œil est impatient de saisir tout ce qui nous montre le résultat de leurs travaux et de leurs souffrances ${ }^{198}$.

Mais c'est aussi un premier voyage pour lui dans les régions qu'il traverse. Il ouvre grand les yeux sur le pays:

La terre me semblait à peine dépasser le niveau de l'eau. S'il est un pays de plaine dans l'univers, c'est bien cette partie du Canada [les environs de Sandwich]. Quand le fleuve est pris de glace et que les terres sont couvertes de neige, on doit se trouver là comme au bout du monde. Habitué comme je le suis au pays des montagnes, il me semblait que jamais les plaines ne me paraîtraient belles; mais ici elles sont si vastes qu'il y a dans leur étendue, comme dans la vue de l'Océan, quelque chose qui élève l'âme vers l'auteur de tant de merveilles. On se voit si abandonné, au milieu de ces contrées immenses, que le coeur a besoin de se reposer dans la pensée de Dieu comme la colombe dans l'arche de Noé ${ }^{199}$.

Le père Kohler s'intéresse beaucoup aux personnes qu'il rencontre le long de sa route et il a le don d'en faire des connaissances, quelles que soient leurs origines. Il éprouve de la sympathie pour les Amérindiens, mais il porte des jugements sévères sur

\footnotetext{
${ }^{198}$ Ibid., p. 413, par. 1.

199 Ibid., p. 416, par. 2.
} 
les protestants et les voyageurs canadiens. De ces derniers, il écrit:

Chez eux, l'ivrognerie, les scandales domestiques et le blasphème sont à l'ordre du jour; et plusieurs s'abaissent jusqu'a faire le métier le plus ignoble, celui de colporter de la boisson afin d'enivrer les sauvages et ensuite de leur arracher plus facilement leurs pelleteries ${ }^{200}$.

On peut aussi classer dans la même catégorie de récits les lettres ou les parties de lettres dans lesquelles les pères ne font que raconter, pour l'agrément ou l'édification de leur destinataire, la façon et les difficultés de voyager au Canada pendant les diverses saisons de l'année, que ce soit en forêt ou sur les lacs et rivières.

Une lettre ${ }^{201}$ du père Choné à un père de la même Compagnie en fournit un bon exemple. Parti de Sandwich un 29 juin pour retourner à Wikwemikong, le père et ses deux compagnons amérindiens ont dû lutter pendant près de vingt jours à cause du vent qui enflait les vagues du lac et de la difficulté qu'ils eurent à reconnaître leur île; comme ils n'avaient pas prévu un si long voyage, ils en furent réduits à se nourrir de groseilles sauvages durant les derniers jours. Voilà pour le voyage d'été. Quant au voyage d'hiver, le même père en donne une description dans sa lettre du 24 février 1848 à un scolastique jésuite ${ }^{202}$, tandis que le père Kohler renseigne sur les dangers qu'il y a de circuler sur le lac Supérieur à cette période de l'année ${ }^{203}$ et que le père Frémiot raconte son voyage

\footnotetext{
${ }^{200}$ Ibid., p. 422, par. 6.

${ }^{201}$ Lettre 23, Sainte-Croix, Grande Manitouline, 22 juillet 1846, dans ibid., pp. 340-343.

${ }^{202}$ Lettre 45, Sainte-Croix, Grande Manitouline, dans ibid., pp. 487489 , par. 2 et 3 .

${ }^{203}$ Lettre 73, Sault-Sainte-Marie, 21 décembre 1850, dans ibid., pp. 686-688, par. 5-6.
} 
de misère au lac Nipigon avec deux traîneaux et six chiens $^{204}$.

Pour le voyage d'automne, on peut lire le récit que ce dernier père introduit comme suit dans sa lettre ${ }^{205}$ du 18 octobre 1851 à un scolastique jésuite:

[...], de vouloir aller à pied dans ce pays, tant qu'il n'y a pas au moins un mètre de neige qui permette d'escalader sans danger les broussailles et les arbres tombés çà et là sous l'effort des vents ou le poids des années; ou bien encore, à moins qu'un pont de glace ne permette de traverser les lacs et les rivières à pied sec, ce serait, je vous assure, perdre son temps et sa peine, puisqu'il n'y a sur la terre ferme ni chemins, ni sentiers, ni quelque chose qui y ressemble. Aussi comme nous n'étions au temps ni des neiges ni des glaces, ma promenade ne pouvait avoir lieu que par eau 206 .

Il s'agissait d'aller de la mission de l'ImmaculéeConception, installée à deux ou trois milles du FortWilliam [Thunder Bay], jusqu'à l'île Royale, située au nord-ouest du lac Supérieur et au sud dudit fort. Le vent ayant été de la partie, il va sans dire que le terme "promenade" prend un sens ironique dans le texte du narrateur, mais il résonne comme un défi dans l'esprit du lecteur qui sait que le père Frémiot se noiera le 4 juillet 1854 , donc moins de trois ans plus tard, dans les eaux de la rivière Mississagi, près de Blind River, en se rendant chez les Sauteux. Faut-il rappeler aussi que, après avoir écrit, dans sa lettre du 2 février 1851, que les voyages étaient, de toutes les occupations missionnaires en Amérique, la plus fatigante et la plus dangereuse, et avoir longuement

${ }^{204}$ Lettre 84, Lac Nipigon, Haut-Canada, 19 mars 1852, dans ibid., pp. 803-804, par. 3-6.

${ }^{205}$ Lettre 78, L'Immaculée-Conception, près le Fort William, dans ibid., pp. [752]-762.

206 Ibid., p. 753, par. 2. 
illustré cette affirmation par le récit de l'une de ses excursions, le missionnaire avait conclu sa démonstration en bravant la mort:

[...] que sont, $[\ldots]$, toutes ces aventures, toutes ces fatigues, tous ces dangers, même si, à ce prix, un indigne Missionnaire est assez heureux pour arracher quelques âmes aux griffes de satan! [...], ne dût-il ajouter qu'une seule âme [...], aurait-il le droit de plaindre le peu qu'il lui en coûte, le peu qu'il a sacrifié? Asssurément non. Il se rappellerait la sentence de saint François Xavier: «Aller au bout du monde, sauver une âme et mourir, c'est là un sort digne d'envie ${ }^{207} . "$

On peut considérer comme voyage de printemps celui que le père Frémiot fit à la fin d'avril 1850 au temps des glaces fondantes. C'est pourtant comme un voyage d'hiver qu'il le raconte dans quatre paragraphes de sa lettre ${ }^{208}$ du 11 mai 1850 . On en débusque la raison dans sa lettre du 2 février 1851 :

Les forêts et les lacs gardent longtemps leur triste manteau d'hiver. Mais aussi l'ont-ils à peine dépouillé, que déjà la végétation est en pleine vigueur; et bientôt elle répare, par sa prodigieuse rapidité, le temps qu'elle a perdu sous les neiges. S'il n'y a point de printemps en Amérique, en revanche, il y a un long et bel automne ${ }^{209}$.

\section{LA LETTRE DESCRIPTION}

Unique en son genre dans les Lettres ontariennes, la lettre ${ }^{210}$ description du père Frémiot à monsieur Micard, supérieur du Séminaire de Saint-Dié, serait

${ }^{207}$ Lettre 75, Sault-Sainte-Marle, dans ibid., p. 736, par. 40 (le récit commence à la page 732 , par. 37 ).

${ }^{208}$ Lettre 66, L'Immaculée-Conception, près le Fort-William, dans ibid., pp. 618-619, par. 3-4, et pp. 621-622, par. 10-11.

${ }^{209}$ Lettre 75, Sault-Sainte-Marie, dans $t$ bid., pp. 730-731, a la fin du long paragraphe 34, qui est consacré aux informations sur la température.

210 Ibid., pp. 707-751. 
un pur document, voire un rapport officiel sinon une étude sur une région et sa population, s'il n'y avait le "je» ou le "nous" - et les adjectifs possessifs correspondants à ces pronoms - par lesquels le destinateur rappelle régulièrement à son destinataire, au fil de la description ${ }^{211}$, entre une brève introduction ${ }^{212}$ et une longue interpellation finale ${ }^{213}$, que ce qu'il représente dans son écrit, c'est ce qu'il a perçu par ses propres sens et pesé à la balance de son jugement personnel et qu'il veut faire voir, sentir et prendre en considération par le «vous» singulier à qui il s'adresse d'abord tout au long de la description, puis par le "vous" pluriel de l'appel final:

Voyez donc, $[. .$.$] , regardez, écoutez; ne vous lassez point$ de contempler cette scène si tragique et malheureusement trop réelle: arrêtez-y vos yeux, attachez-y vos oreilles, fixez-y votre âme, collez-y votre cœur [...]; bientôt vous prendrez ces âmes en pitié, vous compterez pour rien les distances, les privations, les sacrifices, car l'amour ne connaît pas tout cela, et l'amour, un amour surnaturel, généreux, héroïque, pour ces pauvres âmes, aura rempli votre cœur; et vous n'aurez plus qu'un désir, qu'une ambition sur la terre, le désir de voler au secours de tant d'infortunés, l'ambition d'embraser ces froides régions $\mathrm{du}$ feu céleste qui vous dévore ${ }^{214}$.

La partie centrale qu'est la description est divisée de façon assez lâche en neuf parties marquées par les premiers mots en majuscules d'autant de paragraphes. Les deux premières parties (par. 3-8 et 923) portent à la fois sur les pères et leurs ouailles: L'Immaculée-Conception (situation géographique, perspectives d'avenir, récit de conversion d'une indienne); exercices religieux (ministère des pères,

${ }^{211}$ Ibid., pp. 708-736, par. 3-39.

${ }^{212}$ Ibid., p. 708, par. 1-2.

${ }^{213}$ Ibid., pp. 736-741, par. 40-44.

${ }^{214}$ Ibid., pp. 738-739, par. 42. 
pratique des fidèles et façon de subsister de ces derniers). Les six parties suivantes décrivent les mœurs et coutumes amérindiennes: occupations domestiques (par. 24); repas, festins, hospitalité, simplicité des mœurs antiques (25-27); visites (28); habillement (29-32); langue (33); température (34). La neuvième partie a trait aux missionnaires: occupations des missionnaires - voyages (par. 35-39).

\section{LES DESCRIPTIONS EPARSES}

Rares sont les lettres qui ne renferment aucune description. La plupart en contiennent plusieurs. On les trouve même en nombre dans presque toutes les lettres récits. Comme elles ont alors pour rôle d'étayer, d'expliciter ou d'illustrer les propos du narrateur, elles y apparaissent éparses et portent sur les sujets les plus divers, mais le plus souvent sur ceux que nous venons de relever dans la lettre description du père Frémiot.

Les portraits complets n'abondent pas dans les Lettres ontariennes ${ }^{215}$, mais il est possible, en rassemblant ce qui est dit ici et là du Canadien français, de l'Odjibwé, de l'Irlandais et de l'Allemand, de constituer des portraits plus ou moins complets de chacun de ces types. C'est ce que le père Cadieux s'est efforcé de faire, dans l'introduction de son recueil, pour le Canadien des années $1840^{216}$ et l'Odjibwé du milieu ontarien $^{217}$. Nous nous limiterons donc ici à citer quelques extraits des Lettres à titre d'exemples d'écriture.

\footnotetext{
${ }^{215}$ Dans les Lettres québécoises, le père Félix Martin a réussi a faire assez bien un portrait du Canadien d'origine française (Lettre 1, Montréal, $1^{\text {er }}$ juin 1843 , dans $L N M C$, pp. 94-97, par. 24-27).

${ }^{216}$ LNMC, pp. [1 7]-34.

217 Ibid., pp. [37]-42, [43]-46 et [57]-66.
} 
Le portrait que le père Pierre Point trace du Canadien ressemble, en plusieurs points, à celui qu'avaient dessiné les voyageurs et administrateurs français du dix-huitième siècle, tels l'intendant Hocquart ${ }^{218}$ : les Canadiens sont «naturellement grands, bien faits, d'un tempérament vigoureux»; Claude Lebeau ${ }^{219}$ : «[...], en général tous les Habitans du Canada sont bons, affables, laborieux \& [...] il n'y a presque jamais ni querelles, ni disputes parmi eux. Comme le climat du Pays est froid, ils parviennent à une belle vieillesse. J'y ai vu quantité de bons Vieillards, forts, droits \& point caducs. Je m'imaginois quelquefois en me promenant dans leurs Habitations, être au commencement des premiers Siécles, parmi nos anciens Patriarches qui ne s'amusoient qu'à l'Agriculture.»; le père François-Xavier de Charlevoix ${ }^{220}$ : «Nous n'avons pas dans le Royaume de Province, où le

\footnotetext{
${ }^{218}$ Texte d'un rapport officiel de l'Intendant Hocquart à son ministre, le 30 octobre 1737, cité par Émile Salone, La Colonisation de la NouvelleFrance, étude sur les origines de la nation canadienne-française, Paris, Librairie orlentale \& américaine, E. Guilmoto, éditeur, [1905] p. 431. ${ }^{219}$ Avantures du $S^{r}$. C. Le Beau, avocat en parlement, ou Voyage curieux et nouveau, Parmi les Sauvages de l'Amérique Septentrionale. Dans le quel On trouvera une Description du Canada, avec une Relation très particulière des anciennes Coutumes, Maurs \& Façons de vivre des Barbares quil'habitent \& de la manière dont ils se comportent aujourd'hui. Ouvrage enrichi d'une Carte \& des figures necessaires. Première Partie, À Amsterdam, Chez Herman Uytwerf, MDCCXXXVIII, pp. 62-63. (Réimpression publiée sous les auspices du Conseil Canadien de Recherches en Sciences Soclales[,] de la Malson des Sciences de l'Homme, Paris [,] du Conseil Canadien de recherche sur les Humanités[,] de la Toronto Public Library, [East Eardsley, Wakefield, Yorkshire, England], R. Publishers Limited, [New York], Johnson Reprint Corporation, [The Hague, Netherlands], [and] Mouton \& Co. N. V., 1966, 370, [vi] p.) ${ }^{220}$ Françols-Xavier de Charlevolx, Journal d'un voyage fait par ordre du roi dans l'Amérique septentrionale, édition critique par Plerre Berthlaume, Montréal, les Presses de l'Université de Montréal, «Bibliothèque du Nouveau Monde», 1994, vol. 1, p. 403 [dixième lettre, 22 avril 1721 ].
} 
Sang soit communément si beau, la Taille plus avantageuse, 8 le Corps mieux proportionné.», et d'autres ${ }^{221}$ : "Les Canadiens, note un officier, sont bien faits, grands robustes, adroits à se servir du fusil et de la hache», et le Canadien Ruette d'Auteuil ${ }^{222}$ écrit: «Les Français qui habitent le Canada sont de corps bien faits, agiles, vigoureux, jouissant d'une parfaite santé, capables de soutenir toutes sortes de fatigues [...].»

\section{Un siècle plus tard, le père Point écrit:}

Dans le Canada, on ne voit pas d'hommes très robustes, mais ils sont généralement de belle taille et de bonne mine; on voit rarement un bossu, un bancale, un nain, un vieillard en enfance. Il en est qui parviennent à l'âge de $\mathbf{8 0}$ ans; le petit nombre que l'on rencontre semble avoir échappé à la loi portée contre les autres: labor et dolor [travail et souffrance]; ils sont droits et marchent sans bâton, ils sont gais et de belle humeur; ils meurent en paix, sans regret et sans décrépitude. J'ai rencontré dernièrement un vieux voyageur plus que septuagénaire; il a le visage aussi frais qu'un homme de 50 ans; il m'a dit qu'il avait un frère de plus de 100 ans et que son père est mort à 110 . Nous avons plusieurs familles vraiment patriarchales de 12 et 15 enfants. J'ai vu avant-hier un père de 74 ans, qui a des enfants de 7 à 8 ans. Sans les excès et les imprudences, occasionnées par les courses aventureuses [...], les vieillards seraient ici en très grand nombre.

Le caractère du canadien est la douceur et la bonté; il est jovial et se met rarement en colère. Quand il est fâché, il dit: «J'ai quelque chose sur le cœur»; aussi obtient-il facilement une réconciliation ${ }^{223}$.

${ }^{221}$ Cité par Gustave Lanctot, Histoire du Canada [vol. 3]: du Traité d'Utrecht au Traité de Paris, 1713-1763, Montréal, Lıbrairie Beauchemin, 1964, p. 283.

222 «Mémoire de Ruette d'Auteuil au duc d'Orléans», 12 décembre 1715, dans RAPQ 1922-1923, p. 59, cité par Guy Frégault, La Civilisation de la Nouvelle-France (1713-1744), Montréal, Soclété des Éditions Pascal, 1944, p. 271.

${ }^{223}$ Lettre 43, Sandwich, 10 février 1848 , dans $L N M C$, p. 477, par. 8-9. 
Plusieurs pères ont esquissé un portrait de l'Amérindien, l'Odjibwé ou Sauteux en l'occurrence. Ils l'ont toujours fait de façon sympathique, mus sans doute par leur idéal missionnaire et aussi, vraisemblablement, par la culpabilité qu'ils ressentaient devant la situation pénible à laquelle les porteurs de la civilisation européenne avaient réduit un type autrefois sain, vigoureux et indépendant en un sujet souvent dépendant, voire esclave, et miséreux. Le père Dominique du Ranquet en donne un court portrait qui représente assez bien ce que ses confrères pensaient:

De belles qualités restent encore à ces pauvres sauvages, même dans la condition humiliée où ils se trouvent. La sincérité, l'horreur du vol, la pureté des mœurs devaient vraiment, comme on l'a dit, former l'ancien caractère de la tribu des Sauteux. Plus ils se sont soustraits à une fausse civilisation, plus ces traits demeurent sensibles. Assurément, ils sont encore pour ces vertus un exemple aux Européens. Le défaut d'activité et de constance pour tout autres travaux que la chasse, et les ressources que la vengeance, qui est aussi une de leurs passions, trouve dans la médecine indienne, expliqueraient l'état misérable où ils se trouvent, et l'anéantissement qui semble les menacer. Mais on peut attribuer encore plus leur misère et leur ruine à l'eau de feu, arme que la cupidité a toujours laissée entre les mains de leurs vainqueurs. La religion seule peut sauver les derniers restes de ces peuples si méprisés de ceux qui ont fait leur malheur, mais si plein[s] d'intérêt et si aimables à celui qui les comprend et qui voit leur cœur ${ }^{224}$.

Le père Jean-Pierre Choné a développé plus longuement les mêmes idées en décrivant avec force détails et nuances les mœurs et coutumes de cet Amérindien ${ }^{225}$. Nous lui devons peut-être le meilleur

${ }^{224}$ Lettre 40, Sandwich, $1^{\text {er }}$ décembre 1847, dans ibid., pp. 434-435, par. 5. ${ }^{225}$ Lettre 19, Sainte-Croix, Grande Manitouline, 28 mars 1846, dans 
portrait de l'Odjibwé. Tout comme le père Pierre Chazelle ${ }^{226}$, il s'est efforcé de réfuter certains préjugés des Européens ${ }^{227}$. Cependant, le père Auguste Kohler laisse percevoir la même inquiétude que ses confrères lorsqu'il essaie d'entrevoir ce que sera l'avenir de ses ouailles dans un monde où,

privé de tout, l'enfant des forêts se voit forcé de choisir entre une mort certaine ou le mode d'existence des blancs. Dans les environs de nos trois grands Lacs surtout, il se trouve actuellement à une époque de transition. C'est le moment critique ${ }^{228}$.

Ces portraits pleins de compassion se rapprochent de ceux que les jésuites du dix-septième siècle ont dessinés des Hurons. Les uns et les autres ont, en effet, pour but de faire valoir la qualité humaine de l'Amérindien auprès de l'Européen civilisé. Que l'on en juge par le portrait suivant, extrait des Relations des jésuites de la Nouvelle-France:

Je ne prétends pas icy mettre nos sauvages en parallèle avec les [...] nations parfaitement civilisées, mais seulement les tirer de la condition des bestes, où l'opinion de quelques-uns les a réduits, leur donner rang parmy les hommes et faire paroistre qu'il y a mesme parmy eux quelque espèce de vie politique et civile.

[...] ils cultivent des champs, d'où ils tirent à suffisance pour leur nourriture de toute l'année et [...] ils s'entretiennent en paix et amitié les uns avec les autres. Il est vray que je ne pense pas qu'il y ayt peut-estre nation souz le

ibid., pp. 323-328, par. 8-13. - Voir aussi du même père, la lettre 12, qu'il avait adressée du même endroit le 22 janvier 1845, dans ibid., p. 241, par. 3, et la lettre 45 , écrite au même endroit le 24 février 1848 , dans ibid., pp. 490-494, par. 5-10.

${ }^{226}$ Lettre 16, Sandwich, 17 avril 1845, dans ibid., pp. 289-290, par. 2935.

${ }^{227}$ Lettre 26, Sainte-Croix de la Grande Manitouline, 6 février 1847 , dans ibid., pp. 361-362, par. 4.

${ }^{228}$ Lettre 73, Sault-Sainte-Marie, 21 décembre 1850, dans ibid., p. 683 , par. 1 . 
ciel plus recommandable en ce point qu'est la nation des Ours ${ }^{1229]}$. Ostez quelques mauvais esprits qui se rencontrent quasi partout, ils ont une douceur et une affabilité quasi incroyable pour des sauvages. Ils ne se picquent pas aisément; et encor, s'ils croyent avoir receu quelque tort de quelqu'un, ils dissimulent souvent le ressentiment qu'ils en ont; au moins en trouve-[t]-on icy fort peu qui s'échapent en public pour la colère et la vengeance. Ils se maintiennent dans cette si parfaite intelligence par les fréquentes visites, les secours qu'ils se donnent mutuellement dans leurs maladies, par les festins et les alliance. Si leurs champs, la pesche, la chasse ou la traitte ne les occupe, ils sont moins en leurs cabanes que chez leurs amis. S'ils tombent malades et qu'ils désirent quelque chose pour leur santé, c'est à qui se monstrera le plus obligeant. S'ils ont un bon morceau, [...] ils en font festin a leurs amis et ne le mangent quasi jamais en leur particulier.

[...] ils ont la pluspart l'esprit assez bon, ils s'éveillent et se façonnent merveilleusement, de sorte qu'il n'y en a quasi point qui ne soit capable d'entretien et ne raisonne fort bien et en bons termes, sur les choses dont il a la cognoissance. [...] Adjoutez mesme que l'honnesteté, la courtoisie et la civilité, qui est comme la fleur et l'aggréement de la conversation ordinaire et humaine, ne laisse pas encor de se remarquer parmy ces peuples. [...] ils se rendent de certains devoirs les uns aux autres et gardent par bien-scéance de certaines coustumes en leurs visites, danses et festins, ausquelles si quelqu'un avoit manqué, il ne manqueroit pas d'estre relevé sur l'heure;[...] À la rencontre, pour toute saluade, ils s'appellent chacun de leur nom, ou disent: "Mon amy, mon camarade, mon oncle», si c'est un ancien. Si un sauvage se trouve en vostre cabane lorsque vous mangez et que vous luy présentiez vostre plat, n'y ayant encor guières touché, il se contentera d'en gouster et vous le rendra. Que si vous luy présentez un plat en particulier, il n'y portera pas la main, qu'il n'en ait fait part à ses compagnons, et ceux-cy se contentent d'ordinaire d'en prendre une cuillérée. Ce sont petites choses, à la vérité, mais qui monstrent néantmoins

229 "L'une des quatre tribus membres de la confédération des Hurons." (Voir DBC, vol. 1, p. 13, au mot "Attignaouantan».) 
que ces peuples ne sont pas tout à fait si rudes et mal polis que quelqu'un se pourroit bien figurer ${ }^{230}$.

Il n'existe pas de portraits complets de l'Irlandais et de l'Allemand dans les lettres ontariennes; il est question d'eux plusieurs fois, mais presque toujours en passant. Le père Jean Jaffré, à Chatham, fait l'éloge des ouvriers de chemin de fer irlandais, chrétiens respectueux du prêtre, dévots et généreux ${ }^{231}$. L'Allemand, pauvre, est hospitalier et généreux; il est surtout présent dans une lettre du père Luc Caveng, missionnaire à Wilmot, dans la région de KitchenerWaterloo ${ }^{232}$.

\section{V - LES TEXTES AMÉRINDIENS}

Les Lettres ontariennes renferment plusieurs textes amérindiens. Comme ils sont écrits en français par les narrateurs des lettres, nous devons les apprécier dans cette langue. Nous n'oublions pas, cependant, que, tout excellents que plusieurs soient, ils pourraient fort bien avoir été meilleurs dans la langue de leurs locuteurs, et, parfois, plus ou moins différents, sinon dans le contenu principal, du moins dans les nuances, voire dans le style, quoique les missionnaires aient fait un effort certain pour faire sentir le plus possible le style amérindien.

Le père Pierre Chazelle éclaire quelque peu les destinataires de ses lettres sur les difficultés et la façon d'enregistrer et de traduire en français les tex-

\footnotetext{
${ }^{230}$ Jean de Brébeuf, «Relation de ce qui s'est passé en la NouvelleFrance en l'année 1636", dans Monumenta Nova Francia, III: fondation de la mission huronne (1635-1637), pp. 371-373.

${ }^{231}$ Lettre 89, Chatham, 30 septembre 1852 , dans $L N M C$, pp. 852-853, par. 3.

${ }^{232}$ Lettre 42 , Wilmot près Petersburg, $1^{\text {er }}$ février 1848, dans ibid., pp. 465-470.
} 
tes odjibwés. Dans l'une de ses premières lettres, datée du 10 août 1844 , il prévenait son provincial que faute de loisir et de connaissance suffisante de la langue, il ne pourrait lui «rapporter au long les harangues» qui lui avaient été "adressées ${ }^{233}$ " le 31 juillet 1844. Cela ne l'empêchera pas de faire l'éloge de l'éloquence amérindienne dans cette lettre et dans la suivante. Mais il y a plus. C'est que dans cette seconde lettre, écrite le 8 septembre 1844 , soit moins d'un mois après la précédente, lui qui n'a pas pu maîtriser la langue en si peu de temps et qui n'était pas présent lors de l'affrontement du 23 juillet précédent entre le père du Ranquet et les Amérindiens de l'île Walpole, raconte avec force détails ce qui s'est passé et donne la traduction des discours sauteux ${ }^{234}$. Nous devons en déduire que ce père supérieur des missions du Canada se comporte comme le supérieur de Québec dans les Relations: ou bien il a gardé bonne mémoire ou pris note de ce qu'est venu lui raconter le missionnaire à la suite de l'affrontement, - ce qui est vraisemblable pour le récit des événements, - ou bien il avait à sa disposition un texte dudit père, - ce qui est absolument requis pour que soient jugées véridiques sinon exactes les quelque quatre pages de propos qui sont cités tant des Amérindiens que du père ${ }^{235}$.

\footnotetext{
${ }^{233}$ Lettre 7, Sandwich, 10 août 1844 , dans ibid., p. 189, par. 3.

${ }^{234}$ Lettre 10, Sandwich, 8 septembre 1844, dans ibid., pp. 21 19-225, par. 11-25.

${ }^{235}$ Cela est d'autant plus plausible que le père du Ranquet ayant laissé un journal qu'il avait tenu de 1853 à 1877 , il peut fort bien en avoir rédigé un avant cette période ou avoir eu l'habitude de jeter des notes sur papier, lesquels documents ne nous seraient pas parvenus.
} 


\section{LES DISCOURS}

Cette dernière déduction se révèle être la bonne quand nous lisons la lettre que le père Chazelle fait tenir, le 24 janvier $1845^{236}$, au confrère jésuite à qui il avait promis le 8 septembre $1844^{237}$ une lettre qui ne contiendrait que des discours (ceux de l'assemblée du 31 juillet à l'île Walpole). Dans le premier paragraphe de sa lettre, quatre mois et demi après sa promesse, il fait état de la façon dont il a préparé les textes promis. Ainsi, en dépit de l'ignorance dans laquelle nous sommes du soin plus ou moins grand que les différents narrateurs des Lettres ont mis à la traduction de pareils textes, il nous éclaire sur le degré d'authenticité et d'exactitude que pouvaient atteindre les textes amérindiens des Lettres ontariennes. Voici comment le père Chazelle présente ses traductions à son destinataire:

Je vous avouerai que je me suis un peu repenti de ma promesse, pour plusieurs raisons. La difficulté d'être aussi complet et aussi exact que je le désire a été une des principales. Il est vrai j'avais mes réminiscences et mes notes; j'avais surtout les notes du P. du Ranquet qui, pour les rédiger, avait eu recours à mon interprète; mais ce n'était pas encore assez pour moi. Comment me rappeler tout ce qui fut dit, et, surtout, comment le rendre? Je voulais être tout à la fois sauvage et français. Enfin, tel quel, mon travail s'est terminé et je l'ai soumis à l'examen du P. du Ranquet. Nous avons conclu, l'un et l'autre, que rien n'avait été oublié ni dénaturé de tout ce qui appartenait aux idées et au genre caractéristique de ces cinq discours et que ce que je vous envoie peut être regardé comme une copie assez fidèle d'un tableau que nous avons étudiéé 238 .

${ }^{236}$ Lettre 13, Sandwich, dans LNMC, pp. 252-275.

${ }^{237}$ Lettre 10, Sandwich, dans ibid., p. 225, par. 25.

${ }^{238}$ Lettre 13, Sandwich, 24 janvier 1845, dans ibid., p. 253, par. 1. Une note ajoutée par le père Chazelle montre à quel point il s'est 
Les cinq discours sont donnés dans l'ordre où ils ont été prononcés. Les deux Odjibwés ont parlé dans leur langue et le père Chazelle en anglais. Toutes les deux, trois ou quatre minutes, selon le gré de l'orateur, l'interprète Georges-Henri Mongotas ${ }^{239}$ traduisait soit de l'odjibwé à l'anglais, soit de cette langue à l'odjibwé.

Ojaouanon, le chef des guerriers, parla le premier. Il fit valoir le fait que les gens de sa nation possédaient la Sagesse, qu'ils n'étaient pas des fous, qu'ils détenaient les connaissances dont ils avaient besoin, et que, bien loin d'être bêtes, ils étaient intelligents:

Moi, homme sauvage, je sais que le Grand-Esprit nous a donné tout ce que nous avons: les yeux pour voir, les oreilles pour entendre et notre esprit pour penser à lui et pour connaître les choses qu'il a créées. Je sais qu'il est ici,

soucié de respecter le texte qu'il traduisait. C'est celle qu'il a pris la peine d'ajouter au paragraphe 27; elle se lit comme suit dans $L N M C$, p. 266, note 1: «Pétrokijic, ainsi qu'Ojaouanon [deux orateurs odjibwés], à chaque reprise, commençait presque toujours par la formule Minaona ni Kanis: encore mon frère. Je l'ai supprimé pour éviter la monotonie.». Il a cependant gardé la formule «mon frère» qu'utllisaient à profusion les deux Sauteux et le jésuite qui s'adressait à eux.

${ }^{239}$ Selon le père Chazelle, le choix de cet Interprète avait été «singullèrement approuvé». Nous devons à ce père le peu de renseignements que nous avons trouvés sur cet Amérindien: «Georges Henrl Mongotas est un sauvage, bel homme, agréable, parlant anglais, éloquent dans sa langue; exercé d'ailleurs à interpréter les discours publics. C'est lui qui a été l'interprète du Ministre Anglican et qui, à l'occasion des démêlés de celul-cl avec l'agent [du gouvernement], s'est prononcé si fortement contre lui. Je dirai, en passant, qu'll va s'embarquer bientôt à New-York, avec 12 ou 15 autres sauvages dont 3 ou 4 sont de l'île Walpole et presque tous les autres de Port-Sarnia. Il doit être leur interprète et visiter avec eux, l'Angleterre, l'Irlande et l'Écosse. Ils iront aussi en France. Deux ou trois ont fait de ce voyage une spéculation basée sur la curiosité européenne. Ce sera le second envol de ces nouveaux objets de commerce. Il paraît que le premier a bien réussi." Lettre 7, Sandwich, 10 août 1844, dans ibid., pp. 189 190, par. 5. 
je sais qu'il est ailleurs, qu'il est partout. Je sais qu'il nous voit jusqu'au fond du cœur, je sais que nous devons faire sa volonté. Le sauvage connaît bien ces vérités et beaucoup d'autres; elles sont présentes à son esprit partout où il va.

Ce n'est pas dans les livres, mon frère, que j'ai appris ce que je sais. Le Grand-Esprit a enseigné mon ancien [le premier ancêtre] et mon ancien m'a parlé de ce que le Grand-Esprit lui avait dit. Je suis heureux d'avoir eu ces enseignements. Je les conserve dans mon cœur, et jamais je n'y renoncerai ${ }^{240}$.

Passant ensuite à l'attaque, Ojaouanon accusait l'homme blanc d'avoir chassé le fils que lui avait envoyé le Grand-Esprit, puis d'avoir enlevé aux Amérindiens ce qui leur appartenait et de les avoir ainsi réduits à la misère, voire presque anéantis, entre autres par «l'eau de feu». Non, jamais, il ne changerait, n'oublierait le Grand-Esprit: «Je nourris mon feu, il ne s'éteindra point ${ }^{241}$.»

Le père Chazelle prit ensuite la parole ${ }^{242}$. Il présenta le père du Ranquet comme étant son fils d'une manière spéciale, protesta de son amour pour ses frères amérindiens, loua Ojaouanon qui avait bien parlé du Grand-Esprit, répondit aux questions que ce dernier lui avait posées au début de son discours, puis il entreprit de définir la prière, c'est-à-dire la religion chrétienne, en racontant, en un paragraphe remarquable par son caractère synthétique et sa clarté, l'histoire de Jésus, descendu du ciel mil huit cent quarante-quatre ans auparavant et fait homme "pour devenir le frère et le sauveur des hommes de toutes les couleurs». Le père réfuta ensuite quelques

${ }^{240}$ Lettre 13, Sandwich, 24 janvier 1845 , dans ibid., p. 255, à la fin du par. 4.

241 Ibid., p. 257, par. 7.

242 Ibid., pp. 257-263, par. 9-22. 
affirmations de son opposant et termina en reconnaissant que beaucoup d'hommes blancs avaient pillé les Amérindiens et leur avaient fait du mal, mais que les Robes-Noires n'avaient "traversé la grande eau» que pour leur «apporter les richesses du Ciel».

Le Grand-Chef Pétrokijic se leva à son tour ${ }^{243}$. Il s'employa à affirmer son attachement à l'enseignement de son Ancien, par qui le Grand-Esprit l'avait instruit. C'est avec beaucoup de finesse qu'il proclama sa loyauté et opposa ses vues à celles du père. Ce dernier avait présenté sa religion comme la seule bonne. Le Grand-Chef, lui, croyait que le GrandEsprit qui «a fait toutes les choses qui existent, [...] avec une variété infinie» n'avait pas eu pour dessein d'imposer à tous une "seule et même manière de chercher le jour». Le père avait la sienne; lui, il en avait une autre, et, si le Grand-Esprit ne lui avait pas envoyé son fils, c'est qu'il n'en avait pas eu besoin. Mais si ce fils s'était présenté à lui, il l'aurait bien accueilli et n'aurait pas commis l'infidélité de ne pas croire en lui et de le faire mourir. Et il attaquait encore plus fortement le père en lui reprochant sa prédication:

Si j'allais, moi, dans ton pays parler comme tu parles dans le mien, que penserais-tu? Sans doute tu sentirais se réveiller dans ton cœur l'attachement à tes bénédictions. Eh bien! c'est ce que j'éprouve en ce moment lorsque tu viens me dire: accepte les bénédictions de celui par qui nous vivons tous ${ }^{244}$.

Le Grand-Chef poussa plus loin son attaque en évoquant les ravages causés dans le monde par la religion chrétienne et en proclamant de nouveau sa profession de foi en son Ancien:

243 Ibid., pp. 263-267, par. 23-27.

${ }^{244}$ Ibid., p. 265, par. 25. 
Il est vrai qu'un grand nombre d'hommes de tous les pays ont écouté ta parole. Je regarde du côté où le soleil se lève et du côté où il se couche, je regarde de tous les côtés, et je vois que partout tu as fait disparaître les coutumes anciennes. En vérité, ils sont bien nombreux les changements que tu as opérés dans le monde, je les contemple et j'en suis étonné. La plupart des nations ont rejeté les bénédictions de leurs Anciens.

Et voilà donc, mon frère, ce que tu viens me demander à moi aussi, voilà ce que tu me réserves! Après avoir voyagé au loin, de tous côtés, tu arrives à moi, dans cette très petite île où je suis. Tu ne voudrais donc pas m'y laisser jouir en paix des bénédictions de mon Ancien? Donc bientôt il ne m'en resterait pas même le souvenir. Non, cela ne se peut; à mon Ancien je reste fidèle. Ici au moins le feu qu'il m'a laissé vivra pour moi et pour mes enfants. Ainsi, mon frère, n'aie aucun souci à mon égard; cesse de t'occuper de mon sort, et laisse-moi vivre en paix, dans ma petite île, dans ma pauvre demeure ${ }^{245}$.

Le père répondit ensuite longuement au GrandChef ${ }^{246}$. Nous ne citerons que le paragraphe suivant:

Mon frère, tu m'as demandé ce qu'on dirait dans mon île, si tu allais prêcher les coutumes. Je réponds qu'on te laisserait parler et qu'on serait bien aise de te voir et de t'entendre. Or c'est ce que je demande. Ou plutôt je demande beaucoup moins que cela; car je demande seulement que tu ne sois pas fâché, si je demeure dans cette petite île, pour parler à ceux qui voudront venir me voir, m'écouter. C'est là, mon frère, cette chose dont il a été question au commencement de mon discours, cette chose que je te demande et que tu ne pourras me refuser ${ }^{247}$.

Ojaouanon prit la parole une seconde fois. Il réaffirma sa loyauté au Grand-Esprit et conclut en demandant aux pères d'arrêter la construction de leur église, ce qui était l'enjeu du débat. Le père

\footnotetext{
245 Ibid., p. 266, par. 26.

246 Ibid., pp. 267-272, par. 28-32.

${ }^{247}$ Ibid., p. 269 , par. 30.
} 
Chazelle s'étant vu refuser le droit de répondre, il alla s'entretenir avec le Grand-Chef, à qui il rappela qu'il avait obtenu du Gouverneur du Canada la permission de construire cette église; et il n'en arrêterait pas la construction, car le gouvernement anglais était obligé, «par les traités les plus solennels, de protéger la Religion Catholique, et de la laisser jouir au Canada des mêmes privilèges qu'elle avait sous la domination française ${ }^{248}$ ».

Les deux Odjibwés que le père Chazelle $a$ affrontés raisonnaient et se défendaient tout aussi bien que l'Adario du baron de Lahontan. Si l'on compare les trois discours d'Ojaouanon et de Pétrokijic et les deux du père Chazelle avec les répliques de la première partie du célèbre dialogue de Lahontan, celle qui a pour objet la religion ${ }^{249}$, on a tôt fait de s'apercevoir que plusieurs points sont communs. En face du baron, le Huron de la fin du dix-septième siècle se défend d'être sans religion; il affirme qu'il reconnaît un dieu créateur, le Grand-Esprit, qu'il croit en l'immortalité de l'âme, et que le Grand-Esprit l'a doué, lui aussi, d'une raison capable de distinguer le bien et le mal. Devant le jésuite, l'Odjibwé du milieu du dix-neuvième siècle se défend d'être aussi bête que certains le croient; il fait valoir sa propre religion; il la considère tout aussi bonne que celle du père et il veut lui être fidèle, car il la tient de ses ancêtres; comme Adario, il croit que si le Christ était Dieu fait homme, il se serait manifesté à tous les

\footnotetext{
${ }^{248}$ Ibid., p. 274, par. 35.

${ }^{249}$ Lahontan, «Dialogues ou Entretiens entre un Sauvage et le baron de Lahontan», EEuvres complètes, édition critique par Réal Ouellet, avec la collaboration d'Alain Beaulieu, Montréal, les Presses de l'Université de Montréal, "Bibliothèque du Nouveau Monde», 1990, vol. 2, pp. 821-828 [pagination continue]: "[De la religion]».
} 
peuples et non à un seul; cependant, moins instruit que l'Adario de Lahontan, qui connaissait les jésuites depuis longtemps, l'Odjibwé, chez qui le père ne vient que d'arriver, ne discute pas de l'authenticité et de la véracité de la Bible.

Les principales différences entre les textes résident dans leurs tons et leurs formes. Le ton des personnages de Lahontan est cynique, agressif, voire grossièrement insultant, et la voix est la même pour les deux: française. Les jouteurs du dix-neuvième siècle, au contraire, parlent comme des gens bien élevés: ils se respectent; chacun a sa voix: l'une purement odjibwée et l'autre française mais teintée d'odjibwé; et tout comme l'argumentation, ces voix sont toujours marquées au coin de la sincérité. Cette dernière qualité est d'autant plus présente que les discours sortent de la bouche d'orateurs de chair et de sang, c'est-à-dire d'êtres réels, alors que les dialogueurs de Lahontan sont des êtres fictifs, créatures porte-parole d'un auteur qui a travesti non seulement le chef Kondiaronk, qui lui a servi de modèle, mais aussi sa propre personne: les paroles de l'un et de l'autre sont au service de l'idéologie philosophique du baron.

On peut aussi rapprocher les discours des orateurs odjibwés du 31 juillet 1844 de ceux des Relations ${ }^{250}$. Les ressemblances sont frappantes. Dans les deux cas, la qualité des textes est excellente, au point que l'on pourrait, comme on l'a fait pour les discours des Hurons, mettre en doute l'authenticité des discours odjibwés. Les auteurs des Relations s'étaient défendus en affirmant que leur traduction était loin de

${ }^{250}$ On trouve quelques-uns de ces textes dans Éloquence indienne, textes choisis, présentés et annotés par André Vachon, Montréal, Fides, «Classiques canadiens», 34, 1968, 95[1]. 
rendre la richesse et la beauté des discours indiens, la langue française n'offrant pas les moyens nécessaires pour faire valoir les subtilités de l'original, les métaphores du cru et maintes tournures. Les auteurs des Lettres ontariennes, tel le père Chazelle, comme nous l'avons vu plus haut, ne prétendaient qu'à une "copie assez fidèle» de ce que ce père appelait un «tableau ${ }^{251}$ ». Il voulait probablement signifier par ce mot que le discours indien était aussi un spectacle et que, pour rendre justice à l'orateur, il aurait fallu, comme l'écrit André Vachon, «décrire dans le détail ses gestes et ses attitudes, ses chansons et ses danses. Car l'éloquence indienne n'était pas faite pour être lue, mais pour être vue et entendue ${ }^{252}$."

Le même auteur affirme que l'on peut, aujourd'hui encore, "prouver l'authenticité» des discours indiens des Relations:

il suffit de comparer entre elles des pièces de sources différentes pour constater des caractéristiques communes, des images et des tournures semblables; au surplus, on a retrouvé des discours indiens traduits directement en anglais, qui présentent les mêmes caractéristiques, les mêmes images et les mêmes tournures que les versions françaises. Les témoignages anglais et hollandais sur l'éloquence des Indiens corroborent du reste ceux des Français ${ }^{253}$.

Il serait possible de prouver de la même façon l'authenticité des discours indiens des Lettres ontariennes, mais nous croyons que la lecture comparée des discours indiens et des discours français que nous avons décrits plus haut illustre assez bien que les rapporteurs de ces discours essaient

${ }^{251}$ Lettre 13 , Sandwich, 24 janvier 1845 , dans $L N M C$, p. 253, par. 1. 252 Éloquence indienne, p. 11.

${ }^{253}$ Ibid. 
d'indianiser les discours français bien plus qu'ils n'essaient de franciser les discours indiens. Si le Chazelle traducteur sent le besoin de dire qu'il veut "être tout la fois sauvage et français ${ }^{254}$ », le Chazelle missionnaire n'a pas besoin d'avertir son lecteur qu'il s'efforce d'être tout "sauvage" lorsqu'il s'adresse à l'Amérindien. C'est visible dans son style; lui-même le constate lorsqu'il évalue son discours du 31 juillet: "Je répondis d'une manière claire et précise, cherchant à formuler mes pensées, selon leurs usages et le génie de leur langue ${ }^{255}$.»

\section{LES DLALOGUES}

Le même effort est tout aussi visible dans les dialogues entre le missionnaire et l'Amérindien. Les répliques varient en longueur selon les circonstances et les sujets, mais elles sont toujours directes, claires, précises, imagées très souvent. Le dialogue prend quelquefois la forme d'un interrogatoire mené soit par l'Amérindien ${ }^{256}$, soit par le missionnaire ${ }^{257}$; il se présente aussi sous la forme de bribes de discussion ou de discours ${ }^{258}$; le plus souvent, il est simple échange bref $^{259}$.

Dans ces dialogues comme dans les discours, les missionnaires remarquent la musicalité de la langue

\footnotetext{
254 Lettre 13, Sandwich, 24 Janvier 1845, dans $L N M C$, p. 253, par. 1. ${ }^{255}$ Lettre 7, Sandwich, 10 août 1844, dans ibid., p. 191, par. 10.

${ }^{256}$ Plerre Chazelle, lettre 10 , Sandwich, 8 septembre 1844 , pp. 220221, par. 12.

257 Id., «Les Deux Sauvagesses du Haut-Canada», dans ibid., p. 298, par. 11 ; pp. 302-304, par. 18 et 19.

${ }^{258}$ Plerre Chazelle, lettre 10 , Sandwich, 8 septembre 1844 , pp. 221224, par. 13, 18, 20, $21,22$.

${ }^{259}$ Jean-Plerre Choné, lettre 12, Sainte-Croix, Grande Île Manitouline, 22 janvier 1845 , dans ibid., p. 245, par. 7.
} 
odjibwée. Le père Chazelle insiste sur le caractère expressif de cette langue:

Moi, qui n'entendais que des sons lorsqu'elle [une Odjibwée] parlait, je comprenais néanmoins quelque chose. Car nos sauvagesses ont, en général, la voix douce et harmonieuse. Plusieurs chantent bien et apprendraient facilement la musique. Mais quand, sous l'impression de quelque souvenir de douleur, elles répondent à vos questions, vous êtes étonné de trouver si parfaite cette musique de la conversation qui ne s'apprend point. Dans cette langue, il y a beaucoup de sons qui viennent de la poitrine et que le gosier modifie de mille manières. Or, ces modulations deviennent très sensibles quand le sentiment anime une voix naturellement douce et sonore ${ }^{260}$.

Le père Frémiot fait aussi l'éloge de cette langue pour sa douceur et son harmonie, la cadence de son accentuation, l'énergie de ses tournures, la richesse sonore de ses polysyllabes, la simplicité et la variété de ses combinaisons, son «allure libre et dégagée qui convient si bien à la noble fierté de l'enfant des forêts». Lui qui avait adoré les "moelleux accents" musicalement cadencés de la langue grecque, bien qu'ils lui fussent parvenus «défigurés par une voix étrangère", voilà qu'il était séduit davantage par la langue odjibwée:

Depuis que je commence à m'initier aux beautés de la langue des sauvages, où j'ai fait des progrès bien autrement rapides que dans celle de Démosthènes ou de Cicéron, depuis que j'ai entendu couler de ces lèvres, que notre

260 «Les Deux Sauvagesses du Haut-Canada», dans ibid., pp. 295-296, par. 6. - Voir aussi les jugements portés sur l'éloquence indlenne par le même père dans la lettre 7 , Sandwich, 10 août 1844 , p. 189, par. 4; p. 193, par. 15-16 (dans la seconde partie de ce dernier paragraphe, à propos de l'élocution indienne, il écrit que le père du Ranquet affirme que la langue odjibwée «a des beautés et une certaine richesse et que, s'il pouvait avoir écrits les discours prononcés [lors de l'assemblée du 31 juillet 1844 à l'île Walpole], Il laisserait volontlers de côté tous ses livres et ses cahiers». 
dédain se plaît à flétrir du nom de sauvages, une parole si facile, si douce, si mielleuse, si naturellement éloquente, et j'oserais dire si énergiquement séduisante, je me persuade que la nature ne fut point avare envers le sauvage sous le rapport du don de la parole, et je cesse d'envier à la Grèce ses beaux parleurs ${ }^{261}$.

Dérivé de l'algonquin et considéré comme un dialecte de cette langue mère ${ }^{262}$, l'odjibwé n'était pas sans poser quelques problèmes aux missionnaires. Il était difficile à apprendre ${ }^{263}$, ne se prêtait pas facilement à l'expression de la pensée abstraite ${ }^{264}$ et son vocabulaire était restreint ${ }^{265}$.

\section{LES RECITS DE CONVERSION}

Les récits de conversion indiens ne sont pas très nombreux. Deux méritent d'être considérés pour la richesse de leur contenu. Nous devons leur traduction au père Dominique du Ranquet. Cependant, le père Chazelle a mis la dernière main à celui que l'on trouve comme un hors-texte après la lettre 17 sous le titre «Les Deux Sauvagesses du Haut-Canada. Relation écrite

${ }^{261}$ Lettre 75, Sault-Sainte-Marie, 2 février 1851, dans ibid., pp. 713714 , par. 12 .

${ }^{262}$ Nicolas Frémiot, ibid., p. 729, par. 33.

${ }^{263}$ Jean-Pierre Choné, lettre 45, Sainte-Croix, Grande Manitouline, 24 février 1848., dans ibid., p. 493, par. 9.

264 "Cette langue [odjlbwée] n'a qu'un petit nombre de mot[s] racines qui se combinent avec une prodigieuse variété. Riche et féconde pour tout ce qui tient aux Idées physiques et sociales, elle est pauvre sous le rapport des idées métaphysiques et abstraites.» Nicolas Frémiot, lettre 75, Sault-Sainte-Marie, 2 février 1851, dans ibid., p. 729, par. 33.

${ }^{265}$ Parlant de la difficulté de traduire en odjibwé un mandement de l'évêque de Toronto, le père Choné écrit: «[...]: il n'y a pas de mots sauvages pour rendre les choses par leurs noms. La langue sauvage n'est pas chrétienne; d'ailleurs elle est presque tout verbe.» Lettre 12, Sainte-Croix, Grande île Manitouline, 22 janvier 1845, dans ibid., p. 239, par. 3. - À propos de la grammaire odjibwée, voir L. Cadieux, «Indroduction», ibid., pp. [67]-69, par. 1-6. 
par le P. Chazelle peu de temps avant sa mort ${ }^{266}$ ".

Le $1^{\text {er }}$ août 1844 , deux sauvagesses méthodistes de Port-Sarnia qui vivent ensemble arrivent à l'île Walpole et demandent à devenir catholiques. La tante, dans la cinquantaine, n'a jamais été mariée. La nièce, plus jeune, a été abandonnée par les deux maris qu'elle a eus; elle vient de perdre son fils de huit à neuf ans, lui restent un fils de onze ans et une fille de cinq à six ans. Deux jours plus tard, elles seront suffisamment instruites pour que le père les baptise ainsi que les deux enfants. La tante s'appellera désormais Catherine et la nièce, Marguerite. Ce sont les circonstances qui ont amené celle-ci au catholicisme qui intéressent le père Chazelle. Comme il connaît encore mal la langue odjibwée, c'est en compagnie du père du Ranquet qu'il l'interroge, «désireux l'un et l'autre de connaître une histoire qui semblait promettre quelque chose d'extraordinaire". Les divisions du récit correspondent aux trois jours que dura l'entretien. La narration est tantôt à la troisième personne, tantôt à la première, selon que le narrateur résume la conversation ou rapporte les paroles mêmes de l'Amérindienne ou de l'interrogateur.

Le premier jour, Marguerite raconta la maladie et la mort de son fils; elle l'avait fait baptiser, comme il le lui avait demandé peu avant de mourir, par un prêtre catholique; l'entourage de Port-Sarnia ne lui avait exprimé aucune marque de sympathie et de commisération; bien plus, c'était son plus gros chagrin, personne n'avait parlé du Grand-Esprit sur la tombe de son fils. Le père lui promit de le faire.

${ }^{266}$ Dans ibid., pp. 294-305. 
Le deuxième jour, elle s'informa du moment où elle pourrait recevoir le baptême. Le père profita de l'occasion pour lui poser des questions qui le renseigneraient sur les voies de sa conversion. Elle répondit en faisant part de deux événements importants de sa vie. L'un avait été un songe dans lequel le ciel lui apparut d'un côté - celui de la chapelle catholique de Chatham - tout de lumière, ce qui réjouissait son âme, tandis que, de l'autre côté, il n'était que ténèbres, nuages épais, tempêtes et tombeaux. Elle avait compris que le beau côté est celui des «véritables priants», et l'horrible, celui des "méchants».

Depuis ce temps-là, j'ai toujours vu cette différence qu'il y a après la mort, entre les amis du Grand-Esprit et ceux qui ne le sont pas. Mais lorsque mon fils était malade, lorsqu'il était mourant, cette idée devint beaucoup plus claire et plus forte. Alors je dis: je ne voudrais pas que cet enfant fût du côté de la nuit et des orages. Ensuite, je pensai et je dis: mais le côté de la lumière et du bonheur est celui de l'église de Chatham. Là se trouve donc la bonne Prière. Je ne pensais presque qu'à cela ${ }^{267}$.

Le second événement, selon le père Chazelle, «n'est pas un songe, mais bien une de ces visions intellectuelles dont les esprits les plus solides peuvent se glorifier». Il est narré à la troisième personne:

Elle entra un jour dans une pauvre église catholique. C'était la première fois de sa vie. Il y avait peu de monde dans cette chapelle au milieu des bois. La Robe-Noire parut, et il est probable que la Messe fut célébrée. Marguerite ne peut dire ce qui eut lieu; car, après avoir examiné quelque tems les personnes qui étaient là à genoux, elle se mit à comparer ce qu'elle voyait avec ce qu'elle avait vu chez les Méthodistes. - Ici, quel calme! quel recueillement! Le cœur prie. Ces visages annoncent la joie de l'âme, le véri-

${ }^{267}$ Ibid., p. 301 , fin du par. 14. 
table bonheur. Dieu est présent en ce lieu: c'est sa maison.

Voilà sans doute ici la véritable Église ${ }^{268}$.

Le troisième jour, les pères continuèrent d'instruire leurs catéchumènes, puis le père Chazelle les baptisa. Marguerite expliqua que, n'ayant jamais eu l'occasion de rencontrer une "véritable Robe-Noire", elle avait fini par se joindre aux méthodistes qui «la tourmentaient». Mais elle n'avait jamais été heureuse chez eux. L'Esprit n'était jamais venu en elle, malgré ses efforts. Et quand elle voyait les autres se démener, se jeter par terre, tomber comme morts, cela lui «faisait horreur»:

Je ne pouvais m'empêcher de croire que ces choses-là ne devaient pas plaire au Grand-Esprit. Cette prière des Méthodistes m'a toujours paru ressembler beaucoup à l'état des personnes qui ont trop bu d'eau de feu ${ }^{269}$.

Maintenant elle était heureuse et sa tante aussi.

L'auteur du second récit est Ataghewinini, un vieux chef sauteux que le père Chazelle avait vu influencer la tribu de Port-Sarnia par ses exemples et ses leçons. Depuis, il s'était établì dans une petite île de la région de Penetanguishene. Il était devenu «le soutien de la foi dans son village» et il y présidait «à la prière». Au cours de l'été de 1844 , le père Chazelle le fit venir "pour visiter les sauvages de l'île Walpole». Une fois sur place, le vieillard raconta sa conversion au père Chazelle. Frappé par la qualité des propos et avide de ce genre de récit, ledit père demanda aussitôt au père du Ranquet de mettre immédiatement par écrit ce que tous deux venaient d'entendre. Vingttrois mois après la mort du père Chazelle, le père du Ranquet retrouvait le texte dans ses propres papiers

${ }^{268}$ Ibid., par. 15.

269 Ibid., p. 303, fin du par. 18. 
et en faisait la matière de quatorze des quinze paragraphes d'une lettre qu'il adressait à un père de la même Compagnie ${ }^{270}$.

Ce récit de conversion repose essentiellement sur trois songes que le narrateur a eus et qu'il appelle visions, car ce ne sont pas, dit-il, des songes ordinaires. Il eut les deux premières, aux derniers moments de maladies qui confinèrent à une mort qu'il jugeait certaine, et la troisième, la nuit qui suivit son baptême. Chacune de ces visions a eu un effet déterminant sur la conduite de sa vie.

Tombé malade une première fois alors que son fils était encore jeune, et croyant sa dernière heure arrivée, il avait dit un dernier mot d'encouragement à sa femme, puis avait ajouté: "couvre-moi la tête, je vais mourir». Tout à coup, il vit un chemin qui montait au ciel; il le suivit, rencontra deux Français qui descendaient vers la terre et l'encouragèrent à poursuivre sa route, puis il côtoya un lieu de ténèbres, mais sans quitter la lumière qui le guidait vers le haut. Elle devint si brillante qu'il dut s'arrêter et la voix du gardien de la porte l'avertit qu'il ne pourrait entrer dans la lumière qu'après être redescendu sur terre et s'y être purifié en devenant catholique. Nullement découragé, il entreprit la descente, passa outre de nouveau le chemin des ténèbres, reconnut la terre de plus en plus en détail à mesure qu'il s'en approchait, puis se retrouva dans son wigwam, étendu comme avant son voyage, mais le cœur "plein de joie». Il dit à sa femme qu'il allait vivre et lui demanda d'avertir les chefs et les anciens de la tribu qu'il désirait les "voir tous réunis dans sa cabane». Ils vinrent, il leur annonça sa résolution de se faire chrétien et de-

${ }^{270}$ Lettre 30, Île Walpole, 26 juillet 1846, dans LNMC, pp. 377-385. 
manda leur avis. Ils s'objectèrent, arguant que le Grand-Esprit avait sur leur "race» des desseins bien différents et qu'il ne devait pas renoncer aux bénédictions qu'il leur préparait. Il suivit leur conseil et guérit $^{271}$.

Quatre années plus tard, il se morfondit dans les bois et dut s'aliter. Les anciens ne parvenant pas à le guérir, il se vit de nouveau aux portes de la mort. Lui revint le souvenir de la vision de naguère et il eut peur que sa désobéissance ne lui coûtât le ciel. Il envoya quérir le Français (le père) par son beaufrère. Celui-ci revint en disant que le Français et l'agent anglais avaient jugé qu'il ne désirait le baptême que parce qu'il était malade et que, une fois guéri, il reprendrait sa vie habituelle. Cette nouvelle lui fit mal et il entra bientôt en agonie. Un homme lui apparut en songe. Il lui parla de l'amour du GrandEsprit, de la connaissance que celui-ci avait de son repentir, puis lui prédit que le lendemain à midi, il serait chrétien. Il sentit dans son cœur une grande joie et cessa de souffrir. Il se découvrit le visage et annonça à sa femme la bonne nouvelle. S'étant recouvert le visage, le même personnage lui apparut et le réconforta encore: «L'homme disparut me laissant consolé, plein de joie. J'entrai dans un sommeil paisible; il ne me restait de maladie que la faiblesse, et dans mon cour si longtemps triste un point comme un souvenir de la miséricorde de Dieu; il y est encore et $y$ restera toujours." De fait, deux Français l'instruisirent et le baptisèrent le lendemain tel que pré$\mathrm{dit}^{272}$.

La nuit suivante, il eut une autre vision. Les jongleurs

${ }^{271}$ Ibid., pp. 378-381, par. 3-6.

${ }^{272}$ Ibid., pp. 381-384, par. 7-11. 
et les vieillards s'employaient à le guérir par leurs jongleries et leurs chants. Mais «la voix d'une foule innombrable» s'éleva au-dessus de la leur; elle disait au chef des jongleurs: «Non, ce n'est pas toi qui l'as guéri; il m'appartient: c'est moi qui lui ai fait Charité; il est à moi, il ne t'appartient plus, il ne t'appartiendra jamais; et quand même tu le verrais tomber encore, ne crois pas qu'il t'appartienne, je lui ferai encore charité." Alors, quatre de ces anges dont il avait entendu la voix descendirent, s'approchèrent de son lit, et le regardèrent avec un sourire aimable. Il ne pouvait arrêter la vue sur eux, tellement ils étaient beaux ${ }^{273}$.

Ataghewinini savait maintenant que «le GrandEsprit appelle aussi les sauvages à la prière ${ }^{274}$ ». Il conclut son récit en faisant état des résultats de sa conversion et de la notion de devoir qui avait orienté son dévouement de chrétien reconnaissant pour les bénédictions reçues:

Ma conversion fut le signal de celle de ma tribu: tous étaient frappés du changement que le baptême avait produit en moi. Ma parole était puissante. Lorsque Mgr MacDonnald vint visiter notre île, je lui racontai tout ce qui m'était arrivé. - Le Grand-Esprit t'a fait charité, me dit-il; il faut que tu travailles pour le Grand-Esprit et pour tes frères! - Ainsi j'ai fait, ne désirant d'autre récompense que celle que donne le Grand-Esprit. J'ai ouvert le sentier; que les Robes-Noires viennent maintenant ${ }^{275}$.

On aura remarqué que les songes de ces deux récits se déroulent sur un arrière-fond chrétien que, sans doute, l'on doit à l'enseignement des missionnaires catholiques des siècles précédents ainsi qu'à

\footnotetext{
${ }^{273}$ Ibid., p. 384, par. 12-13.

${ }^{274}$ Ibid., par. 14.

${ }^{275}$ Ibid., par. 15.
} 
la présence, depuis la conquête anglaise, des missionnaires de diverses sectes, venus d'outre-mer ou des États-Unis. À remarquer aussi, non seulement que les Amérindiens du dix-neuvième siècle, tout comme ceux des Relations, accordent beaucoup d'importance aux rêves, mais qu'ils croient aussi, comme l'avaient constaté les premiers missionnaires, qu'il y a des songes plus importants que d'autres et que plusieurs savent bien faire les distinctions qui s'imposent. C'était ici le cas d'Ataghewinini qui insistait sur le fait que ses songes, qu'il appelle plutôt visions, n'étaient pas ordinaires et n'omettait pas de signaler s'ils les avaient eus ou non pendant son sommeil. Il faut noter aussi que les rêves sont moins abondants dans les Lettres que dans les Relations et que les missionnaires du dix-neuvième siècle y portent beaucoup moins d'attention que leurs prédécesseurs. Enfin, dernière remarque sur le récit d'Ataghewinini, son style est simple et ses images se calquent sur la réalité plutôt qu'elles n'empruntent à l'imaginaire fantastique.

\section{Conclusion}

Au début de notre étude, nous avons mentionné que, pour diverses raisons et à cause de certaines circonstances, les Lettres des nouvelles missions du Canada, 1843-1852, n'avaient pas eu.le même succès auprès des lecteurs que les Relations du dixseptième siècle et les Lettres édifiantes du dixhuitième. Il faut ajouter que les Relations avaient profité du fait qu'elles s'inséraient dans un siècle de découvertes pendant lequel ne cessa d'exister une forte curiosité pour tout ce qui touchait aux Amérindiens, tandis que les Lettres édifiantes eurent 
l'heur de contribuer à la réflexion du siècle des $\mathrm{Lu}$ mières sur l'humanité et le "Sauvage» de l'Amérique. Les Lettres ontariennes, elles, ne révélaient aucun nouveau monde, mais seulement des parcelles d'un monde de plus en plus civilisé à l'européenne ou à l'américaine, dans lequel se perdaient en quelque sorte des Amérindiens exilés de leurs terres, voire de leur culture, et déchus de leur puissance.

Pourtant, au moment de conclure, nous pouvons affirmer que ces lettres ne manquent pas d'intérêt pour autant et qu'elles sont, comme nous l'avons écrit ailleurs ${ }^{276}$, l'œuvre la plus substantielle de la deuxième période de la littérature franco-ontarienne, celle qui s'étend de 1760 à 1865 . Elles ont seulement eu le malheur de n'être diffusées qu'à un public restreint au moment de leur première édition (vers 1857), puis, au moment de la seconde (1973), d'être offertes à des lecteurs canadiens-français qui ne s'intéressaient plus guère aux Amérindiens, et surtout pas aux efforts que des missionnaires catholiques avaient pu faire pour les convertir plus d'un siècle auparavant. Cependant, elles auraient dû intéresser les Franco-Ontariens, car elles confirmaient l'importance de la présence française en Ontario dans un champ où elle avait été marquante dès le dix-septième siècle. Bien plus, quoique publiée à Montréal, l'édition Cadieux était l'œuvre d'un professeur d'histoire de l'Université Laurentienne, et ce citoyen de Sudbury depuis 1940 avait été, dès 1942, le fondateur de la Société historique du Nouvel-Ontario, laquelle faisait la promotion de tout ce qui avait été marqué par

\footnotetext{
276 "La Littérature franco-ontarienne. Esquisse historique (1610-1987)", dans les Franco-Ontariens, sous la direction de Cornelius J. Jaenen, Ottawa, les Presses de l'Université d'Ottawa, "Ontario Historical Studies Series», pp. 349-350.
} 
la présence française dans les diverses régions ontariennes. Et plus encore, il se trouvait que, en 1973, les jeunes Franco-Ontariens du Nord venaient de fonder, à Sudbury même, les Éditions Prise de parole. Toutefois, il ne se trouva personne, pas même un des quatre critiques qui rendirent compte de l'édition Cadieux dans des revues ${ }^{277}$, pour insérer cet ouvrage dans la tradition littéraire franco-ontarienne. Pourtant, il s'y inscrit, car les Lettres sont avant tout création d'un espace idéologique et description d'une société et de son territoire par des auteurs qui connaissent parfaitement la langue française et qui utilisent à plein les richesses lexicales et syntaxiques dont cette langue s'est enrichie à la faveur du mouvement romantique et du développement industriel.

L'espace des Lettres ontariennes est d'abord et avant tout un espace missionnaire, tout comme c'était le cas dans les Relations. Il n'y est guère question que de conversions à faire, que de catholicisme romain à répandre malgré l'opposition et la concurrence des sectes protestantes ou à faire revivre chez les descendants des ouailles des jésuites du dix-septième siècle. Les auteurs des lettres ne se posent plus de questions philosophiques au sujet de l'Amérindien: ces questions ont été suffisamment débattues durant les deux siècles précédents. Préoccupés principalement du sort spirituel de l'Amérindien odjibwé, ils donnent souvent l'impression de s'inquiéter, sinon de se décourager, devant l'ampleur de la tâche à accomplir, tellement ils insistent pour que leurs supérieurs envoient des renforts en nombre. En revanche, jusqu'à un certain point, ils semblent déçus de ne pas avoir à conquérir un monde à la mesure de

${ }^{277}$ Voir supra, note 12. 
celui des Relations et ils sont peinés de voir s'effondrer et se décimer des groupes culturels qui, forts et fiers jadis, ne survivent qu'humiliés et miséreux, tant ceux qui prétendaient leur apporter la "civilisation" les ont exploités en s'emparant de leur commerce et de leurs terres, et détruits en les habituant à l' eau-devie.

L'espace missionnaire se déploie principalement, en effet, sur un Ontario amérindien dont les habitants végètent et souffrent de se voir mis en retrait, voire au rancart, repoussés qu'ils sont de plus en plus vers une arrière-forêt où le gibier et le poisson se font rares maintenant. Ils dépendent même de plus en plus du gouvernement fédéral pour leur survie. Certains habitent depuis 1827 dans les réserves de l'île Walpole, de Sarnia et de l'île Manitouline, mais un grand nombre vivent en bandes éparpillées. Chaque été, tous se rassemblent en un même endroit pour recevoir les présents du gouvernement. C'est dans cet espace amérindien dévalué que se démènent les missionnaires, et on croirait cet espace tout à fait isolé et presque sans vie et sans réalité, s'il n'y avait l'opposition que l'Amérindien offre, d'une part, aux «Robes-Noires» et aux ministres protestants qui veulent l'arracher à sa culture religieuse traditionnelle, et, d'autre part, aux agents du gouvernement qui grugent ses terres et minimisent ses droits. Le récit de ces luttes demeure un des éléments intéressants des Lettres ontariennes. Alors que la description de la situation donne à voir les effets néfastes d'une déculturation forcée, le récit incite à admirer ceux qui, fidèles à leurs origines et à leurs traditions, résistent de leur mieux et le plus possible à l'acculturation. Il fournit une explication, parmi bien d'autres, à la survie des communautés amérindiennes 
et invite à la modestie et à la compréhension ceux qui ne croient qu'en une seule culture, la leur.

Les deux espaces que nous venons de considérer, le missionnaire et l'amérindien, appartiennent au récit. Le troisième relève de la description; il est géographique et permet au lecteur de connaître deux aspects de l'Ontario du milieu du dix-neuvième siècle. Le plus souvent, les missionnaires nous décrivent les grands espaces sauvages et peu habités que, pour le plus grand bien de leurs ouailles, ils parcourent encore, comme au dix-septième siècle, sur leurs deux jambes ou en canots aux dépens de leur forces corporelles, mais avec une résistance physique qui étonne et révèle leur caractère. Grâce à eux, nous découvrons l'aspect primitif de l'Ontario qui reste à construire et à exploiter. L'autre aspect que révèlent les Lettres, c'est celui d'un Ontario qui se développe soit par le défrichement soit par l'exploitation minière, un Ontario qui se peuple d'immigrants et qui profite déjà de certains moyens modernes de communications, tels les bateaux à vapeur qui circulent sur le Saint-Laurent et les Grands Lacs. La description de ces deux aspects de l'espace géographique ontarien au milieu du dix-neuvième siècle n'est pas sans intérêt pour l'Ontarien du vingtième, pour peu qu'il soit un peu curieux du passé de sa province.

Cependant, les Lettres ontariennes publiées par le père Lorenzo Cadieux ne présentent que dix années du dix-neuvième siècle et qu'une partie marginale de l'Ontario géophysique et de sa population. Il serait à souhaiter que soient aussi éditées les lettres des années 1853-1870. Le père Cadieux a eu, semble-t-il, l'intention de le faire, et ce serait un texte préparatoire que la Société historique du Nouvel-Ontario a 
publié de façon posthume à Sudbury, en 1982, sous le titre les Robes noires à l'île du Manitou, 1853-1870 (coll. «Documents historiques", 75.) L'ouvrage comprend deux parties, trois appendices (pp. 54-69) et une bibliographie (70-72). La première partie, intitulée «Aperçu historique» (5-31) est du père Lorenzo Cadieux; la seconde, signée par le père Robert Toupin, a pour titre «la Vie interne de la mission" (33-54). Les deux auteurs font référence aux lettres des années 1853-1870 et les citent, mais n'en éditent pas. Cependant, le père Toupin a sur le métier un manuscrit dans lequel ces lettres pourraient être éditées, et le seront, espérons-nous, car elles nous feraient connaître une période plus intéressante encore.

S'impose aussi la publication des lettres des pères oblats et des religieuses de langue française qui ont œuvré en Ontario au dix-neuvième siècle en même temps que les jésuites, car ces lettres ajouteraient au tableau de la présence française en Ontario et beaucoup d'entre elles seraient un apport valable à la littérature franco-ontarienne du dix-neuvième siècle. 